\title{
Modelling and Control of Inverters in a Single-Phase Nanogrid
}

\author{
by \\ Nikolay Radimov
}

A thesis submitted to the Faculty of Graduate and Postdoctoral Affairs in partial fulfillment of the requirements for the degree of

Doctor of Philosophy

in

Electrical and Computer Engineering

Carleton University

Ottawa, Ontario

(C) 2020, Nikolay Radimov 


\begin{abstract}
Traditionally, a microgrid relies on electro-mechanical generators to achieve reliable and stable operations. With recent technical advancement in the fields of renewable energy and energy storage, a modern microgrid can operate autonomously with only inverter-based energy sources. While the three-phase microgrid has been extensively studied in recent years, the single-phase microgrid has been barely investigated. However, massive numbers of single-phase microgrids (or nanogrids in some references and this thesis) are now being deployed in conjunction with the introduction of electric vehicles (EVs) and household power generators (such as photovoltaic solar) to the 130 million single-phase consumers in North America. The lack of single-phase microgrid analysis represents a significant knowledge gap.

The objective of this thesis is to advance the understanding of single-phase nanogrids consisting of both grid-supporting and grid-forming inverters. Three topics are covered in this thesis.
\end{abstract}

- Integration of the EV in the nanogrid: a novel control and optimization strategy for On-board Battery Charger (OBC) is proposed. It is based on Direct Current Hysteretic Control (DCHC) with optimized switching patterns and dead time. The strategy can significantly reduce the switching losses of Silicon Carbide (SiC) based inverters.

- A voltage control loop tuning approach for grid-forming inverters: by extending the Modulus Optimum algorithm to the stationary reference frame, the proposed approach provides a simple and reliable method when tuning the voltage control loop. 
- A systematic single-phase modelling methodology: a synchronous dq0 frame model of the single-phase inverters is developed. It allows the application of three phase stability analysis techniques/tools to single phase systems. 


\section{Acknowledgements}

I would like to thank my wife, Liana and my kids Tamara and Henri for their support.

I would like to thank Solantro Semiconductors management, especially VP of Engineering Mr. Mihai Varlan for his support.

I would like to thank all my current and former colleges from Solantro Semiconductors for their help and friendly advice.

Special thanks to my supervisor, Professor Xiaoyu Wang, for guiding me through this complicated process.

I would also like to acknowledge the financial support from the Province of Ontario's Smart Grid Fund initiative. 


\section{Table of Contents}

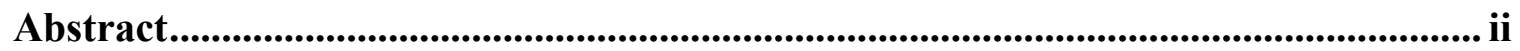

Acknowledgements ......................................................................................................................... iv

Table of Contents ....................................................................................................................... v

List of Tables ............................................................................................................................... vii

List of Illustrations...................................................................................................... viii

List of Abbreviations .......................................................................................................... xiii

List of Symbols ............................................................................................................................... Xv

Chapter 1. Introduction........................................................................................

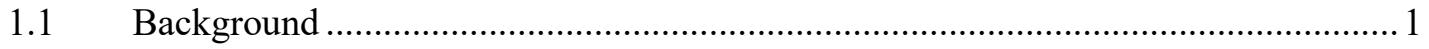

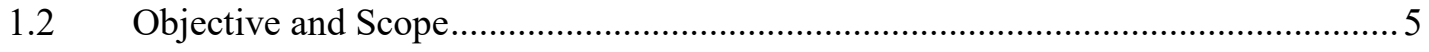

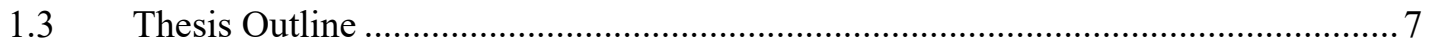

Chapter 2. The Single-phase Nanogrid Project …………………………………………..... 9

2.1 Single-Phase Nanogrid Project Overview .............................................................

Chapter 3. Literature Review and Gap Analysis ……………………………………...... 13

3.1 Bi-Directional OBC Performance Optimization …………………………………..... 14

3.2 Resonant Controller Tuning Optimization........................................................... 15

3.3 Nanogrid Modelling ………………………………………………………...2

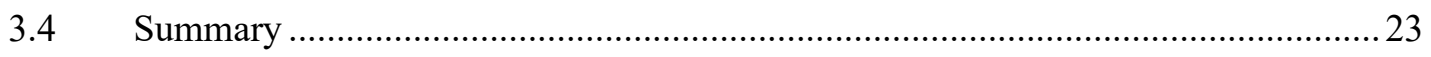

Chapter 4. Three-Stage SiC-Based Bi-Directional OBC with Titanium Level Efficiency ...24

4.1 Topology and the Principle of OBC Operations ………………………………......25

4.2 The Efficiency and Control Optimization Strategy ……………….........................2.

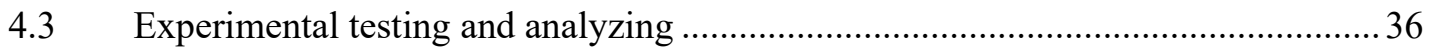

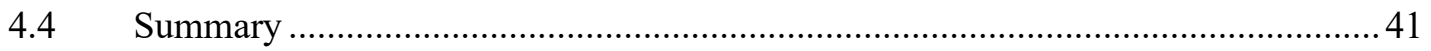


Chapter 5. Tuning the Voltage Control System based on an Extended Modulus Optimum Method 43

5.1 The PR Controller and the Stationary Reference Frame Extension of the Modulus

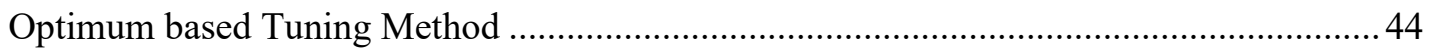

5.2 Off-Grid Battery Inverter Tuning Example .................................................... 48

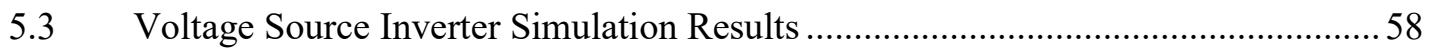

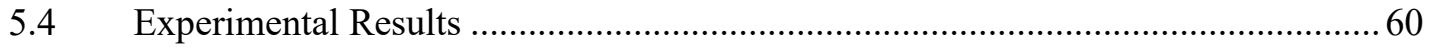

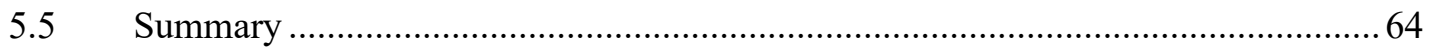

Chapter 6. Novel Systematic Approach for Single-Phase Nanogrid Stability Analysis ....... 66

6.1 Theoretical Analysis of the Proposed Modelling Approach ....................................67

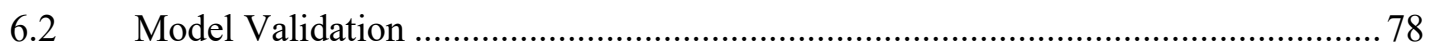

6.3 Application of the Proposed Modelling Approaches for Voltage Control Loop and

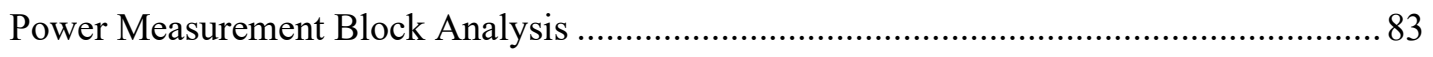

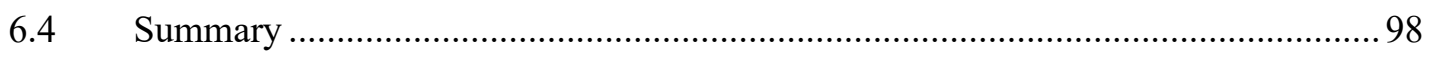

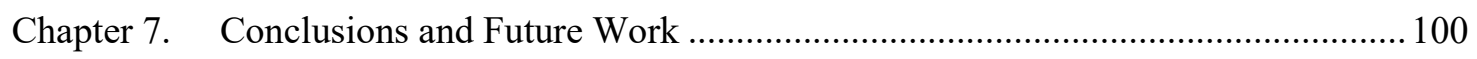

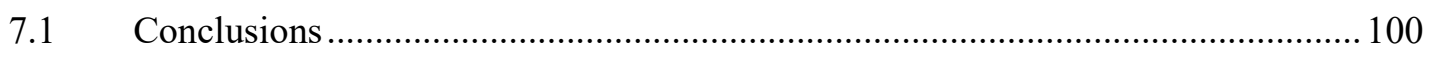

7.2 Thesis Limitation and Suggestion for Future Work ........................................... 101

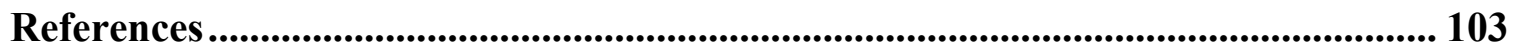




\section{List of Tables}

Table 4-1 Parameters of Bi-Directional On-Board Battery Charger under Considerations

Table 4-2 Efficiency optimization test results for inverter stage of OBC 33

Table 5-1 Output Cascade Parameters of the 500VA Off-Grid Battery Inverter under Test

Table 5-2 Output Cascade Parameters of the 1kVA Bi-Directional Off-Grid Battery

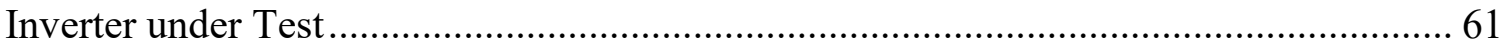




\section{List of Illustrations}

Fig. 1-1 Consumers of electrical energy per sector in North America ............................... 2

Fig. 1-2 Electrical energy consumption per sector in North America ................................. 4

Fig. 2-1 Single-phase nanogrid topology ……………............................................. 12

Fig. 4-1 The diagram of the on-board battery charge under consideration ..................... 24

Fig. 4-2 Three-stage Titanium efficiency $\mathrm{SiC}$ based hardware platform. Initially used as bidirectional $\mathrm{OBC}$, later adopted as a grid-forming battery inverter for islanded applications

Fig. 4-3 DCHC block diagram (top), and DCHC settings for CRM (middle) and CCM (bottom).

Fig. 4-4 Plot of internal microcontroller's variables: hysteretic controller settings over the grid cycle, switching frequency, and operation modes for $1 \mathrm{~kW}$ charge operation. 34

Fig. 4-5 Isolated bi-directional DC/DC stage simplified schematics (Top) and its equivalent circuit (Bottom). 35

Fig. 4-6 The setup for efficiency and THD, and dynamic measurements. Setup is not energized. 1) PA4000 power analyzer by Tektronix; 2) $2.4 \mathrm{~kW}$ electronic load by BK Precision; 3) 3kVA AC source by California Instruments; 4)Oscilloscope; 5) Unit Under Test. 36

Fig. 4-7 OBC power flow direction change from grid supporting mode at $750 \mathrm{~W}$ (discharge) to battery charging mode $(-375 \mathrm{~W})$

Fig. 4-8 OBC reactive power flow direction change from inductive (-950VA) to capacitive (950VA) power in grid support mode 
Fig. 4-9 OBC total conversion efficiency, and OBC per stage conversion efficiency compared with the 80 PLUS Titanium Standard in battery charging mode. The red line is the Titanium Standard, blue is total OBC efficiency, green is the Isolated Bi-Directional DC/DC stage efficiency, yellow is the inverter stage efficiency, and magenta is the BuckBoost stage efficiency. 39

Fig. 4-10 OBC total conversion efficiency, and OBC per stage conversion efficiency compared with the 80 PLUS Titanium Standard in battery discharging mode (grid support operations). The red line is the Titanium Standard, blue is the total OBC efficiency, green is the Isolated Bi-Directional DC/DC stage efficiency, yellow is the inverter stage efficiency, and magenta is the Buck-Boost stage efficiency. 40

Fig. 5-1 Bode plot of MO shaping curve (solid line), and proposed extension stationary frame extension of MO shaping curve (dashed line). $T_{O L}=1 /(2 \pi 1000) \mathrm{s}, \omega_{c}=10 \mathrm{rad} / \mathrm{s} \ldots . .47$ Fig. 5-2 The simplified block-diagram of the off-grid voltage source inverter output cascade

Fig. 5-3 Simplified block-diagram of the hysteresis non-linear current controller connected to $\mathrm{CPU}$ on the top, and hysteretic control settings on the bottom 50 Fig. 5-4 Eigenvalues migration of voltage source inverter with varying load. The magnified view of the dominant pole region is on the left, and the magnified view near zero region is on the right. From top to bottom: inductive load $\left(Z_{L} \in\left[100 Z_{L \max }, Z_{L \max }\right]\right)$ with dissipation factor $1 \%$; resistive load $\left(\mathrm{R}_{\mathrm{L}} \in\left[100 \mathrm{R}_{\mathrm{L}}, \mathrm{R}_{\mathrm{Lmax}}\right]\right)$; and capacitive load $\left(Z_{C} \in[100 \mathrm{ZCmax}\right.$, $\left.\mathrm{Z}_{\mathrm{Cmax}}\right]$ ) with dissipation factor $1 \%$ 57 
Fig. 5-5 Simulation results: inverter output voltage (upper left) and load current (bottom left). The upper right and bottom right are magnified views of the inverter voltage and load current around transient time respectively ................................................................. 58 Fig. 5-6 Step response of 500VA bi-directional off-grid battery inverter for 300W resistive load step. Channel 3 is an output voltage; Channel 4 is an output current 62

Fig. 5-7 Step response of 1kVA wide-bang semiconductor based bi-directional off-grid battery inverter for 300VA inductive load Channel 1 is an output voltage; Channel 2 is an output current; Channel 3 is an inverter bulk voltage, and Channel 4 is a battery current63 Fig. 5-8 Step response of 1kVA wide-bang semiconductor based bi-directional off-grid battery inverter for 100VA capacitive load step. Channel 1 is an output voltage; Channel 2 is an output current; Channel 3 is an inverter bulk voltage, and Channel 4 is a battery current

Fig. 6-1 Active and reactive power sharing by active power droop method 67 Fig. 6-2 Output cascade of single-phase grid-forming inverter with power-sharing loop. The stationary signals are in blue, the synchronous signals are in red, and interface between two systems are in light green.. 68

Fig. 6-3 Artificial three-phase grid. Black is an original single-phase grid, and grey is an original one shifted by $120^{\circ}$ and $240^{\circ}$ degree respectively. 73 Fig. 6-4 Block-diagram of the original $a b c$ to $\alpha \beta$ interface vs its $d q 0$ representation ...... 76 Fig. 6-5 Step response of the GOSG-SOGIdq $(s)$ transfer function. 77 Fig. 6-6: Simulation test bench for the numerical verification of the proposed method. The simulation where performed in MATLAB/SIMULINK. 80 
Fig. 6-7 Output voltage and load current of the inverter. Upper left is the resulting stationary model voltage, lower left, modulated synchronous model voltage. Upper right: stationary model load current and lower right is modulated synchronous model load current. 81

Fig. 6-8. Step response for $300 \mathrm{~W}$ resistive load step. Channel 3 is an output voltage; Channel 4 is an output current. 82 Fig. 6-9 Measured instantaneous output active and reactive power. Upper left is an active power from stationary model, lower left is synchronous model instantaneous reactive power. Upper right is an instantaneous reactive power from stationary model, lower left is instantaneous reactive power from synchronous model. Dashed line: is an actual instantaneous power. 83

Fig. 6-10 Block diagram of the system under investigation. 84

Fig. 6-11 Single-wire Thevenin model of the single-phase grid-forming inverter presented by voltage control loop. 87

Fig. 6-12 Normalized internal impedance of inverter. The magnitude is normalized with factor $K_{P}, \omega_{c}=10 \mathrm{rad} / \mathrm{s}, Z=0$. 89

Fig. 6-13 Original (blue) and simplified (red) system in sub-stability region. In(1) is a inverter voltage reference, $\operatorname{In}(2)$ is an infinite bus voltage, Out(1) is an inverter current, and Out(2) is a bus current. 91

Fig. 6-14 Bode plot of linearized transfer function $\mathrm{P}_{\mathrm{SOGI}}(\mathrm{s}) / \mathrm{P}_{\mathrm{MEAS}}(\mathrm{s})$ at $\mathrm{V}_{\mathrm{d}}=1, \mathrm{I}_{\mathrm{d}}=1$, $\mathrm{V}_{\mathrm{q}}=0, \mathrm{I}_{\mathrm{q}}=0$ (blue), and $\mathrm{V}_{\mathrm{d}}=0, \mathrm{I}_{\mathrm{d}}=0, \mathrm{~V}_{\mathrm{q}}=1, \mathrm{I}_{\mathrm{q}}=1$ (red) 93

Fig. 6-15 Bode plot of linearized transfer function $\mathrm{Q}_{\text {sogI }}(\mathrm{s}) / \mathrm{Q}_{\mathrm{MEAS}}(\mathrm{s})$ at $\mathrm{V}_{\mathrm{d}}=1, \mathrm{I}_{\mathrm{d}}=0, \mathrm{~V}_{\mathrm{q}}=0$, $\mathrm{I}_{\mathrm{q}}=1$ (blue), and $\mathrm{V}_{\mathrm{d}}=0, \mathrm{I}_{\mathrm{d}}=1, \mathrm{~V}_{\mathrm{q}}=1, \mathrm{I}_{\mathrm{q}}=0(\mathrm{red})$ 94 
Fig. 6-16 Single-wire diagram of the test bench for investigation of load sharing during transient and non-linear load sharing. Artificial impedance $Z=0$, and $\omega_{c}=10 \mathrm{rad} / \mathrm{sec}$. The wire impedance, $Z_{w}$ is negligible. 95 Fig. 6-17 Load step on AC. Channel 3 is an AC bus voltage Channels 1, and 4 are output currents of battery inverter $\# 1$, and $\# 2$ respectively. Artificial impedance $Z=0$, and $\omega_{\mathrm{c}}=10 \mathrm{rad} / \mathrm{sec}$, wire impedance, $Z_{w}$ is negligible. 96

Fig. 6-18 Sharing of high crest-factor load by four grid-forming inverters. Harmonic compensator is off. Channel 1 is an inverter 1 current, Channel 2 is an inverter 2 current, Channel 3 is inverter 3 current, and Channel 4 is self-forming microgrid voltage. Current of the fourth inverter is not presented due to scope channels imitation. Artificial impedance $Z=0$, and $\omega_{c}=10 \mathrm{rad} / \mathrm{sec}$. Wire impedance, $Z_{w}$ is negligible. 97

Fig. 6-19 Single-line diagram of air compressor start-up experimental setup. Artificial impedance $Z=0$, and $\omega_{c}=10 \mathrm{rad} / \mathrm{sec}$. The wire impedance, $Z_{w}$ is negligible. 97 Fig. 6-20 Air-Compressor start-up. Air-compressor is connected through step-down transformer to AC bus formed by four inverters. Channel 3 is an AC bus voltage Channels 1, 2 and 4 are output currents of battery inverter \#1, \#2 and \# 3 respectively. Output current of battery inverter \#4 was not acquired due to scope channel limitation. Artificial impedance $Z=0$, and $\omega_{c}=10 \mathrm{rad} / \mathrm{sec}$. The wire impedance, $Z_{w}$ is negligible. 98 


\section{List of Abbreviations}

CCM Continuous Current Mode

CLLLC Capacitive-Inductive-Inductive-Inductive Oscillation Tank

CPU Central Processor Unit

CRM CRitical conduction Mode

DAB Dual Active Bridge

DCHC Direct Current Hysteretic Control

DG Distributed Generator

EMI Electro-Magnetic Interference

EV Electrical Vehicle

IDP Intelligent Distribution Panel

LCL Inductive-Capacitive-Inductive Filter

LTI Linear Time-Invariant

LV Low-Voltage

MCU Microcontroller

MO Modal Optimum

OBC On-Board Battery Charger

OSG Orthogonal System Generator

PFC Power Factor Correction

PI Proportional-Integral

PID Proportional-Integral-Derivative

PR Proportional-Resonant

PV Photovoltaic 


$\begin{array}{ll}\text { PWM } & \text { Pulse-Width Modulation } \\ \text { RFI } & \text { Radio Frequency Interference } \\ \text { SGF } & \text { Smart-Grid Fund } \\ \text { SOGI } & \text { Second-Order General Integrator } \\ \text { THD } & \text { Total-Harmonic Distortion } \\ \text { UPS } & \text { Uninterruptible Power Supply } \\ \text { VSI } & \text { Voltage Source Inverter } \\ \text { WBS } & \text { Wide-Bandgap Semiconductors } \\ \text { ZCS } & \text { Zero-Current Switching } \\ \text { ZVS } & \text { Zero-Voltage Switching }\end{array}$




\section{List of Symbols}

\section{Symbol Description}

$A$

System Matrix of Continuous State Space Model

B Input Matrix of Continuous State Space Model

C Output Matrix of Continuous State Space Model

Cf Total Output Capacitance of the Voltage Source Inverter

D Initial State Matrix of Continuous State Space Model

$f_{s w} \quad$ Switching Frequency of the Switching Mode Power

Supply/Inverter

$f_{\text {target }} \quad$ Target Switching Frequency of the Switching Mode Power

Supply/Inverter

$I_{D C} \quad$ Operation Point Current of the Switching Mode Power

Supply/Inverter

Irecirculated $\quad$ Recirculated Current for ZVS

$I_{\text {ref }}(n) \quad$ Reference Current for Hysteretic Controller

$I_{\text {RippleMax }}(n) \quad$ Hysteresis Band of the Hysteretic Controller

$I_{r P e a k}(n) \quad$ Peak Current Settings of the Hysteretic Controller

$I_{r \operatorname{Trough}}(n) \quad$ Trough Current Settings of the Hysteretic Controller

$K_{I} \quad$ Integral Coefficient of the PID Controller in Synchronous

Frame or Resonant Coefficient of PR Controller in Stationary

Frame. Symbol is kept due to duality reasons

$K_{p} \quad$ Proportional Coefficient of the PR Controller

$P_{k}^{i n} \quad$ Input Active Power of the Cascade of the Multistage Inverter 


\begin{tabular}{|c|c|}
\hline$P_{k}^{\text {out }}$ & $\begin{array}{l}\text { Output Active Power of the Cascade of the Multistage } \\
\text { Inverter }\end{array}$ \\
\hline$R_{L}$ & Resistive Load \\
\hline$s$ & Laplace Operator \\
\hline$T$ & Device Temperature \\
\hline$T_{C L}$ & Time constant of the internal current loop \\
\hline$T_{O L}$ & Time Constant of the MO Shaping Function \\
\hline$T_{\text {sample }}$ & MCU Sampling Time \\
\hline$V_{A C}(n)$ & Instantaneous Main Voltage of the Inverter \\
\hline$V_{D C}(n)$ & Instantaneous Bulk Voltage of the Inverter \\
\hline$v_{\text {droop }}$ & Artificial Voltage Droop \\
\hline$v_{g}$ & Instantaneous Output Voltage of the Voltage Source Inverter \\
\hline$v_{\text {ref }}$ & $\begin{array}{l}\text { Instantaneous Reference Voltage for Inverter Voltage Control } \\
\text { Loop }\end{array}$ \\
\hline$Z_{f}$ & Inverter's filter impedance \\
\hline$Z_{\text {int }}$ & Inverter's Internal Impedance \\
\hline$Z_{L}$ & Impedance of the Inductive Load \\
\hline$Z_{w}$ & Wire's Impedance \\
\hline$\Delta P_{\text {cond }}$ & Conductive Power Losses of the Switching Semiconductors \\
\hline$\Delta P_{\text {copper }}$ & Copper Power Losses of the Inductor \\
\hline$\Delta P_{\text {core }}$ & Core Power Losses of the Inductor \\
\hline$\Delta P_{s w}$ & Switching Power Losses of the Switching Semiconductors \\
\hline$\zeta$ & Damping factor \\
\hline
\end{tabular}




\begin{tabular}{|c|c|}
\hline$\eta$ & Total Converter Efficiency \\
\hline$\theta_{i n v}$ & Inverter's Angle \\
\hline$\omega_{c}$ & Leakage Term of the PR Controller \\
\hline$\omega_{\text {inv }}$ & Inverter Frequency \\
\hline$\omega_{n}$ & Main Nominal Frequency \\
\hline Subscript & Description \\
\hline$C C L$ & Current Controller \\
\hline$F$ & Output Filter of Inverter \\
\hline$V$ & Stationary Frame PR Controller \\
\hline SOGI & SOGI Filter \\
\hline$S T$ & Stationary Frame \\
\hline$d, q$ & Variables in Synchronous $d q 0$ Frame \\
\hline$\alpha, \beta$ & Variables in the stationary $\alpha \beta$ Frame \\
\hline$a$ & Phase a \\
\hline
\end{tabular}




\section{Chapter 1. Introduction}

\subsection{Background}

Currently, electrical transmission and distribution losses in North America constitute more than $5 \%$ of total electrical energy production[1], [2]. This is enough electricity to power the Canadian province of Ontario for an entire year.

One promising approach to reduce energy losses while also improving reliability is the use of Distributed Generators (DGs) in microgrids [3], [4]. A microgrid is defined as:

Microgrid: a group of interconnected loads and distributed energy resources within clearly defined electrical boundaries that acts as a single controllable entity with respect to the grid. A microgrid can connect and disconnect from the grid to enable it to operate in both grid-connected or island mode. ${ }^{1}$

DGs reduce transmission and distribution losses by bringing power generation closer to the consumer's site losses. DG formed microgrids can connect to a grid or operate autonomously in islanding mode [4].

Nowadays, a microgrid can operate without the support of electromechanical generators using power electronics based inverters powered by renewable energy sources, battery storage or fuel cells. [5].

Moreover, Electrical Vehicles (EVs) connected to the microgrid can act as Distributed Storage (DS) for peak power shaving or peak delivery [4], [6], [7].

\footnotetext{
${ }^{1}$ Definition from the federal US Department of Energy (DOE).
} 
While the size of the microgrid (which varies from a few $\mathrm{kW}$ to $\mathrm{GW}$ [8], [9]) has a significant impact on its modelling, analysis and control [9]-[12], the number and type of the components in the microgrid is also crucial.

The massive introduction of EVs in the foreseeable future may have a substantial socioeconomic impact on the 130M single-phase consumers in Canada and USA (see Fig. 1-1), who currently consume (see Fig. 1-2) more than $30 \%$ of electrical energy produced in these countries [1], [2]. EVs can provide the consumer distributed mobile storage [4], [6], [7], [13], [14], which can be used for peak shaving and even to transport energy from one place to another.

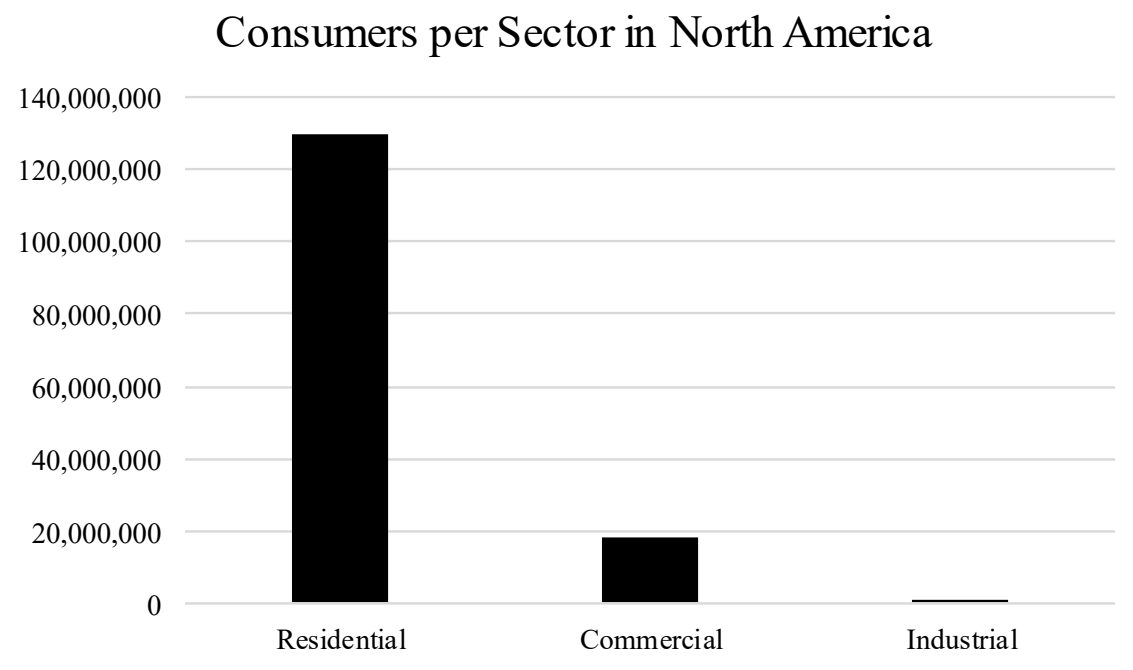

Fig. 1-1 Consumers of electrical energy per sector in North America

Massive EV deployment could, however, stress the current power infrastructure, especially the distribution transformers. It could also cause increased losses on the distribution lines 
[15]-[24]. Community-based, single-phase nanogrids could help to relieve this stress and reduce these losses

A nanogrid is defined as:

Nanogrid: a small electrical domain connected to the grid of no greater than 100 $\mathrm{kW}$ and limited to a single building structure or primary load or network of off-grid loads not exceeding $5 \mathrm{~kW}$, both categories representing devices (such as DG, batteries, EVs, and smart loads) capable of islanding and/or energy self-sufficiency through some level of intelligent DER management or controls. ${ }^{2}$

Deployment and integration of EVs into nanogrids will therefore stimulate electrical production from renewable sources, and co-generation from both residential and office spaces [17].

\footnotetext{
${ }^{2}$ A term originated by Lawrence Berkeley National Laboratory.
} 


\section{Consumption per Sector in North America}

(Thousands Megawatts)

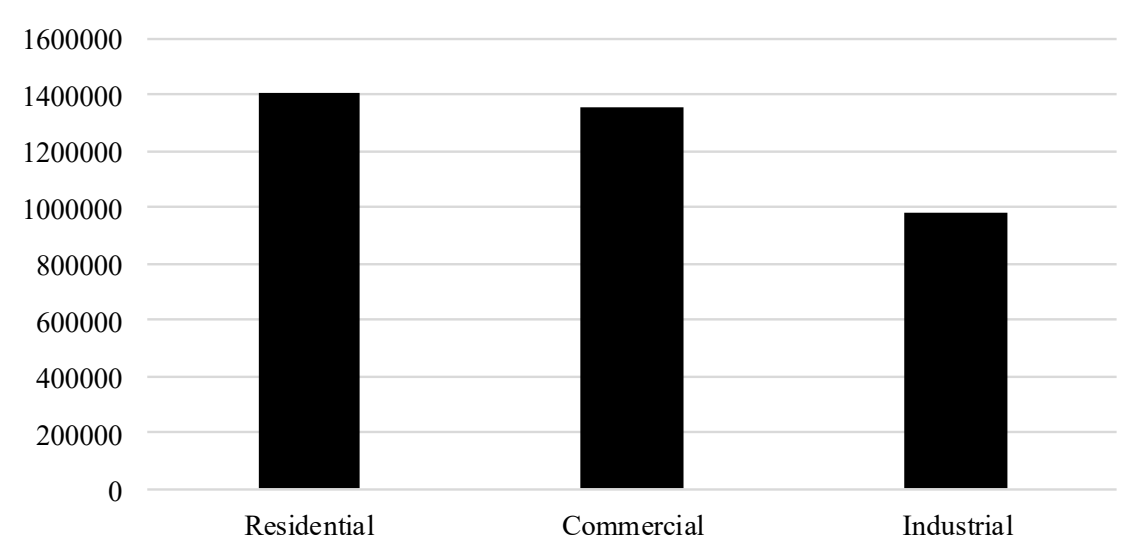

Fig. 1-2 Electrical energy consumption per sector in North America

To fully prepare the grid and/or electric system for the massive integration of EVs, the Ontario government created the Smart Grid Fund (SGF) initiative. It is aimed at addressing the challenges mentioned above and gathering experimental data from the integration of DGs and energy storage. [25].

A specific integration challenge is the control of grid-forming inverters during autonomous operation of household nanogrids without the support of the main grid. Data gathered includes the data associated with grid-support operations, such as peak shaving and timeshifting of generation. 
This research originates from the Ontario Smart Grid Fund (SGF) initiative. It is focused on the small-signal stability problem associated with the control of grid-forming inverters in community-based single-phase nanogrids.

\subsection{Objective and Scope}

Over the past two-decades, microgrid research has mainly focused on three-phase systems. Single-phase systems were neglected.

This research originates from the technical challenges observed during the implementation of a single-phase nanogrid project. The aim of the thesis is to continue the research recently started by [9] and answer the following general question: What are the similarities and differences between the small scale single-phase nanogrid and the traditional electromechanical generator based grid and why?

More specifically, this thesis tries to answer the following four specific questions:

- What are the benefits of Direct Current Hysteretic Control (DCHC) in AC-DC converters using wide-bandgap semiconductor (WBS) switches?

- How to generalize the tuning process for the resonant controller used in the gridforming inverter application? Which parameters of the load affect the inverter's performance? 
- How to model inverters in a single-phase nanogrid in order to apply classical stability analysis?

- How to validate the methodologies and conclusions resulting from the above three questions?

The scope of this thesis can be summarized as follows:

- To conduct a comprehensive literature survey in the area of modern control methods for WBS based power converters and inverters, resonant controller tuning optimization, and nanogrid modelling and stability analysis. The survey covers the topics of (1) control and optimization strategy for bi-directional AC-DC converters, (2) control and tuning optimization methods for stand-alone and grid-connected inverters, (3) the modelling and control of single-phase grid-forming inverters, and (4) the nature and characteristics of the small scale nanogrid.

- To establish a method for efficiency optimization of the bi-directional SiC-based AC-DC converter

- To establish a generic optimization method for tuning resonant controllers in the stationary frame

- To establish adequate mathematical models to represent the single-phase gridforming inverter in synchronous $d q 0$ frame without losing information regarding inner stationary frame voltage and current loops. The validity of the developed models is evaluated using both circuit level simulation (Matlab/Simulink) and 
experimentation. The mathematical models developed form the foundation on which the single-phase grid-forming inverter and single-phase nanogrid can be investigated and evaluated.

\subsection{Thesis Outline}

This first chapter briefly described the challenges observed during the implementation of a single-phase household nanogrid project. The remainder of the thesis is organized as follows:

The single-phase household nanogrid project mentioned above is presented in Chapter 2 . Chapter 3 provides a comprehensive literature review related to the observed problems. It also presents a methodology of how the literature review was conducted.

Chapter 4 pre introduces a novel control and optimization strategy for a bi-directional, three-stage, On-board Battery Charger (OBC) achieving 80 PLUS Titanium efficiency (previously published [26]).

Chapter 5 addresses the lack of a generalized tuning method for a resonant controller (which is an essential component of an off-grid inverter voltage control system). The Modulus Optimum tuning method is revised for application to a resonant controller. This research work has been presented at CCECE, Edmonton, 2019 [27]. 
A modelling approach for analyzing the single-phase nanogrid and its components is proposed in Chapter 6. It introduces a time-invariant model in the synchronous frame for the single-phase grid forming inverter.

Further discussion and conclusions of this thesis along with suggestions for future work are presented in Chapter 7. 


\section{Chapter 2. The Single-phase Nanogrid Project}

This chapter provides a brief overview of the single-phase nanogrid project and the practical challenges observed during project execution. These observed challenges and the lack of publications on the single-phase nanogrid triggered this research.

\subsection{Single-Phase Nanogrid Project Overview}

Hydro Ottawa and the Government of Ontario initiated a single-phase household nanogrid project in 2015 to address issues related to integration of distributed sources, storage and EV in the traditional grid [25], [28]-[31]. The program goal is a "smart" integration of DGs in Ontario's grid on the community level. It aims to help mitigate the negative effect from the time difference between EV charging and solar energy production on the local distribution grid including its transformers. In this project, ten nanogrid field sites were installed in Hydro Ottawa's coverage area. The size of PV generation in the nanogrids ranged from $3 \mathrm{~kW}$ to $6 \mathrm{~kW}$. Battery storage size ranged from between $6.8 \mathrm{kWhr}$ to 11.2 kWhr. Nanogrids were installed in single-family houses with compatible roofs. Fig. 2-1 shows a typical single-phase nanogrid topology diagram. The main nanogrid components consist of:

- Photovoltaic (PV) inverters;

- On-board battery charger (OBC) (for experimental laboratory installation).

- Bi-directional grid forming battery inverters (see Fig. 4-2 for details); 
- Intelligent Distributed Panel (IDP);

- Grid-Tie Switch (GTS);

- Utility communication and control, homeowner monitoring device.

The nanogrid can operate in two modes: grid-tie and autonomous (islanded or selfforming).

Grid-tie mode is intended to provide the following grid support services:

- Time shift PV power production using storage;

- Smooth short term (minutes) fluctuations in load or PV generation;

- California Rule 21 [32] behaviours e.g. fault ride through, Volt -Watt, Volt - Vars;

- Hard limit on peak demand, e.g. $10 \mathrm{~kW}$;

The self-forming nanogrid mode has the following distinguishing features:

- No "master" generator setting grid voltage or frequency;

- Battery inverters provide four-quadrant power flow and operate as a grid-forming inverter;

- PV inverters provide two-quadrant power flow and operate the same as grid-tie operation mode;

- The grid is formed by the first battery inverter to start;

- Next battery inverter connects and synchronizes its phase and frequency to the first battery inverter; 
- PV inverters connected by the IDP once the grid is formed. 


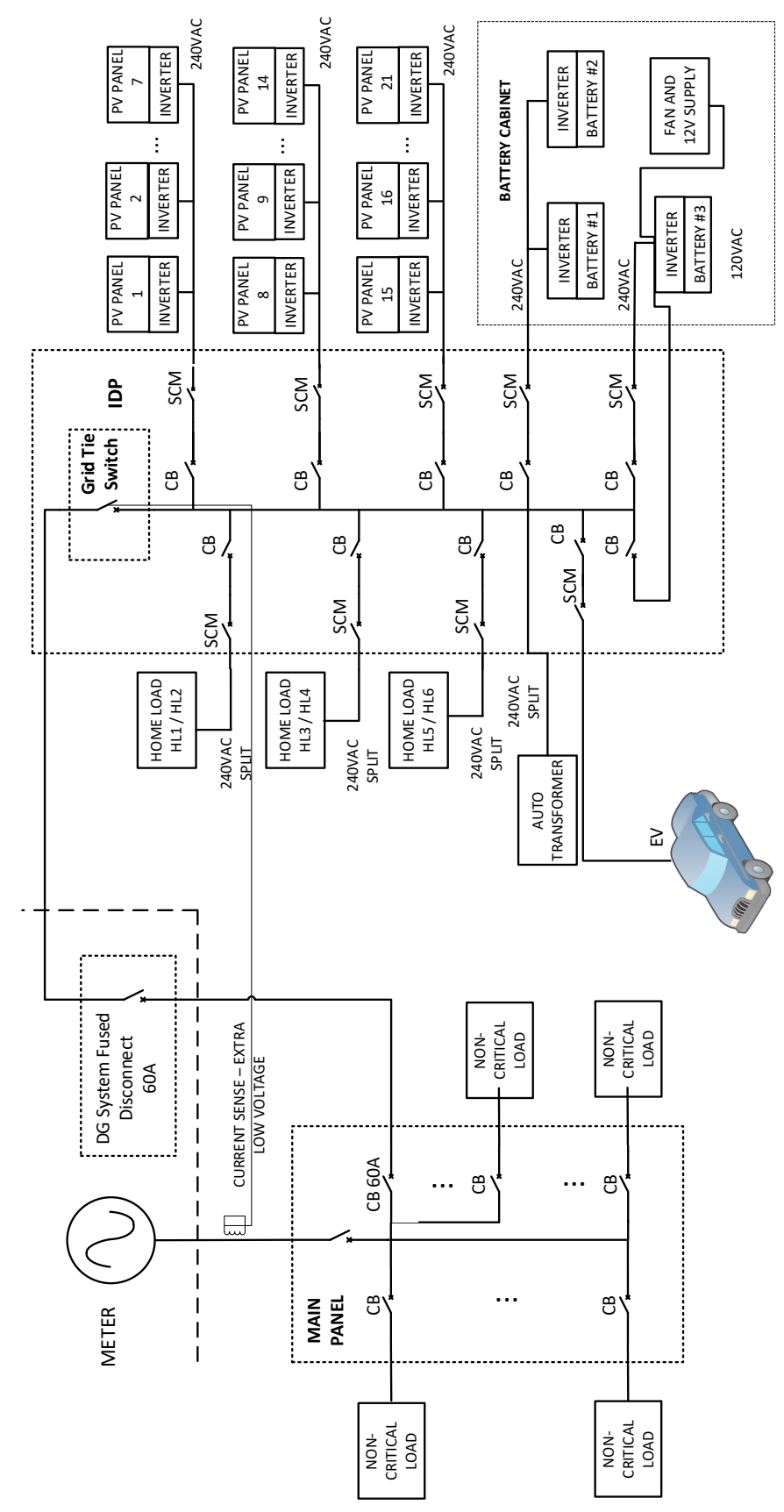

Fig. 2-1 Single-phase nanogrid topology 


\section{Chapter 3. Literature Review and Gap Analysis}

The literature review was conducted to shed light on the problems found during the initial nanogrid test. A variety of control methods, from traditional to state-of-the-art were reviewed and are summarized in this section. Literature search strategy is an important topic for thesis research. The following search strategy was used:

- Separate search methodology for Classical and State of the art control methods;

- The search time frame for Classical methods was restricted to the past twenty-five years (1994-2019).

- Moreover, The search time frame for the state-of-the-art methods was restricted to the past five years (2014-2019).

IEEE and IET journals, conference papers, and books in the IEEE Xplore digital library were searched. The Carleton University library website was used for papers and books not available on IEEE Xplore.

The keywords used in the literature search include: hysteresis current control, proportional-resonant controller, small-signal stability, microgrid, nanogrid. Any search results concerning hybrid microgrids (i.e. involving rotational machinery) were discarded. This rest of this chapter is organize as follows Section 3.1 presents the results of the OBC performance optimization literature review ; Section 3.2 provides a literature review and gap analysis of tuning optimization for the inverter voltage control loop in off-grid systems. 
Section 3.3 details the literature review and gap analysis in the field of nanogrid modelling. Lastly, section 3.4 summarizes the major findings.

\subsection{Bi-Directional OBC Performance Optimization}

An increasingly popular application for EVs is to serve as distributed storage and provide

grid support during peak hours by integration into the grid. option [33]. An OBC would provide the interface between the EV's battery and the grid. The choice of the OBC's power topology and control scheme is crucial for a successful integration of EVs [34], [35].

A Bi-directional OBC typically includes a bi-directional Power Factor Correction (PFC) stage and an isolating DC-DC stage. The primary side of the DC-DC stage connects to the PFC and its secondary side connects to the battery. One of the favorite candidates for the isolating portion of the DC-DC stage is the Dual-Active Bridge (DAB). The main advantages of the DAB are its simple current control scheme and its ability to reverse energy flow within a few switching cycles [36], [37]. However, there are two major disadvantages of the DAB: its limited Zero-Voltage Switching (ZVS) operating zone and its large recirculating current. Although the ZVS operating zone can be extended by using Wide-Bandgap Semiconductors (WBS) devices such as Silicon Carbide (SiC) or Gallium Nitride $(\mathrm{GaN})$, the recirculating current is still a problem and can significantly reduce efficiency. 
Recently, a Capacitor-Inductor-Inductor-Inductor-Capacitor (CLLLC) resonant converter topology was reported as another candidate for an OBC's bi-directional isolating DC-DC stage [38], [39]. This topology provides high efficiency with low recirculating current near the unity gain operation point. Because the gain of CLLLC is unity, its operating range is achieved by widely varying the bulk voltage on the PFC stage. However, this can result in high switching losses on the PFC stage and thus a reduction on efficiency [38].

Direct Current Hysteretic Control (DCHC) was developed for control of the current in the inverter stage to enhance the control bandwidth and improve steady-state performance [40]-[44]. The switching pattern is optimized by using variable frequency and adaptive dead-time provided by the software-hardware based DCHC.

\subsection{Resonant Controller Tuning Optimization}

Nowadays, distributed generators produce a significant amount of energy for both gridtied and off-grid applications. Control of distributed generators has attracted research attention in the past twenty years, along with advancements in the areas of power electronics and renewable energy [40], [45]. There are two basic types of controllers for distributed generators: synchronous frame controllers and stationary frame controllers [46]-[48]. For the synchronous frame controller, the reference variables and the controlled variables under steady-state conditions are DC values. For the stationary frame controller, 
the reference variables and the controlled variables are sinusoidally varying wave forms [49].

Stationary frame resonant controllers are widely used in distributed power generation control [50].

A Proportional Resonant (PR) controller eliminates the need for the $a b c$ to $d-q$ transformation in the case of single-phase systems [49] and provides zero steady-state error at $\mathrm{AC}$ frequency with minimal computational burden [49], [51], [52]. The PR controller is valid for both single- and three-phase systems with grid-tie and off-grid inverters. The behavior of the PR controller can be described through analogy with the better known PID controller. The resonant term is analogous to the integral term of the PID controller and allows precise steady-state regulation at the AC frequency[49], [53].

Optimization of the PR controller for the grid-tie inverter current control loop is widely presented in publications [49], [51]-[60]. The optimization methods include rootplacement analysis [54], [56], [58], duality with PID controller [51]-[53], [59], and artificial intelligence approaches [55],[57]. The effect of the inverter's parameters on controller coefficients and the control loop stability for the optimized control loop are discussed in [51], [52].

Research efforts in the past decades were focused mostly on application-oriented performance optimization for grid-tie operation. A PR controller for off-grid applications is only reported in a few papers related to Uninterruptable Power Supplies (UPS) [61], 
[62], and more recently for single-phase nanogrid applications [63], [64]. However, singlephase nanogrid research is essential for North America, where a massive introduction of EVs to the continent's 130M single-phase consumers is beginning [1], [2]. EVs can act as a household's distributed mobile storage [4], [6], [7], [13], [14] but can also stress the grid infrastructure. Community-based, single-phase nanogrids could help to reduce this stress and mitigate transmission and distribution losses associated with the introduction of EVs. To understand the importance of optimizing the inverter's inner voltage control loop, a closer look should be taken at the latest trend in three-phase microgrid research and the influence of the fast inner control loop on the stability of the slower modes [9]-[12], [65][67]. This motivated this research to study the stability and optimization of the voltage loop of the single-phase off-grid inverter.

The general idea of PID controller optimization is to find a set of control coefficients, which provides a fast response to high frequency command, zero or near-zero static error, disturbance rejection, and reasonable phase and gain margins.

The most common optimization criteria include the Integral Absolute Error (IAE), the Integrated Time Absolute Error (ITAE), and the Integrated Square Error (ISE) [68], [69]. The Modulus Optimum (MO) is also a PID controller design approach based on optimization [69]. The MO shapes a transfer function to desired optimized characteristics by adding a control function. Therefore, $\mathrm{MO}$ is considered to be a loop-shaping technique. 
The tuning optimization of a control loop in the stationary frame must consider the sine wave signal nature of controlled variables. Therefore, the following additional requirements for tuning optimization in the stationary frame should be considered [49]:

- High rejection ratio for undesirable harmonics content $\left(\mathrm{DC}, 3^{\text {rd }}, 5^{\text {th }}, \ldots, n^{\text {th }}\right)$;

- Zero or near-zero static phase tracking error;

- Zero or near-zero static amplitude tracking error.

This research intends to extend the MO tuning technique to tune the PR controllers in a stationary reference frame while satisfying all the requirements listed above. The wide variety of operating conditions and their dynamics present a challenge for the tuning optimization of the voltage control loop for off-grid voltage source inverters. Root-Loci and pole-placement analysis represent the current research activities of PR controller tuning optimization in the voltage control loop [61], [62]. A thorough root-loci analysis for single-loop voltage control of off-grid inverter is given in the paper [61]. However, the main focus of the analysis is the effect of the controller digitizing method on the control loop. The paper does not establish the relationship between proportional and resonant part of the controller. In addition, it does not analyze the effect of the different operating conditions. Reference [62] investigates the effect of Smith's predictor on improving the inner current loop dynamics, and as a consequence, an improvement in the voltage loop is achieved. Optimization of the voltage control loop, however, is not discussed in this paper. 
Reference [63] discusses the harmonic compensation of a voltage source inverter in an islanded single-phase nanogrid. This is an important topic, as it allows producing a lowTHD voltage, even while supplying a highly non-linear load. Harmonic compensation is realized using a group of resonant controllers, each tuned to control different harmonics of the voltage. However, the tuning method of the harmonic compensation is not provided. Reference [64] provides a comprehensive analysis of another nanogrid operating mode: the transition between islanded and grid connected operation. However, similar to previously discussed references, the optimization and stability concerns of the inner voltage control loop are not considered.

To help address these gaps, Chapter 5 of this work proposes a modified MO tuning method, which extends the MO method to the stationary frame. The proposed technique has the same dynamic behavior as the original MO method, but the steady-state performance is revised to mitigate steady-state amplitude and phase errors in the stationary frame. This method can be directly applied to the transfer function of the voltage source inverter in a stationary frame. Optimum utilization of the presented control bandwidth is achieved, and the relationship between the PR controller's proportional and resonant coefficients is obtained. 


\subsection{Nanogrid Modelling}

Although single-phase, grid-connected and stand-alone inverters modelling, control and analysis [49], [51]-[53], and single-phase instantaneous power theory [70]-[73] have been heavily explored during last two decades, the single-phase nanogrid was off of most researchers' radar. Single-phase nanogrid research has only appeared in a few isolated publications, initially related to paralleling Uninterruptable Power Supply (UPS) [63], [64], [74]-[81]. This could be explained by the simple fact that single-phase nanogrids did not represent a significant source of power productions and disturbance in the past.

Therefore, the lack of single-phase nanogrid research represents a significant knowledge gap and could potentially influence or delay the introduction of single-phase, community base nanogrids in North America.

Historically, the stability control scheme and the analysis techniques for a power electronics inverter driven microgrid or nanogrid were similar to those used in the conventional grid. A reduced-order model, similar to the synchronous generator model [82], was used during these studies [77]. This approach yields good results for systems with low-frequency dynamics and significant wire impedance.

In recent years, however, researchers began to study the behavior of small-scale inverter driven three-phase microgrids [9]-[12], [65], [67], [83]-[89]. These small-scale microgrids have $\mathrm{L} / \mathrm{R}=3.1 \mathrm{~ms}-10 \mathrm{~ms}$ and the typical line length is between $1 \mathrm{~km}$ and $5 \mathrm{~km}[9]$. These studies conclude that the network dynamics, despite their fast nature, appear to have a 
major influence on the stability of slower modes. Therefore, a major emerging trend in the stability analysis of the small-scale microgrids is to use a detailed inverter model [84], [85], [87], and to study the mechanism of fast variables participation in the dynamic of slow modes [9]-[12], [65]-[67]. Although it would be preferable to obtain a compact, simplified model of the single-phase inverter for nanogrid stability analysis, a detailed model is required to understand the dynamic behavior of the inverter.

In light of the trends listed above, single-phase nanogrid related publications were reviewed. Paper [77] investigates the dynamics of the single-phase stand-alone AC-supply system. The inverter was modelled las an ideal voltage source with controlled amplitude and frequency however the dynamics of the control loop and inverter filter were excluded from the investigation. According to recent research [9], this approach cannot provide high-fidelity results for a single-phase nanogrid. Additional consideration of the inner control loop is required.

Reference [75] presents the most comprehensive small-signal stability analysis of a singlephase nanogrid to date. However, stability analysis was conducted in the same manner as [77] and using a simplified inverter model that only took considered the external power loop, and not the effect of the internal control loop.

The same short comings apply to [74], where the researcher credited the power-sharing control loop for power-sharing under non-linear load conditions even though the power measurement loop does not have enough bandwidth for this. 
Reference [64] provides a comprehensive analysis of another nanogrid operation mode: the transition between islanded and grid connection operation. Similar to the references discussed above, all of the credit for power control and sharing is given to the powersharing loop despite the power measurement circuit's low bandwidth in single-phase applications.

It can be concluded that recent studies in the field of single-phase nanogrids do not take into consideration the dynamics and stability of the inner control loop and are all based on a simplified dynamic model of the power-sharing loop. This contradicts the latest research trend for small-scale, three-phase microgrid studies [9]-[12], [65], [67], [83]-[89]. It can partially be explained by the complexity of system modelling when one part of the system is operating in the synchronous frame and another one in the stationary frame. Papers [63], [64], [74]-[77] use $d q 0$ synchronous frame to conduct stability analysis of converters in a nanogrid without consideration of the stationary frame dynamic and its contribution to the final result. To overcome this problem, a number of research papers convert the synchronous frame part of the inverter to the stationary frame and apply the theory of oscillators to solve the stability problem of the system [78]-[81]. Although this approach has promising results, interpretation is not as straightforward as the commonly used $d q 0$ frame for stability analysis. Moreover, the inverter's control loop parameters are not easily correlated with the obtained results. 
The conclusion of this literature review is that there is a significant knowledge gap in modeling techniques for stability control and analysis of single-phase nanogrids. Chapter 6 of this work attempts to fill this gap.

\subsection{Summary}

This chapter provides a comprehensive literature review of the topics of this thesis including: WBS's based bi-directional OBC performance optimization, tuning of PR controllers for off-grid applications, and modeling the single-phase nanogrid. The following gaps have been discovered:

- Lack of information regarding hysteretic controller for WBS's

- Lack of generalized optimization method for the stationary frame controller;

- Lack of modelling methodology for single-phase nanogrid and grid-forming inverters.

These gaps are addressed in the following chapters of this thesis. 


\section{Chapter 4. Three-Stage SiC-Based Bi-Directional OBC with Titanium}

\section{Level Efficiency}

This chapter proposes a novel control and optimization strategy for a bi-directional, threestage, OBC that meets the 80 PLUS Titanium efficiency standard.

An OBC can be an integral part of the nanogrid or work with the conventional grid. The proposed control strategy utilizes the benefits of Silicon Carbide (SiC) devices and is based on Direct Current Hysteretic Control (DCHC) with optimized switching patterns and dead time.

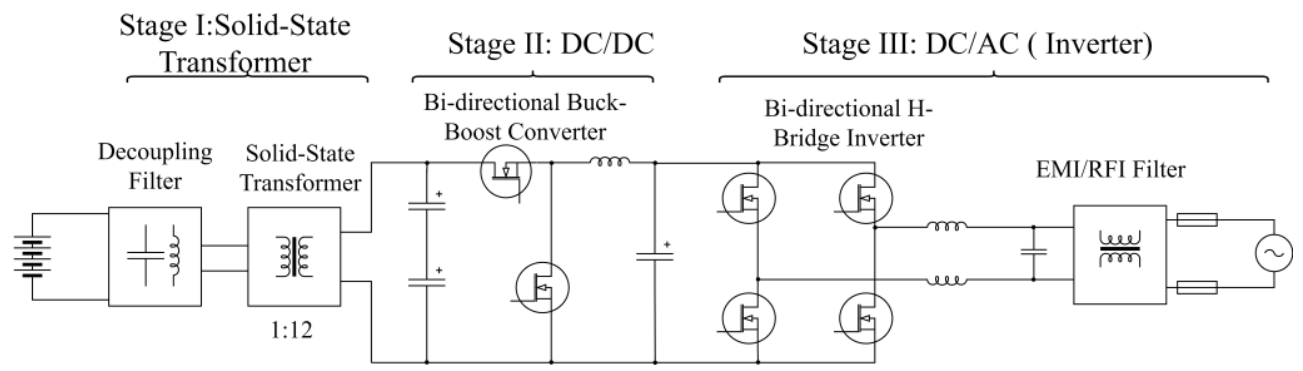

Fig. 4-1 The diagram of the on-board battery charge under consideration

As shown in Fig. 4-1, the first stage of the OBC is an isolated bi-directional DC/DC stage, which consists of a Solid-State Transformer (SST) that provides the isolation barrier and is operated under Zero-Current Switching/Zero-Voltage Switching (ZCS/ZVS) conditions. The second stage of the $\mathrm{OBC}$ is a bi-directional buck-boost converter that operates in CRritical conduction Mode (CRM) with automatic dead time optimization to achieve ZVS operation. The third stage is a high-efficiency H-bridge inverter with a DCHC controlled 
current loop to optimize dynamic and steady-state performance and provide a smooth transition between CRM and Continuous Conduction Mode (CCM). The DCHC is implemented using a hybrid software/hardware approach.

The experimental results in Section 4.3 confirm that the OBC can not only change the power flow direction within a few milliseconds but can also provide reactive power support for the grid. Additionally, the $\mathrm{OBC}$ achieves a peak efficiency of $96.65 \%$ and a minimum Total Harmonic Distortion (THD) equal to $1 \%$.

This chapter is based on the results [26] previously published in IET Power Electronics. The rest of this chapter is organized as follows. Section 4.1 presents the topology and basic operation of the proposed OBC. In Section 4.2, the principle of the improved DCHC is explained. Section 4.2 also discusses the switching pattern optimization technique. Experimental results and analysis are presented in Section 4.3. The summary and conclusion are presented in Section 4.4.

\subsection{Topology and the Principle of OBC Operations}

Fig. 4-2 shows the bi-directional OBC design used in this research and Table 4-1 lists the design parameters of the OBC. The $1 \mathrm{kVA}$ OBC prototype was designed for $48 \mathrm{~V}$ LithiumIon batteries. The control of the OBC is implemented using Solantro Semiconductor's IXC2 digital power processor. 
The OBC's charging mode operates as follows. The inverter sinks power from the grid. The buck-boost converter controls the power flow to the battery via the isolated bidirectional DC/DC stage and provides the voltage conditioning between the isolated bidirectional DC/DC stage's input voltage and the inverter stage's bulk voltage to extend and widen the operating range. The isolated bi-directional DC/DC stage operates with a constant gain and transforms voltage and current to the battery while providing galvanic isolation. In discharge mode (grid-support), the OBC operates in the same manner except for the direction of the power flow. Moreover, the $\mathrm{OBC}$ can also provide reactive power to support the grid in this mode. 
Table 4-1 Parameters of Bi-Directional On-Board Battery Charger under Considerations

\begin{tabular}{lc}
\hline Parameter & Value/Type \\
\hline Nominal Battery Voltage & $48 \mathrm{~V}(\mathrm{DC})$ \\
Battery voltage range & $33-63 \mathrm{~V}(\mathrm{DC})$ \\
Nominal Battery Current & $21.5 \mathrm{~A}(\mathrm{DC})$ \\
Nominal AC voltage & $230 \mathrm{~V}(\mathrm{AC})$ \\
Nominal AC current & $4.4 \mathrm{~A}(\mathrm{rms})$ \\
$\begin{array}{l}\text { Isolated bi-directional DC/DC stage operating } \\
\text { frequency }\end{array}$ & $125 \mathrm{kHz}+/-10 \%$ \\
Buck-boost and H-Bridge operating frequency & Variable 40kHz-400kHz \\
High side switches & C3M0065090J by CREE \\
Low side switches & IPT012N08N5 by Infineon
\end{tabular}




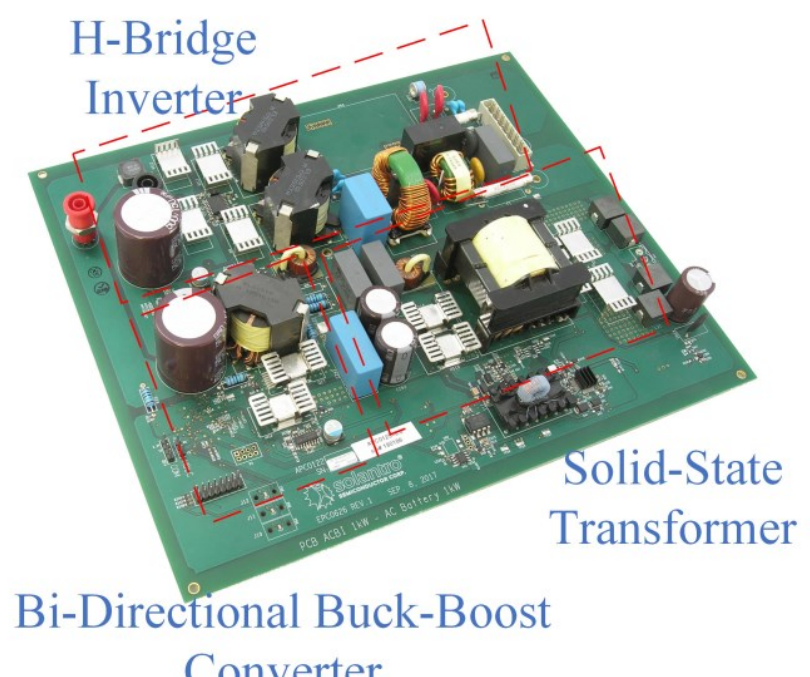

Fig. 4-2 Three-stage Titanium efficiency SiC based hardware platform. Initially used as bi-directional $\mathrm{OBC}$, later adopted as a grid-forming battery inverter for islanded applications

\subsection{The Efficiency and Control Optimization Strategy}

\subsubsection{Principle of Hybrid DCHC Operations}

The inner current loop of the inverter stage and the bi-directional buck-boost stage are implemented using DCHC. Fig. 4-3 shows the DCHC block diagram and the DCHC settings for both Critical Conduction Mode (CRM) and Continuous Conduction Mode (CCM) mode. DCHC is achieved using a hybrid software-hardware approach. The significant difference between DCHC and a traditional hysteretic control method is a controllable hysteretic band. In traditional hysteretic control the hysteretic band is defined 
by a constant hysteresis value. The settings for the DCHC hysteretic band however, are calculated by IXC2's CPU and updated on each interrupt cycle based on the geometrical relationship described by equations (4-1) - (4-3) (see Fig. 4-3).
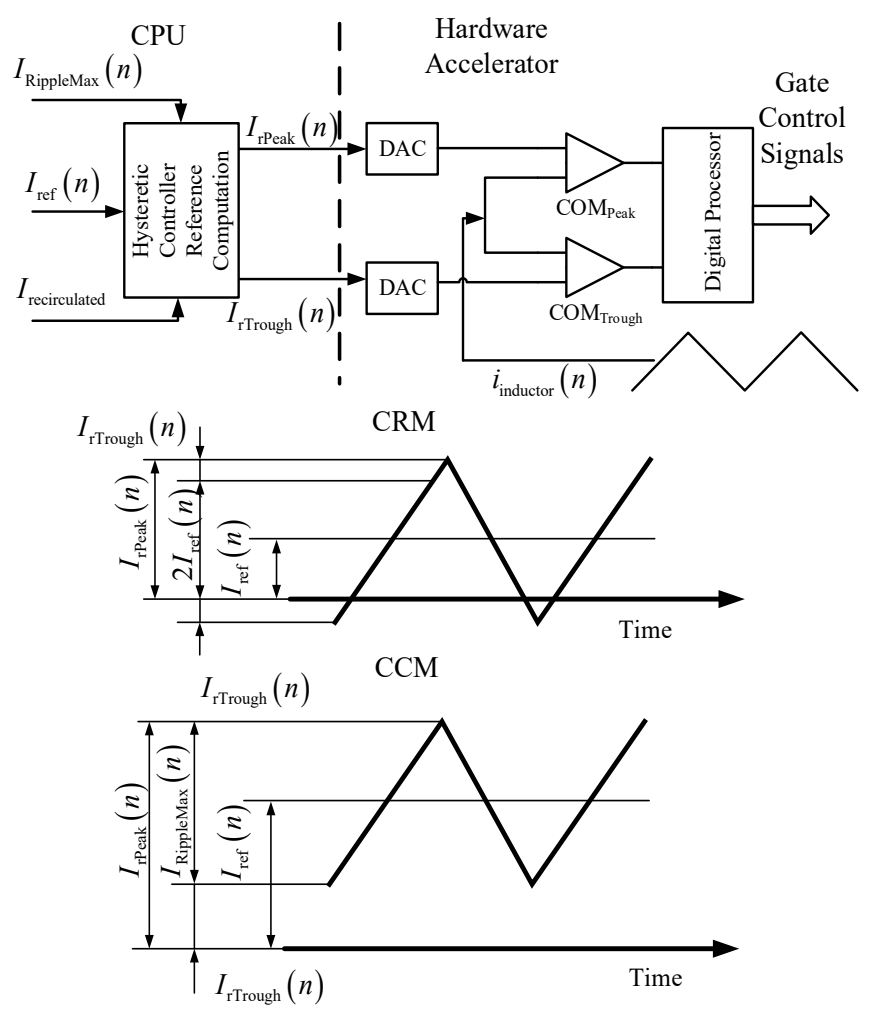

Fig. 4-3 DCHC block diagram (top), and DCHC settings for CRM (middle) and CCM (bottom)

DCHC is implemented by the IXC2's hardware which includes low-latency comparators and a dedicated hardware accelerator. The operating frequency is independent of the CPU interrupt cycle. This method provides flexibility for the DCHC and mitigates the 
computation burden when WBS switches are used. To ensure self-resonance of the switching node and ZVS conditions in CRM mode, the lower limit of the inductor current is set to a negative value. The upper limit of the inductor current is set to twice the current reference $\left(I_{r e f}(n)\right)$ plus the recirculated current (4-1). The value of the recirculated current is a constant and depends on the type of semiconductor switch and the switching inductor value. The inductor current in CCM mode is limited around the current reference by the value of the hysteresis band $I_{\text {RippleMax }}(n)(4-2)$. The transition between CRM and CCM occurs seamlessly when the current reference reaches a half value of the hysteresis band $I_{\text {RippleMax }}(n)(4-3)$.

$$
\begin{gathered}
I_{\text {rTrough }}(n)=I_{\text {recirculated }} \\
I_{\text {rPeak }}(n)=2 I_{\text {ref }}(n)+I_{\text {rTrough }}(n) \\
I_{r \text { Trough }}(n)=I_{\text {ref }}(n)-I_{\text {RippleMax }}(n) / 2 \\
I_{r \text { Peak }}(n)=I_{\text {ref }}(n)+I_{\text {RippleMax }}(n) / 2 \\
I_{\text {ref }}(n) \geq I_{\text {RippleMax }}(n) / 2
\end{gathered}
$$

It should be noted that the inductor ripple current, $I_{\text {Ripple}}$, varies during CRM operation and is constant during CCM operation.

$$
I_{\text {Ripple }}= \begin{cases}2 I_{\text {ref }}(n)+2 I_{\text {recirculated }} & \mathrm{CRM} \\ I_{\text {RippleMax }}(n) & \mathrm{CCM}\end{cases}
$$


In hysteretic control, the state of the switches is a result of the current peak and current trough hysteretic control settings $\left(I_{r P e a k}, I_{r \text { Trough }}\right)[41]$ - [42].

\subsubsection{Inverter Efficiency and Control Optimization Strategy}

The inverter is controlled in the following way: the CPU computes the current reference $I_{\text {ref }}(n)$ for the inverter based on the mode of operation (charging or grid supporting). The DCHC settings are calculated according to equations (4-1) to (4-3). At low power, the inverter operates in CRM with a dead-time, which is automatically optimized to achieve optimum ZVS condition. However, at high power, the inverter operates in a combination of CRM and CCM to reduce conductive losses.

Unlike classical pulse width modulation (PWM) control with a constant switching frequency and variable ripple current, DCHC operates with a variable switching frequency[41] - [42]. High-frequency switching during CCM would cause excessive switching losses. Therefore, the switching frequency pattern during CCM operations should be optimized to find an optimum balance between inverter's switching and conductive losses. The following observation can be made: most of the losses for a given power level are distributed between the switching semiconductors and the switching inductor [3]. Therefore, the losses can be expressed as the conduction and switching losses of the semiconductors ( $\Delta P_{\text {cond }}$ and $\left.\Delta P_{s w}\right)$ and the core and copper losses ( $\Delta P_{\text {core }}$ and $\left.\Delta P_{\text {copper }}\right)$ of the switching inductor. 
The total loss $\left(\Delta P_{\text {losses }}\right)$ can be expressed as Equation (4-5). It should be noted that the individual losses in Equation (4-5) have a non-linear dependence on the ripple current $I_{\text {Ripple, }}$, the operation point current $I_{D C}$, the switching frequency $f_{s w}$, and the temperature of the device $T$.

$$
\begin{gathered}
\Delta P_{\text {losses }}=\Delta P_{\text {cond }}\left(I_{\text {Ripple }}, I_{D C}, T\right)+\Delta P_{\text {sw }}\left(I_{\text {Ripple }}, I_{D C}, f_{s w}, T\right) \\
+\Delta P_{\text {core }}\left(I_{\text {Ripple }}, f_{s w}, T\right)+\Delta P_{c u}\left(I_{\text {Ripple }}, I_{D C}, f_{s w}, T\right)
\end{gathered}
$$

The switching frequency and the inductor ripple current have a significant impact on the high-frequency losses. This work proposes to find the optimum switching frequency and inductor ripple current for the system experimentally. During the experiment, the ripple current becomes a dynamic variable, and it is modified when the frequency during CCM operations stays almost constant near the target value $f_{\text {target }}(4-6)$. In (4-6), $V_{\mathrm{DC}}(n)$ is the instantaneous bulk voltage, and $V_{\mathrm{AC}}(n)$ is the instantaneous mains voltage. The experiment was first carried out at full power. The inverter stage losses were measured by the integration of the input power under steady-state temperature conditions. After the optimum switching frequency for a full power level is determined, the experiment was repeated at other power levels.

$$
I_{\text {ripple }}[n]=\frac{V_{d c}^{2}[n]-V_{a c}^{2}[n]}{2 f_{\text {target }}[n] V_{d c}[n] L}
$$

Table 4-2 lists the inverter losses and the switch temperature test results at full power vs maximum switching frequency at CCM. The temperature was measured using a Type-K 
thermocouple and a Keithley 2700 data acquisition system. The temperature of the device under test is a reasonable indicator of the switching semiconductor power losses. The temperature of the switching semiconductors monotonically increases with the maximum switching frequency. However, a minimum in he overall losses is achieved at the switching frequency of $50 \mathrm{kHz}$ due to the losses in the inductors.

Table 4-2 Efficiency optimization test results for inverter stage of $\mathrm{OBC}$

\begin{tabular}{ccc}
\hline $\begin{array}{c}\text { Maximum Switching } \\
\text { Frequency at CCM }\end{array}$ & Inverter Stage Losses & $\begin{array}{c}\text { Switching Semiconductor } \\
\text { Temperature }\end{array}$ \\
\hline $40 \mathrm{kHz}$ & $15.2 \mathrm{~W}$ & $70^{\circ} \mathrm{C}$ \\
$50 \mathrm{kHz}$ & $13.8 \mathrm{~W}$ & $75^{\circ} \mathrm{C}$ \\
$60 \mathrm{kHz}$ & $15.5 \mathrm{~W}$ & $83^{\circ} \mathrm{C}$ \\
$70 \mathrm{kHz}$ & $16.6 \mathrm{~W}$ & $92{ }^{\circ} \mathrm{C}$
\end{tabular}

Fig. 4-4 shows the inverter's inner loop controller's variables, which were obtained during the full power $(1 \mathrm{~kW})$ charging tests. The figure plots the current reference, the peak and trough settings of the DCHC and the inverter switching frequency over one grid cycle. It can be observed that the inverter freely transitions from CRM to CCM. The inverter's maximum operating frequency in $\mathrm{CCM}$ is set to around $50 \mathrm{kHz}$ to keep it close to the maximum efficiency point. 


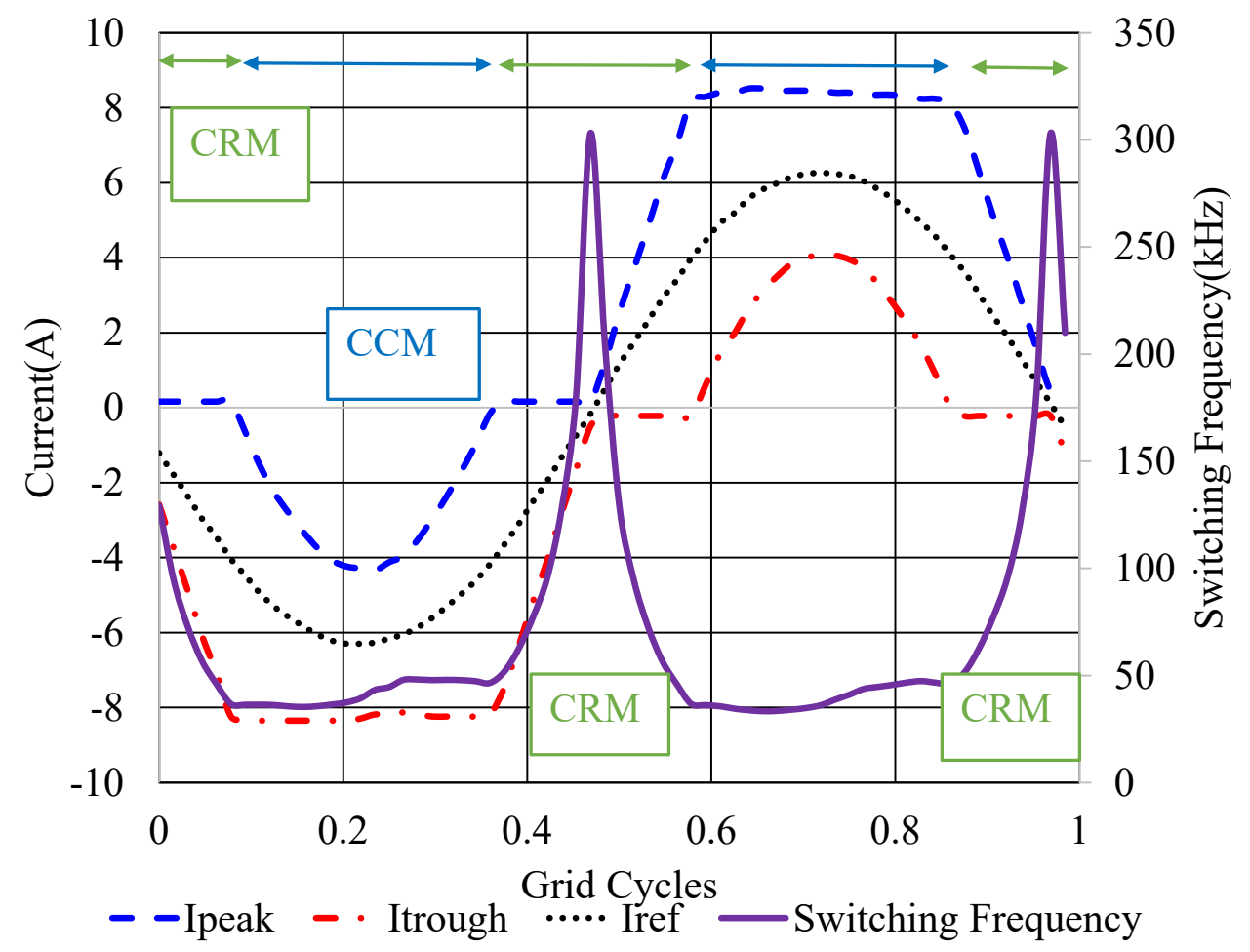

Fig. 4-4 Plot of internal microcontroller's variables: hysteretic controller settings over the grid cycle, switching frequency, and operation modes for $1 \mathrm{~kW}$ charge operation

\subsubsection{Bi-Directional DC-DC stage operations}

The isolated bi-directional DC/DC stage and the buck-boost converter jointly form the OBC's bi-directional DC-DC stage. This stage provides galvanic isolation between the grid and the battery and controls the battery current. The isolated bi-directional DC/DC stage is implemented as a series resonant converter with a high ratio between its resonant and magnetization inductances to mitigate losses associated with magnetization current (see Fig. 4-5). 

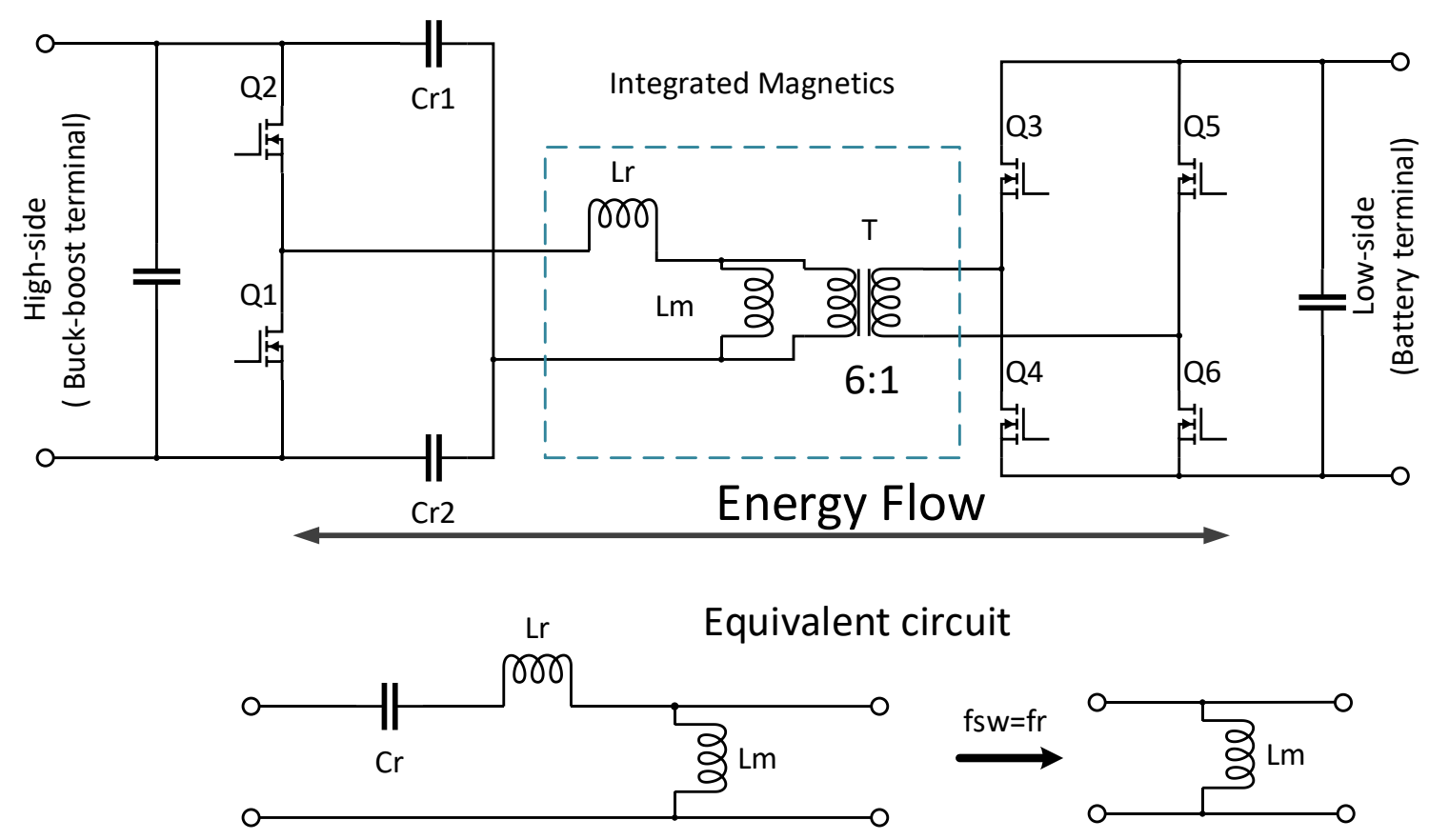

Fig. 4-5 Isolated bi-directional DC/DC stage simplified schematics (Top) and its equivalent circuit

\section{(Bottom)}

The isolated bi-directional DC/DC stage operates near its resonant operation point with unity gain, and the buck-boost converter defines the direction of the power flow and its value. The operating frequency of the isolated bi-directional DC/DC stage is automatically adjusted by the IXC2 control chip to accommodate the tolerances of the resonant tank's components. The isolated bi-directional DC/DC stage inherits ZVS switching on its primary switches and ZCS on its secondary switches from the nature of a series resonant converter [90]. The bi-directional buck-boost converter is responsible for the battery 
current and its direction, as well as the voltage conditioning for the inverter. To optimize performance, this stage operates with a high voltage (400V to $575 \mathrm{~V})$ and a nominal current of $2.5 \mathrm{~A}$ in CRM.

\subsection{Experimental testing and analyzing}

Dynamic performance, THD, and efficiency tests were carried out to validate the effectiveness of the proposed control and optimization approach. The control algorithm is implemented in the IXC2 digital power processor. Fig. 4-6 depicts the test setup for the efficiency and THD measurements. The test setup for dynamic measurements includes a 48V Li-ion battery from Simpliphi instead of an electronic load.

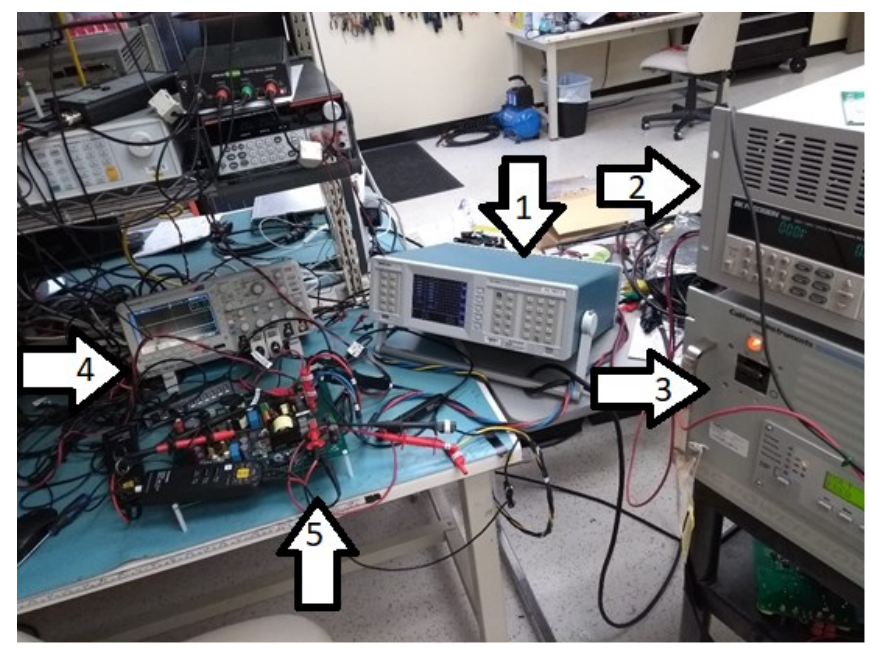

Fig. 4-6 The setup for efficiency and THD, and dynamic measurements. Setup is not energized. 1) PA4000 power analyzer by Tektronix; 2) $2.4 \mathrm{~kW}$ electronic load by BK Precision; 3) 3kVA AC source by California Instruments; 4)Oscilloscope; 5) Unit Under Test 
Fig. 4-7 shows the dynamic performance of the $\mathrm{OBC}$ as it changes operating mode from grid-support mode to battery charging mode.

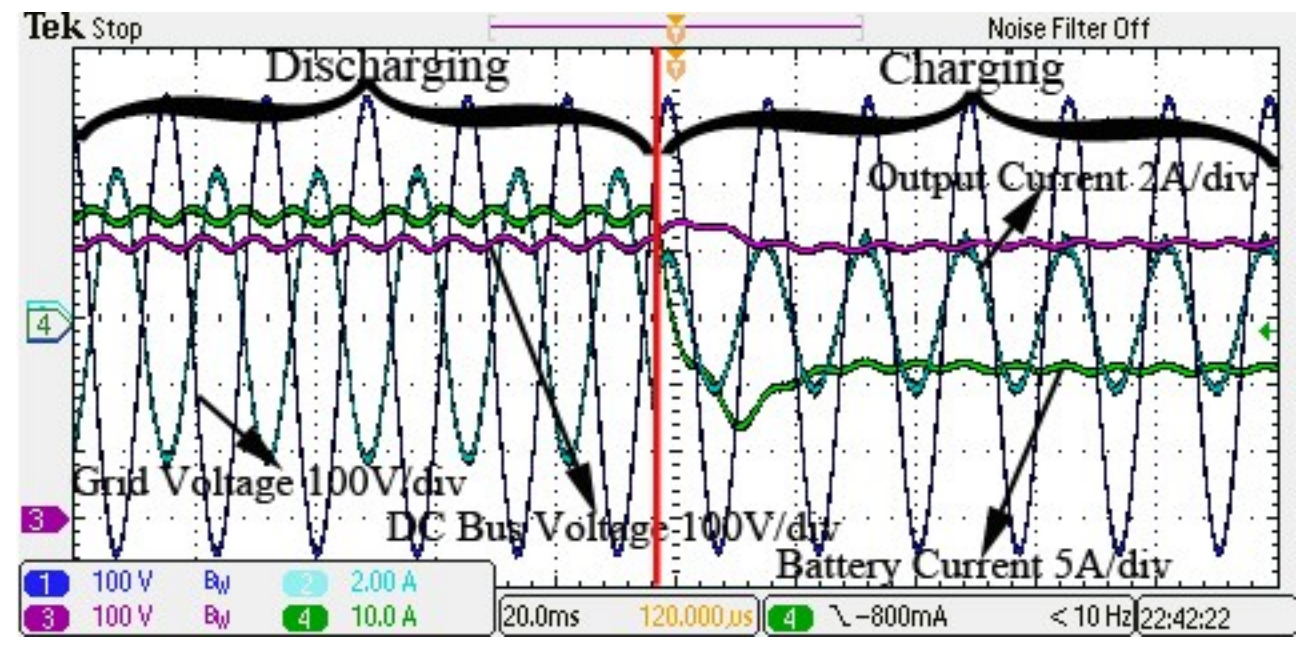

Fig. 4-7 $\mathrm{OBC}$ power flow direction change from grid supporting mode at $750 \mathrm{~W}$ (discharge) to battery charging mode $(-375 W)$

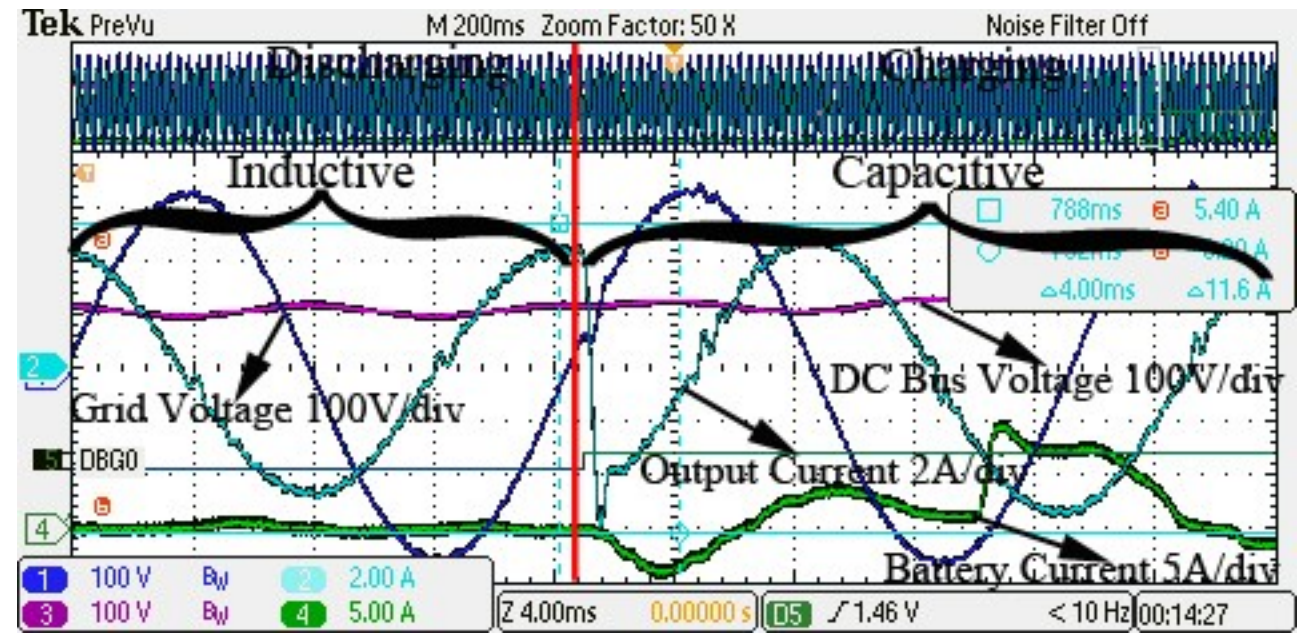

Fig. 4-8 OBC reactive power flow direction change from inductive (-950VA) to capacitive (950VA) power in grid support mode 
Fig. 4-8 shows the OBC's dynamic response to a change of reactive power from inductive to capacitive in grid-support mode. It can be observed that the inverter's current changes direction within $1 \mathrm{~ms}$ for both tests, but the battery current's direction change (in Fig. 4-7) takes $20 \mathrm{~ms}$ to reduce stress on the battery.

Fig. 4-9 and Fig. 4-10 shows the OBC's per stage and total conversion efficiencies, compared to the 80 PLUS Titanium Standard [91]. The test was performed under nominal operating conditions (see Table 4-1) in battery charging mode (see Fig. 4-9) and discharging (grid support) mode (see Fig. 4-10). 


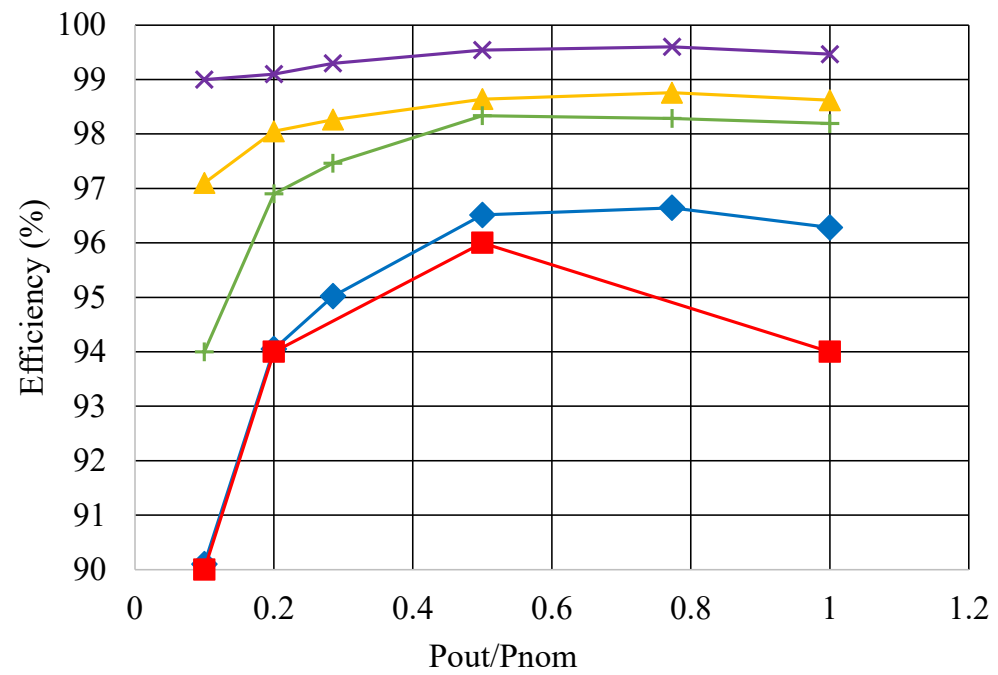

Fig. 4-9 OBC total conversion efficiency, and $O B C$ per stage conversion efficiency compared with the 80 PLUS Titanium Standard in battery charging mode. The red line is the Titanium Standard, blue is total OBC efficiency, green is the Isolated Bi-Directional DC/DC stage efficiency, yellow is the inverter stage efficiency, and magenta is the Buck-Boost stage efficiency. 


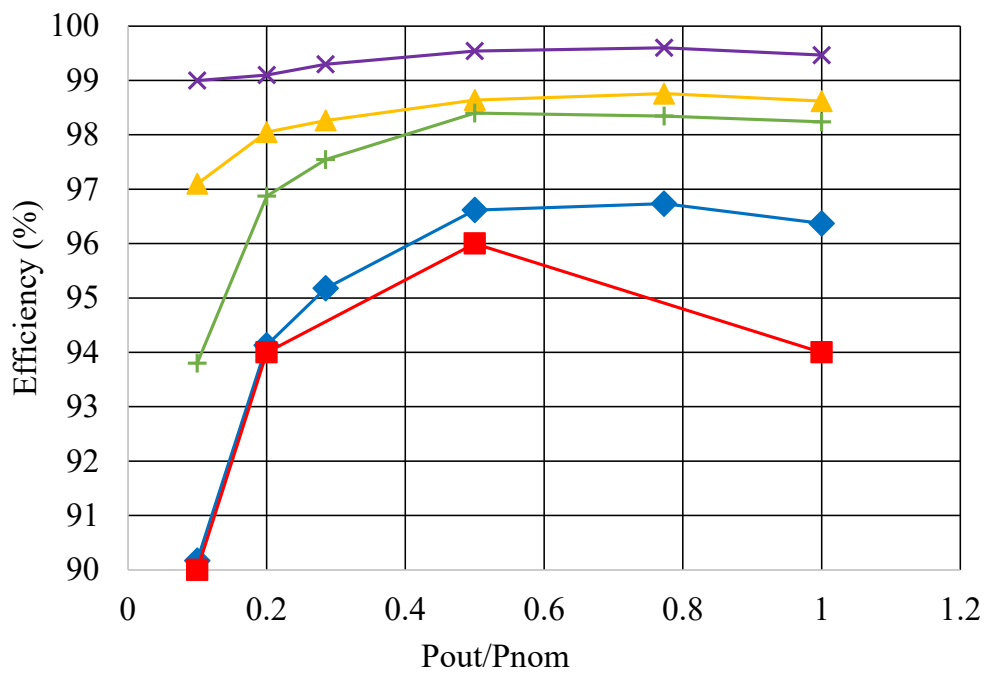

Fig. 4-10 OBC total conversion efficiency, and OBC per stage conversion efficiency compared with the 80 PLUS Titanium Standard in battery discharging mode (grid support operations). The red line is the Titanium Standard, blue is the total OBC efficiency, green is the Isolated BiDirectional DC/DC stage efficiency, yellow is the inverter stage efficiency, and magenta is the Buck-Boost stage efficiency.

The $\mathrm{OBC}$ conversion efficiency was calculated using the expression for multistage converter efficiency (4-7) with an integration window ( $\left.\mathrm{t}_{2}-\mathrm{t}_{1}\right)$ equal to 120 seconds.

$$
\eta=\prod_{n=1}^{k} \frac{\int_{t_{1}}^{t_{2}} P_{k}^{\text {out }}(t) d t}{\int_{t_{1}}^{t_{2}} P_{k}^{\text {in }}(t) d t} \cdot 100 \%
$$

At $750 \mathrm{~W}$, the system has a peak efficiency of $96.65 \%$ during charging operations and $96.73 \%$ during discharging operations. The discharge efficiency is marginally better than the charging efficiency for any given power level. This is because of the additional diode 
reverse recovery losses in the isolated bi-directional DC/DC stage during synchronous rectification. It can also be observed that the overall conversion efficiency results exceed the Titanium Standard for both charging and discharging operation modes. The OBC's THD was measured according to the IEEE 1547 standard at unity power factor. It was $1 \%$ at maximum power, $2 \%$ at $66 \%$ of maximum power, and $3 \%$ at $33 \%$ of maximum power.

\subsection{Summary}

This Chapter proposes a novel control and optimization strategy for a bi-directional, threestage OBC. The proposed technique is based on DCHC and leverages the features of WBS (specifically $\mathrm{SiC}$ ) switches. The $\mathrm{OBC}$, under the proposed control and optimization strategy, exhibited an efficiency above the 80 PLUS Titanium Standard, with a maximum efficiency of $96.65 \%$.

Moreover, a THD of $1 \%$ was also obtained at maximum power. The operating points of each stage in the three-stage topology were individually optimized. A simple experimental optimization technique can be used for the DCHC.

The optimization strategy has the following features and advantages:

- the inverter switching frequency and operating mode are dynamically optimized to achieve optimum efficiency;

- the Buck-boost converter operates in CRM in soft-switching mode, with highvoltage but low current; 
- the isolated bi-directional $\mathrm{DC} / \mathrm{DC}$ stage operates at its resonant point to reduce conductive losses and performs ZCS on the synchronous rectification side. 


\section{Chapter 5. Tuning the Voltage Control System based on an Extended}

\section{Modulus Optimum Method}

Proportional-resonant (PR) controllers are widely used both in grid-tie and off-grid inverters. PR controllers can not only achieve zero steady-state control error at the AC fundamental frequency, but also provide high rejection ratio to the undesired harmonic contents with minimal computational burden. Research effort in the past decade was mainly focus on application-oriented performance optimization for grid-tie inverters. Only a limited number of papers discussed PR controllers for off-grid applications.

In this research, the Modulus Optimum (MO) tuning method was extended to the stationary frame. This extended MO method was then applied to the off-grid inverter voltage control loop. As the extended MO method can be directly applied to the transfer function of the voltage source inverter in a stationary frame, an optimum utilization of the existing control bandwidth can be achieved. Moreover, the relationship between the proportional and resonant coefficients can be obtained.

The tuning procedure for an off-grid inverter's voltage control system is demonstrated via a bi-directional, four quadrant, off-grid battery inverter. Numerical simulations and laboratory tests were used to validate the proposed tuning method. Experimental results are in good agreement with theoretical results.

The initial findings were presented at the CCECE 2019, in Edmonton [92]. In addition to 
those initial findings, this chapter presents the theoretical analysis, numerical simulations, and the experimental tests.

The rest of this chapter is organized as follows. The extension of the MO method and its comprehensive analysis are provided in Section 5.1.

Section 5.2 describes the application of the proposed extension of the MO method to the off-grid inverter voltage control loop tuning, and discusses the numerical simulation results. Voltage source inverter simulation results are presented in section 5.3

The experimental results for the proposed tuning methodology are presented in Section 5.4.

\subsection{The PR Controller and the Stationary Reference Frame Extension of the Modulus Optimum based Tuning Method}

PR controllers have gained significant interest in the past decade both in academic research and industrial applications. A PR controller's transfer function could be derived from the PI controller's in the synchronous frame by modulating it into the stationary frame using equation (5-1) [49].

$$
G_{A C}(s)=\frac{1}{2}\left(G_{D C}(s-j \omega)+G_{D C}(s+j \omega)\right)
$$

References [46], [49], [53], [63] provide a general expression for the transfer function of the PR controller, which includes a non-ideal resonant term with leakage $\omega_{c}$ as shown in $(5-2)$ : 


$$
K_{p}+\frac{K_{I} s}{s^{2}+2 s \omega_{c}+\omega_{n}^{2}}
$$

The performance of the control loop is usually optimized by tuning the control coefficients according to a certain rule [68]. The MO based tuning method shapes the open-loop transfer function to the desired performance by adding additional control elements (usually PID controller). The coefficients of proportional, integral and differential elements are obtained as a result of the optimization process. Equation (5-3) [69] shows the shaping curve for MO:

$$
G_{O L}(s)=\frac{1}{2 T_{O L} s} \frac{1}{\left(T_{O L} s+1\right)}
$$

This method is widely used to tune PID controllers in the synchronous frame. The tuned transfer function exhibits the following features:

- Phase margin equal to 63.50 degrees,

- Two conjugate poles with the natural frequency $\frac{1}{\sqrt{2} T_{O L}}$, and damping ratio $\zeta=$ $\sqrt{2} / 2$

The features mentioned above are a good compromise between response time, overshoot and stability [68], [69]. Additionally, the infinity gain at zero frequency mitigates the steady-state error in the synchronous frame.

However, if both the reference signals and the controlled variables are sinewaves at a frequency in the vicinity of $\omega_{n}$ like in the case of the stationary frame mentioned above, 
then the infinity gain at zero frequency cannot mitigate the steady-state error. Therefore, the MO tuning technique needs be extended to the stationary frame to optimize the PR controller loop.

Transformation (5-1) is applied to the integral term of the MO, and the result combined with the low-pass filter term to obtain a stationary reference frame extension of the MO based tuning method. After these mathematical manipulations, equation (5-3) is transformed to equation (5-4). Fig. 5-1 shows the bode plots of equations (5-3) and (5-4). The proposed extended MO method has a finite high gain at the fundamental frequency, rejection of high-frequency harmonic content and zero gain at DC. The expression for the ideal resonant term is obtained by setting $\omega_{c}=0$ in (5-4).

$$
G_{O L}(s)=\frac{1}{2 T_{O L}} \frac{s}{s^{2}+2 s \omega_{c}+\omega_{n}^{2}} \frac{1}{\left(T_{O L} s+1\right)}
$$

The phase and gain margin are computed to confirm that the loop-shaping function obtained (5-4) inherits the same behavior as the original MO. Equation (5-4) has a value of unity at a frequency of $\omega_{1}=1 /\left(2 T_{O L}\right)$, under the assumption of $1 /\left(2 T_{O L}\right)>>\omega_{n}$. Substituted this value back into (5-4), gives the phase margin (5-5).

$$
P M=180^{\circ}-\varphi\left(1 / 2 T_{O L}\right) \cong 63.5^{\circ}
$$

The gain at the fundamental frequency is infinite for an ideal resonant term and $20 \log \frac{1}{4 T_{O L} \omega_{c}}$ when leakage term $\omega_{c}$ is presented, the high-frequency harmonic content 
mitigation is inherited from the features of the resonant controller [49] for the extended MO method.

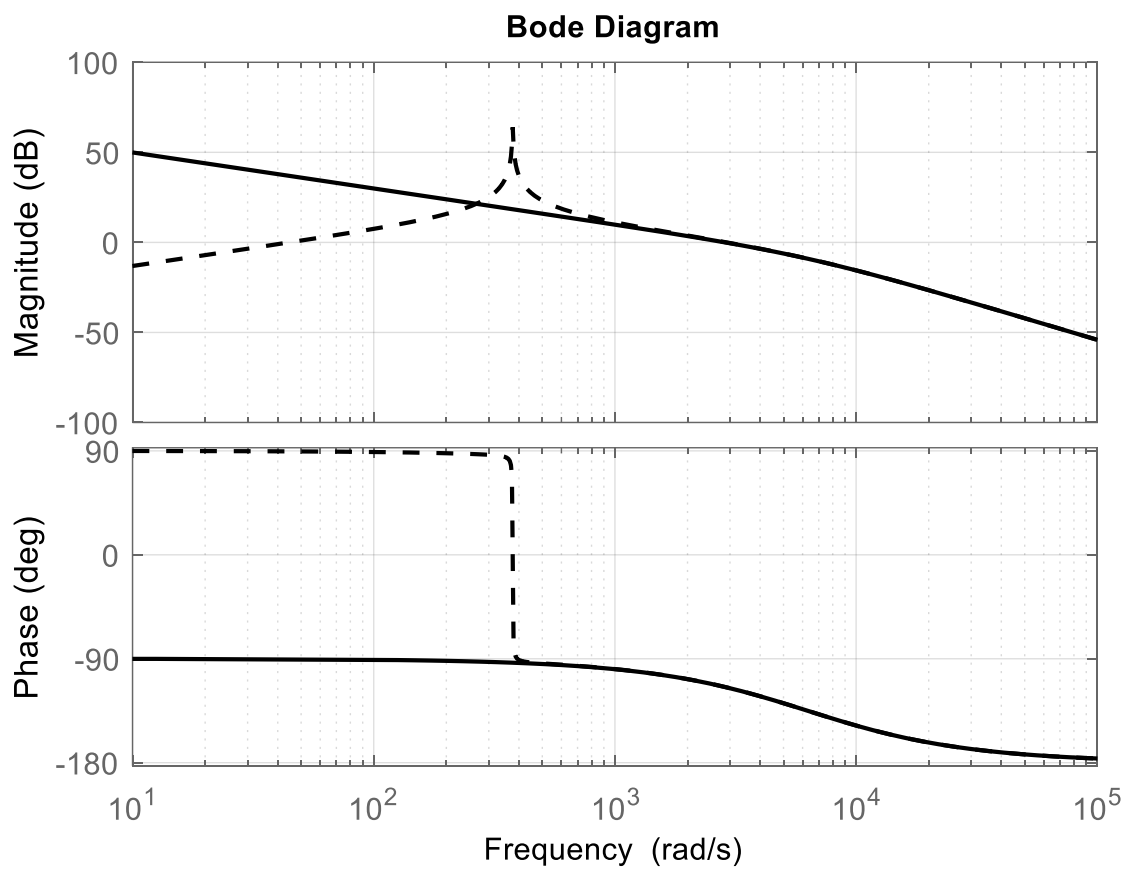

Fig. 5-1 Bode plot of MO shaping curve (solid line), and proposed extension stationary frame extension of MO shaping curve (dashed line). $T_{O L}=1 /(2 \pi 1000) \mathrm{s}, \omega_{c}=10 \mathrm{rad} / \mathrm{s}$

The expression of the closed-loop transfer function can take the form of equation (5-6), under the assumption of $1 / T_{O L} \gg \omega_{n}$.

$$
G_{C L}(s)=\frac{1}{2 T_{O L}^{2}} \frac{s}{\left(s+2 T_{O L} \omega_{n}^{2}\right)\left(s^{2}+\frac{1}{T_{O L}} s+\frac{1}{2 T_{O L}^{2}}\right)}
$$


The settling time and overshoot of the modulated step response signal are defined by two conjugate poles and the damping factor. These parameters have the same values as the original MO tuning method. Section 5.2 below illustrates the tuning process of the voltage control loop using an off-grid battery inverter example.

\subsection{Off-Grid Battery Inverter Tuning Example}

The tuning process described in Section 5.1 is further illustrated using a single-phase, offgrid battery inverter.

\subsubsection{Off-Grid Inverter Model Development}

Fig. 5-2 depicts the block- diagram of the output cascade of an off-grid inverter, and Fig. 5-3 presents the internal hysteretic current control loop. The inverter has the following components:

- A single-phase inverter power train with EMI filter;

- A current control closed-loop system based on the hysteretic current controller;

- An output voltage control loop based on the PR controller. 


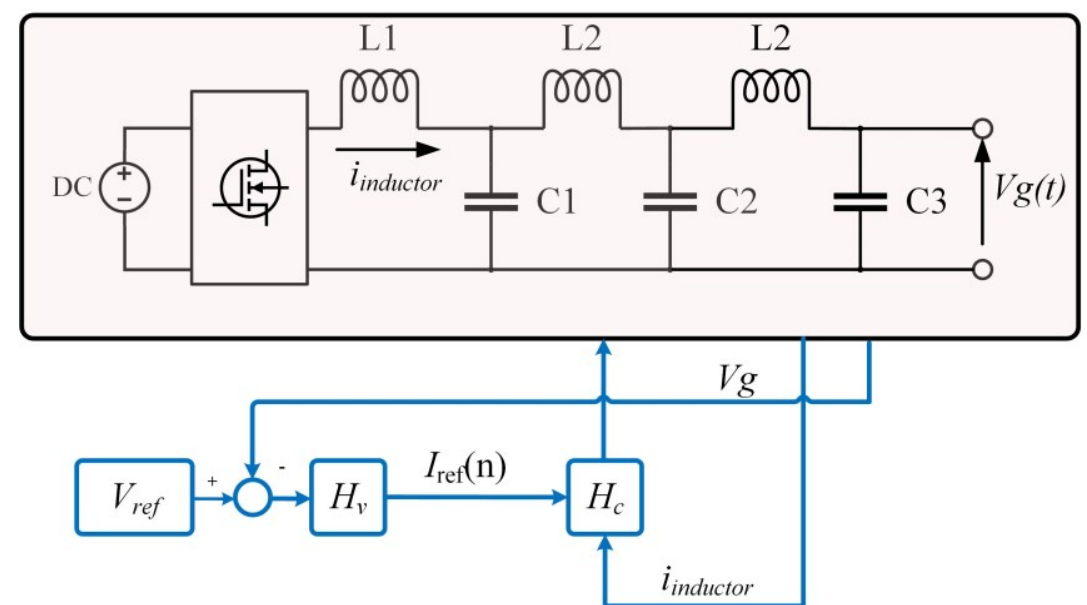

Fig. 5-2 The simplified block-diagram of the off-grid voltage source inverter output cascade

The output filter, except for output capacitor $C_{3}$, is not a part of the load. The voltage feedback signal is measured across $\mathrm{C}_{3}$.

The PR controller calculates the current reference $I_{r e f}(n)$ based on the error between the voltage reference signal and the measured output inverter voltage. Both voltage signals are in sinewave form. 

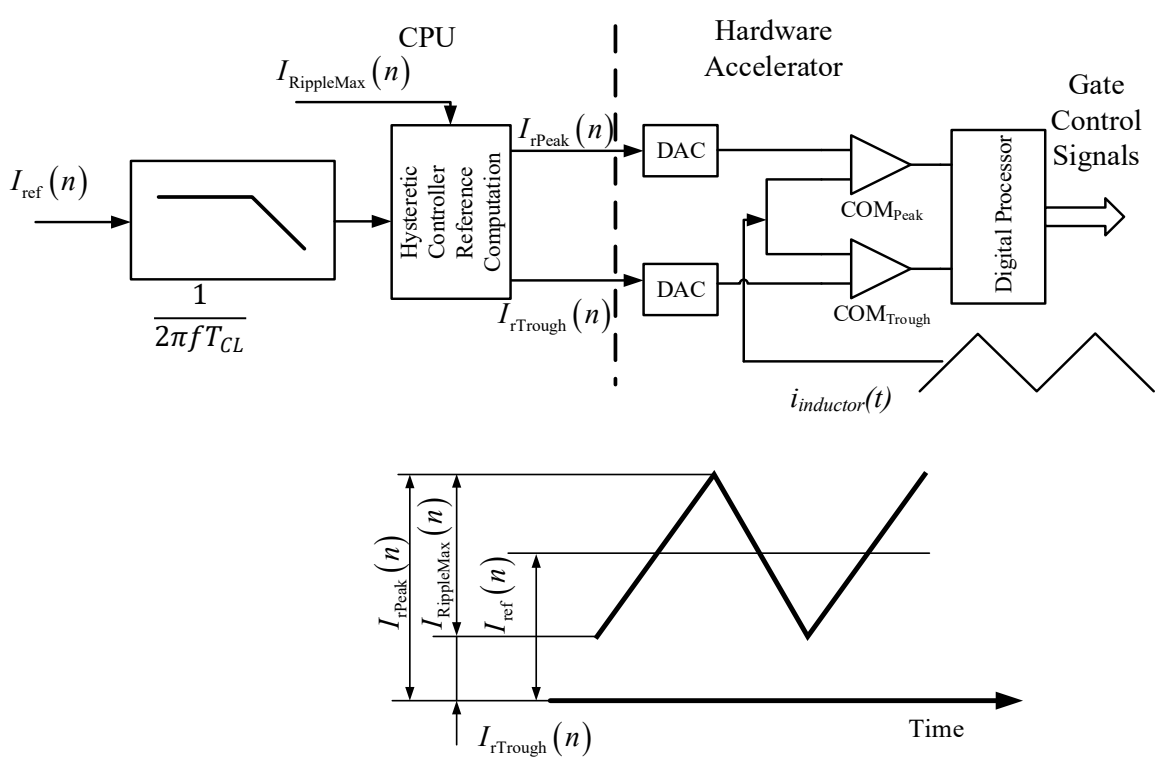

Fig. 5-3 Simplified block-diagram of the hysteresis non-linear current controller connected to CPU on the top, and hysteretic control settings on the bottom

The current reference $I_{\text {ref }}(n)$ feeds into the inner current control loop (Hc). The non-linear hysteresis hybrid software-hardware based controller [40] performs cycle-by-cycle control of the inverter's current loop Hc. The hysteretic controller practically controls the current ripple via an inductor to keep it inside the desired hysteresis band. Unlike the traditional PWM technique, the state of the switches in the hysteretic control technique is a result of the hysteresis band settings $\left(I_{\text {RippleMax }}\right)[41]$, [42]. Therefore, the resulting operation frequency of this controller varies. For this example, the operating frequency varies between $40 \mathrm{kHz}$ and $400 \mathrm{kHz}$. 
The CPU computes the peak and trough settings values $\left(I_{r P e a k}(n)\right.$ and $\left.I_{r T r o u g h}(n)\right)$ of the hysteretic controller based on the current reference command and the desired hysteresis band $\left(I_{\text {RippleMax }}\right)$ as shown in Equation (5-7).

$$
\begin{aligned}
& I_{\text {rTrough }}(n)=I_{\text {ref }}(n)-I_{\text {RippleMax }}(n) / 2 \\
& I_{\text {rPeak }}(n)=I_{\text {ref }}(n)+I_{\text {RippleMax }}(n) / 2
\end{aligned}
$$

The hysteretic controller itself is implemented in the control chip hardware accelerator by low-latency windows comparators and a dedicated digital processor. Its operating frequency is independent of the CPU interrupt cycle. This implementation provides flexibility to the hysteretic controller and mitigates the computation burden when Wide Bandgap Semiconductors (WBS) are used.

The behavior of the hysteresis controller cannot be described by a linear model. However, because the rate of update of the reference is slower than the switching frequency, an approximation, in the form of a first-order transfer function with time constant equal to the interrupt time can be used [40]. Moreover, the low-pass filter with time constant $T_{C L}$ is added after the voltage controller in series with the current controller to guarantee appropriate roll-off of the open-loop transfer function and to prevent unwanted interaction between the current control loop and EMI filter. Therefore, the $T_{C L}$ defines the actual tracking dynamics of the current control loop. Thus, a complete mathematical model of the output cascade of the inverter presented in Fig. 5-2 can be developed to analyze system 
stability and to obtain the optimized parameters of the voltage controller according to the extended MO method shown in (5-8).

The state matrixes $\boldsymbol{A}_{\boldsymbol{F}}, \boldsymbol{B}_{\boldsymbol{F}}, \boldsymbol{C}_{\boldsymbol{F}}$, and $\boldsymbol{D}_{\boldsymbol{F}}$, represent the output filter of the inverter. The state matrixes $A_{C C L}, B_{C C L}, C_{C C L}$, and $\boldsymbol{D}_{C C L}$, represent the current controller, and the state matrixes

$\boldsymbol{A}_{v}, \boldsymbol{B}_{v}, \boldsymbol{C}_{v}$, and $\boldsymbol{D}_{v}$ represent the PR controller in stationary frame. The input and output of the mathematical model are the voltage reference signal $v_{r e f}$ and the generated voltage $v_{g}$, respectively.

$$
\left[\begin{array}{c}
\dot{X}_{v} \\
\dot{X}_{C L L} \\
\dot{X}_{F}
\end{array}\right]=\left[\begin{array}{ccc}
A_{v} & 0 & 0 \\
B_{C L L} C_{v} & A_{C C L} & 0 \\
0 & B_{F} C_{C C L} & A_{F}
\end{array}\right]\left[\begin{array}{c}
X_{v} \\
X_{C C L} \\
X_{F}
\end{array}\right]+\left[\begin{array}{ccc}
B_{v} & 0 & 0 \\
B_{C L L} D_{v} & 0 & 0 \\
0 & B_{F} & 0
\end{array}\right]\left[v_{r e f}\right]
$$

$$
Y=\left[\begin{array}{lll}
\mathbf{0} & \mathbf{0} & C_{F}
\end{array}\right]\left[\begin{array}{c}
X_{v} \\
X_{C C L} \\
X_{F}
\end{array}\right]+\left[\begin{array}{lll}
D_{C C L} D_{v} & D_{F} & 0
\end{array}\right]\left[v_{r e f}\right]
$$

The state-space equation (5-8) is a Linear Time-Invariant (LTI) system under the conditions of constant load.

\subsubsection{Tuning Considerations}

The transfer function of the off-grid voltage source inverter is load-dependent as shown in (5-8). The operating conditions of the off-grid inverter can change rapidly and unpredictably compared to a grid-connected inverter. For instance, the disconnect of a load 
can bring the system from a well-damped condition to an undamped condition within a few microseconds..

Therefore, researchers [61] have proposed to optimize the controller at no-load and then evaluate the performance at other loading conditions. It is important to understand whether the controller coefficients are load-dependent and to investigate the impact of the load variation on system performance. This thesis proposes the following two step method to assess the impact of loading conditions: in the first step the coefficients of the controller are obtained based on a simplified inverter model. In the second step a detailed inverter model is used to trace eigenvalues of the closed-loop system versus load variations.

It is reasonable to assume that the required bandwidth of the voltage control loop is $\omega_{v}$, and it lies below the poles of the EMI/RFI filter. Therefore, the dominant impedance of the output filter $\left(Z_{f}\right)$ can be defined by the total EMI/RFI filter capacitances $C_{f}$ shown in equation (5-9). Hence, a simplified open-loop transfer function can be expressed as equation (5-10), where $Z_{L}$ is the load impedance.

$$
\begin{gathered}
Z_{f}=\frac{1}{s C_{\mathrm{f}}} \\
G_{O L}=\left(K_{p}+\frac{K_{I} s}{s^{2}+2 s \omega_{c}+\omega_{n}{ }^{2}}\right) \frac{1}{T_{C L} s+1} \frac{Z_{f} Z_{L}}{Z_{f}+Z_{L}}
\end{gathered}
$$

The open-loop transfer function (5-10) is compared with the values of the proposed tuning function (5-4) at the cut-off frequency (5-11)-(5-14), and at the nominal frequency (5-15)(5-18) to compute optimized values of proportional and resonant coefficients respectively. 
The optimized value of the proportional coefficient $K_{P}$ is then obtained for resistive loads (5-11), inductive loads (5-12), capacitive loads (5-13) and no-load (5-14) respectively.

$$
\begin{gathered}
\left|\frac{R_{L}}{1+s C_{f} R_{L}} K_{P}\right|_{s=j \frac{1}{2 T_{O L}}}=1 \\
\mathrm{~K}_{\mathrm{P}} \cong \frac{C_{f}}{2 T_{O L}}
\end{gathered}
$$

$$
\begin{gathered}
\left|\frac{s L_{L}}{1+s^{2} C_{f} L_{L}} K_{P}\right|_{s=j \frac{1}{2 T_{O L}}}=1 \\
\mathrm{~K}_{\mathrm{P}} \cong \frac{C_{f}}{2 T_{O L}}
\end{gathered}
$$

$$
\begin{gathered}
\left|\frac{1}{s\left(C_{f}+C_{L}\right)} K_{P}\right|_{s=j \frac{1}{2 T_{O L}}}=1 \\
\mathrm{~K}_{\mathrm{P}} \cong \frac{\left(C_{f}+C_{L}\right)}{2 T_{O L}}
\end{gathered}
$$

$$
\begin{gathered}
\left|\frac{1}{s C_{f}} K_{P}\right|_{s=j \frac{1}{2 T_{O L}}}=1 \\
\mathrm{~K}_{\mathrm{P}} \cong \frac{C_{f}}{2 T_{O L}}
\end{gathered}
$$


The capacitance of the output filter and the capacitive load have a dominant effect on the system bandwidth. As a compromise, the value of $K_{P}$ obtained for resistive, inductive, or no-load operation is taken for further considerations.

The coefficient of the resonant term of PR controller $\left(\mathrm{K}_{I}\right)$ is obtained by comparing the simplified open-loop transfer function and the shaping curve at the nominal frequency for resistive (see Equation (5-15)), inductive (see Equation (5-16)), capacitive (see Equation (5-17)) and no-load (see Equation (5-18)), respectively.

$$
\begin{gathered}
\left|\frac{R_{L}}{1+s C_{f} R_{L}} \frac{K_{I}}{2 \omega_{c}}\right|_{s=j \omega_{n}}=\frac{1}{4 T_{O L} \omega_{c}} \\
\mathrm{~K}_{I} \cong K_{P} \frac{1}{C_{f} R_{L}}
\end{gathered}
$$

$$
\begin{gathered}
\left|\frac{s L_{L}}{1+s^{2} C_{f} L_{L}} \frac{K_{I}}{2 \omega_{c}}\right|_{s=j \omega_{n}}=\frac{1}{4 T_{O L} \omega_{c}} \\
\mathrm{~K}_{I} \cong K_{P} \frac{1}{\omega_{n} C_{f} L_{L}}
\end{gathered}
$$

$$
\begin{gathered}
\left|\frac{1}{s\left(C_{f}+C_{L}\right)} \frac{K_{I}}{2 \omega_{c}}\right|_{s=j \omega_{n}}=\frac{1}{4 T_{O L} \omega_{c}} \\
\mathrm{~K}_{I} \cong K_{P} \omega_{n}\left(1+\frac{C_{L}}{C_{f}}\right)
\end{gathered}
$$




$$
\left|\frac{1}{s C_{f}} \frac{K_{I}}{2 \omega_{c}}\right|_{s=j \omega_{n}}=\frac{1}{4 T_{O L} \omega_{c}} \rightarrow \mathrm{K}_{I} \cong K_{P} \omega_{n}
$$

It can be observed from (5-15)-(5-18) that unlike the proportional coefficient, the resonant coefficient is load-dependent. A theoretical phase margin reduction of $20^{\circ}$ is observed when the resonant coefficient optimized for full load condition is used at no-load. The theoretical phase margin was computed by substituting equations (5-15) to (5-17) into equation (5-10) under the condition that $Z_{L}=\infty$. This also confirms the approach proposed in [61] (i.e., optimizing the controller for no-load operation as the worst-case scenario). Therefore, a conservative approach of optimizing the resonant coefficient should be based on the no-load conditions, i.e., (5-19) should be taken.

$$
\mathrm{K}_{I} \cong K_{P} \omega_{n}
$$

\subsubsection{Stability Validation under Different Load Conditions Using the Full Order Model}

Stability validation of the proposed tuning method was carried out using the full order model (5-8). The PR controller for the voltage loop control has coefficients calculated by equations (5-14) and (5-19). Table 5-1 lists the inverter's output filter and control loop parameters. 

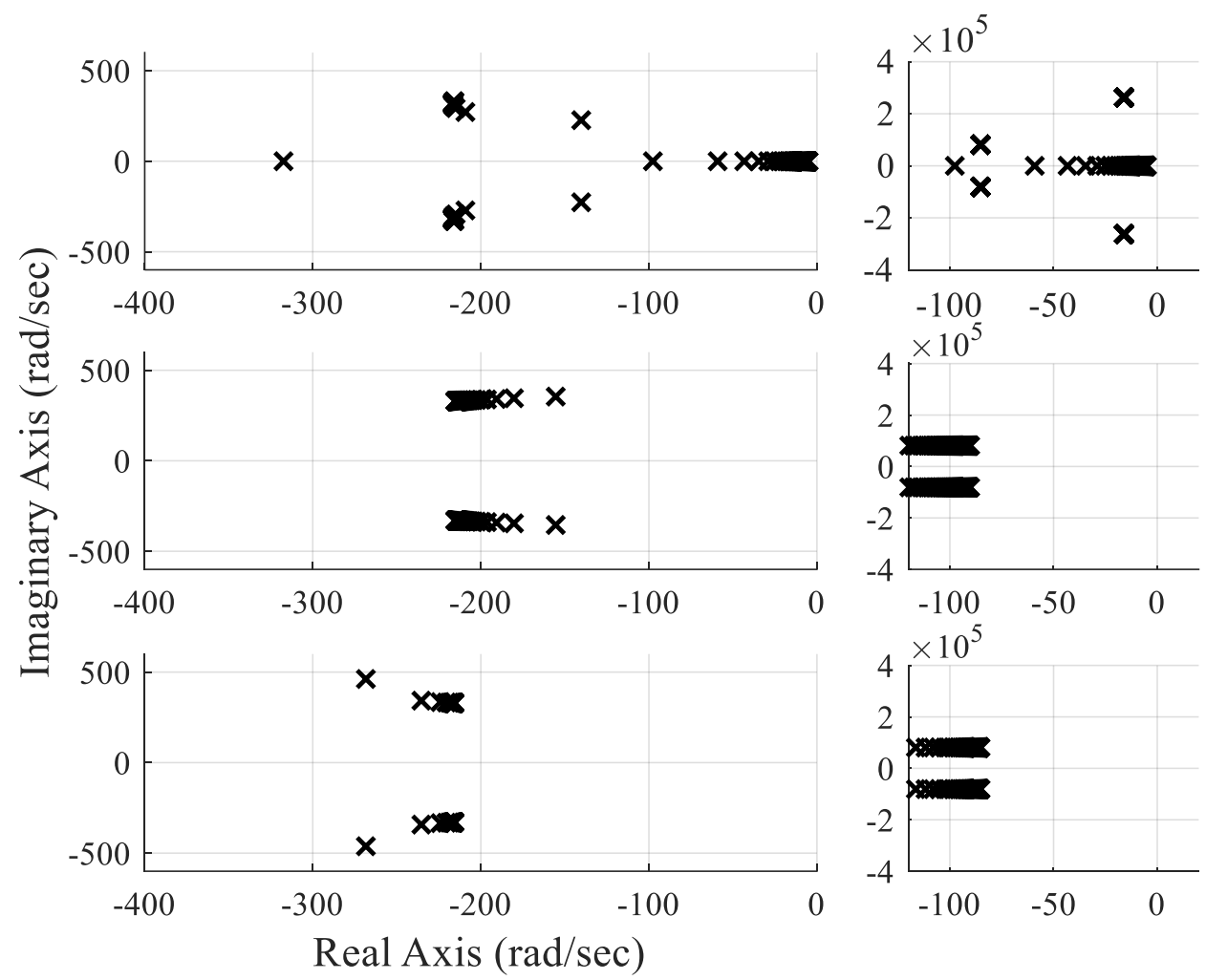

Fig. 5-4 Eigenvalues migration of voltage source inverter with varying load. The magnified view of the dominant pole region is on the left, and the magnified view near zero region is on the right. From top to bottom: inductive load $\left(Z_{L} \in\left[100 Z_{L m a x}, Z_{L m a x}\right]\right)$ with dissipation factor $1 \%$; resistive load $\left(\mathbf{R}_{\mathrm{L}} \in\left[100 \mathrm{R}_{\mathrm{L}}, \mathbf{R}_{\mathrm{Lmax}}\right]\right)$; and capacitive load $\left(Z_{C} \in\left[100 Z C m a x, Z_{C \max }\right]\right)$ with dissipation factor $1 \%$

Fig. 5-4 depicts the eigenvalues of the closed-loop system for the off-grid voltage source inverter under variation of resistive, inductive and capacitive load. The load was swept from $100 Z_{\max }$ to $Z_{\max }$. The eigenvalues migration as a function of load shows that the inverter remains stable under a broad set of load conditions with well-damped dominant poles. 


\subsection{Voltage Source Inverter Simulation Results}

The numerical simulation of an off-grid inverter with the PR controller tuned according to the proposed method is presented in this section (a laboratory test is presented in Section 5.4).

Table 5-1 lists the design parameters of the inverter and Fig. 5-5 depicts the simulation results. The stability at light load is one of the major concerns. Therefore, it was decided to simulate both no-load conditions and resistive load steps.
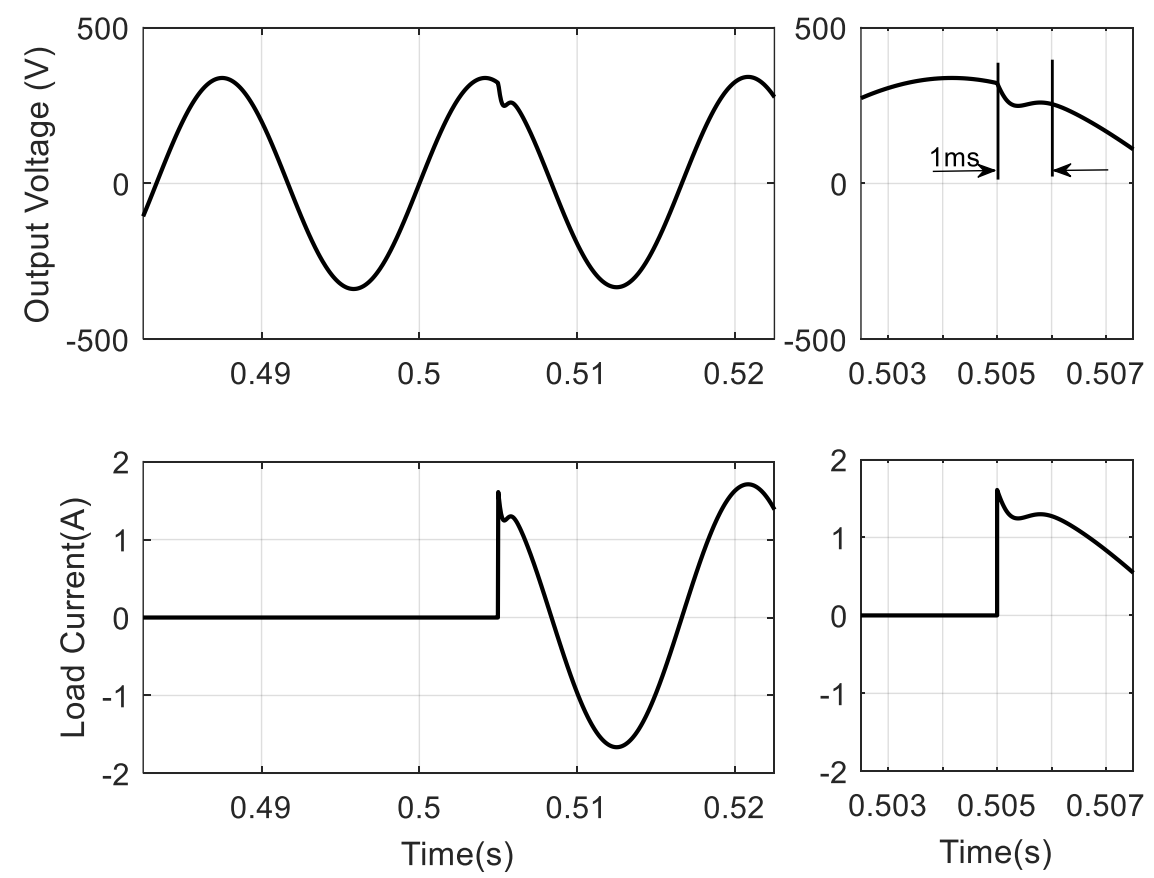

Fig. 5-5 Simulation results: inverter output voltage (upper left) and load current (bottom left). The upper right and bottom right are magnified views of the inverter voltage and load current around transient time respectively 
The simulation results shown in Fig. 5-5 confirm the system is stable at both no-load and resistive load. Fig. 5-5 also shows that the inverter generates a stable sine-wave signal in steady-state conditions and that the settling time meets control loop tuning requirements. Thus, it can be concluded that the theoretical analysis and the numerical simulation results are in good agreement.

Table 5-1 Output Cascade Parameters of the 500VA Off-Grid Battery Inverter under Test

\begin{tabular}{lll}
\hline Parameter & \multicolumn{1}{c}{ Value } & \multicolumn{1}{c}{ Remarks } \\
\hline$C_{1}, C_{2}, C_{3}$ & $1.5 \mu \mathrm{F}$ & EMI filter capacitor \\
$L_{1}$ & $600 \mu \mathrm{H}$ & Switching inductor \\
$L_{2, L_{3}}$ & $150 \mu \mathrm{H}$ & EMI filter line inductor \\
$T_{C L}$ & $1 / 2 / \pi / 2000 \mathrm{~s}$ & Time constant of the internal current \\
& & loop \\
$S_{\text {max }}$ & $500 \mathrm{VA}$ & Maximum output power \\
$f_{\text {sw }}$ & $40 \mathrm{kHz}-400 \mathrm{kHz}$ & Inverter switching frequency \\
$T_{\text {sample }}$ & $16.6 \mathrm{kHz}$ & CPU interrupt time for voltage loop \\
$K_{P}$ & 0.02826 & Proportional coefficient of the PR \\
& & controller \\
$K_{I}$ & $10 \mathrm{rad} / \mathrm{s}$ & Leakage term of PR controller \\
& &
\end{tabular}




\subsection{Experimental Results}

The theoretical analysis and the numerical simulation results were further validated by the laboratory tests presented in this section. Two evaluation platforms were used for this purpose:

- 500VA bi-directional off-grid battery inverter (see Table 5-1); and

- $1 \mathrm{kVA}$ wide-band semiconductors based, 80 PLUS Titanium efficiency, bidirectional off-grid battery inverter (see Table 5-2 and Fig. 4-2).

Three tests were performed:

- Resistive load step response (500VA platform)

- Inductive load step response (1kVA platform)

- Capacitive load step response (1kVA platform).

The 300W resistive load step test results are plotted in Fig. 5-6. It can be observed that both the measured current and voltage waveforms are in the good agreement with the theoretical analysis (see Fig. 5-4) and simulation results (see Fig. 5-5). The inverter under test exhibits a stable waveform under no-load conditions. When the load is applied the output, voltage is stabilizes after 1ms. Moreover, no steady-state error is observed. 
Table 5-2 Output Cascade Parameters of the 1kVA Bi-Directional Off-Grid Battery Inverter under Test

\begin{tabular}{|c|c|c|}
\hline 'Parameter & Value & Remarks \\
\hline$C_{1}$ & $2 \mu \mathrm{F}$ & EMI filter capacitor \\
\hline$C_{2}$ & - & Not Installed \\
\hline$C_{3}$ & $1 \mu \mathrm{F}$ & EMI filter capacitor \\
\hline$L_{1}$ & $400 \mu \mathrm{H}$ & Switching inductor \\
\hline$L_{2}$ & $150 \mu \mathrm{H}$ & EMI filter line inductor \\
\hline$L_{3}$ & $50 \mu \mathrm{H}$ & EMI filter line inductor \\
\hline \multirow[t]{2}{*}{$T_{C L}$} & $1 / 2 / \pi / 2000 \mathrm{~s}$ & Time constant of the internal current \\
\hline & & loop \\
\hline$S_{\max }$ & $1 \mathrm{kVA}$ & Maximum output power \\
\hline$f_{s w}$ & $55 \mathrm{kHz}-400 \mathrm{kHz}$ & Inverter switching frequency \\
\hline$T_{\text {sample }}$ & $16.6 \mathrm{kHz}$ & CPU interrupt time for voltage loop \\
\hline \multirow[t]{2}{*}{$K_{P}$} & 0.0185 & Proportional coefficient of the PR \\
\hline & & controller \\
\hline \multirow[t]{2}{*}{$K_{I}$} & 7.1 & Resonant coefficient of the PR \\
\hline & & controller \\
\hline$\omega_{c}$ & $10 \mathrm{rad} / \mathrm{s}$ & Leakage term of PR controller \\
\hline
\end{tabular}




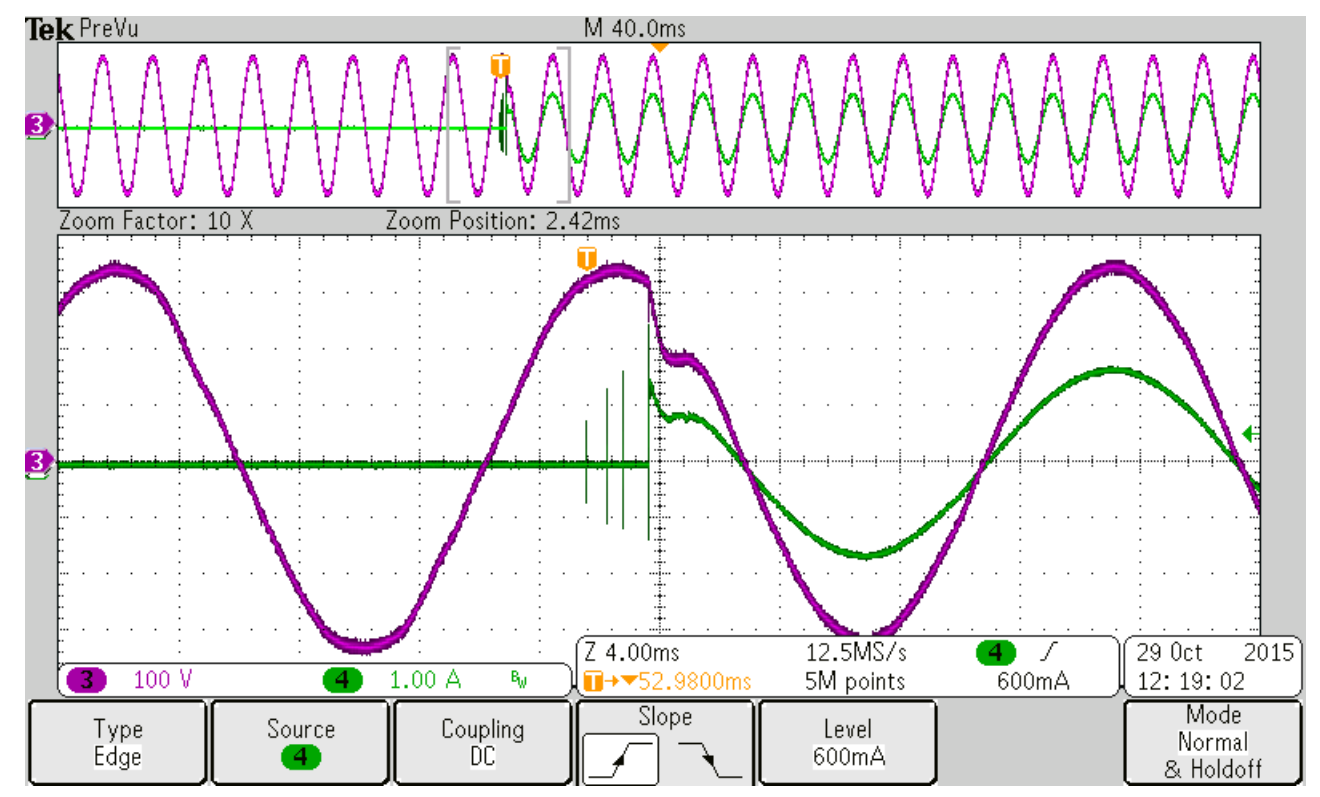

Fig. 5-6 Step response of 500VA bi-directional off-grid battery inverter for $300 \mathrm{~W}$ resistive load step. Channel 3 is an output voltage; Channel 4 is an output current

The remaining two tests were performed on the 1kVA inverter platform. Fig. 5-7 presents the response of the $1 \mathrm{kVA}$ inverter under a $300 \mathrm{VA}$ inductive load step change. The $300 \mathrm{VA}$ inductive load creates resonant pole with inverter output capacitance at approximately $130 \mathrm{~Hz}$.

Fig. 5-8 shows the response under a 100VA capacitive load step change. A 50(Ohm) NTC (Negative Thermal Coefficient) resistor was used as an inrush prevention device in this case. The value of 100VA was chosen to observe the effect of the inverter control loop slow-down by factor of two. The results confirm that the inverter is stable under inductive 
and capacitive load steps. Moreover, the non-linear behavior of the inductive load does not create any negative effects on the voltage waveform using the optimized coefficient $K_{I}$.

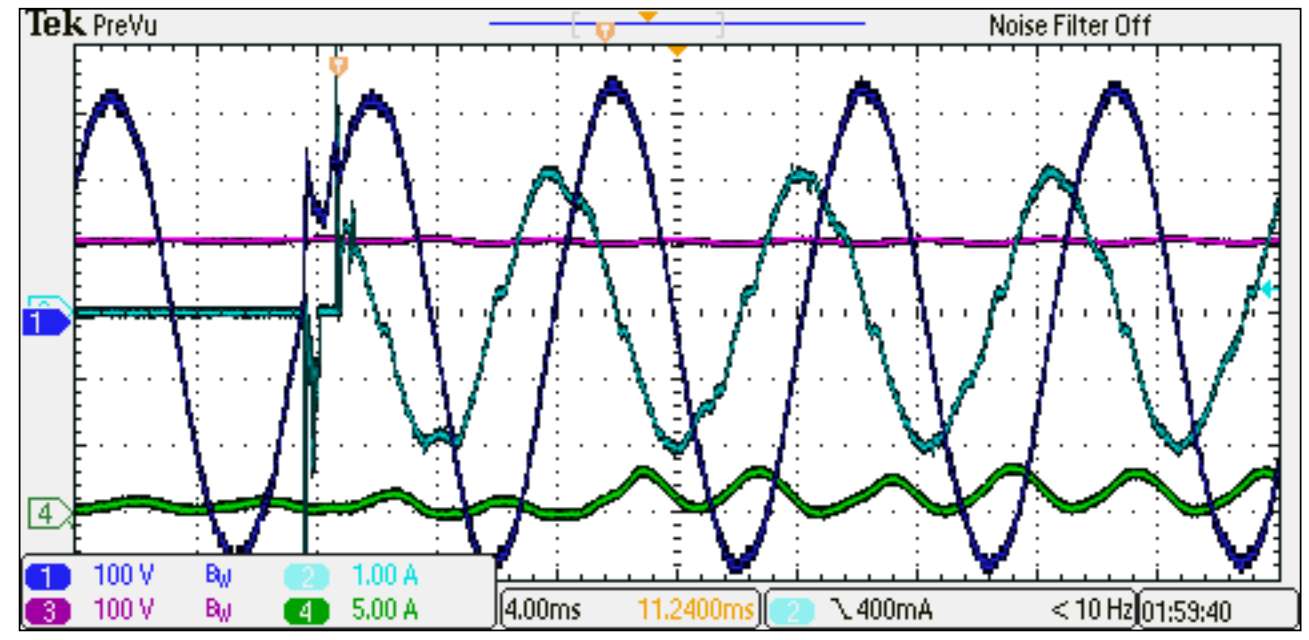

Fig. 5-7 Step response of $1 \mathrm{kVA}$ wide-bang semiconductor based bi-directional off-grid battery inverter for 300VA inductive load Channel 1 is an output voltage; Channel 2 is an output current; Channel 3 is an inverter bulk voltage, and Channel 4 is a battery current 


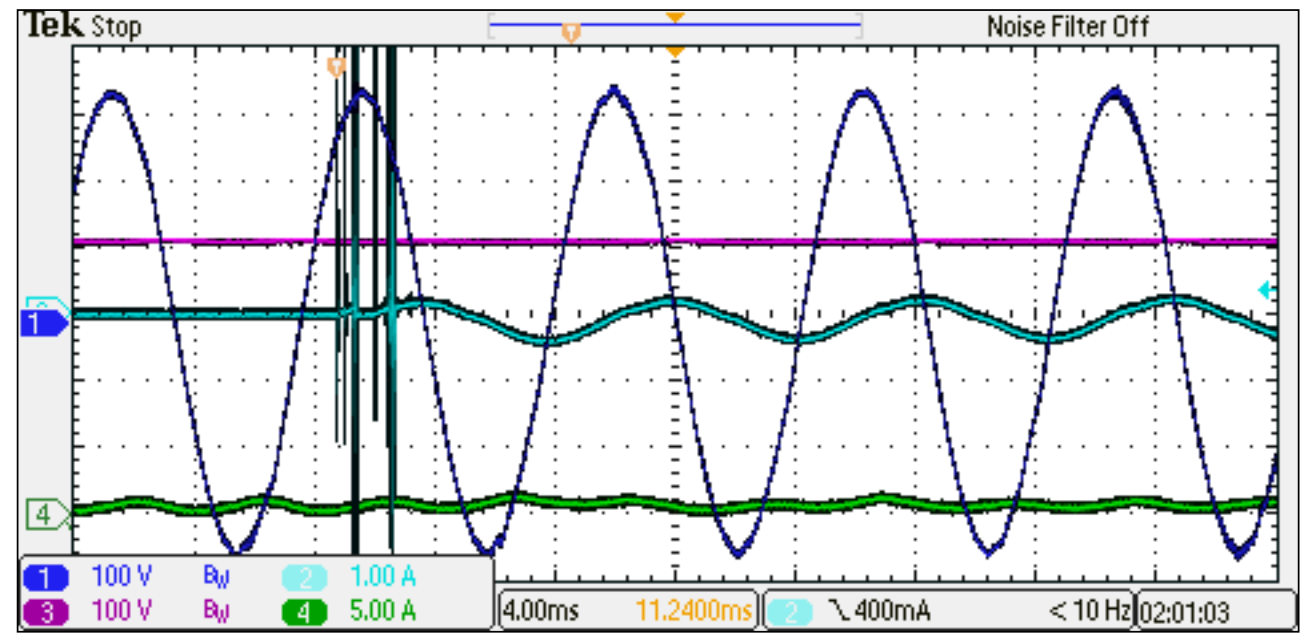

Fig. 5-8 Step response of $1 \mathrm{kVA}$ wide-bang semiconductor based bi-directional off-grid battery inverter for 100VA capacitive load step. Channel 1 is an output voltage; Channel 2 is an output current; Channel 3 is an inverter bulk voltage, and Channel 4 is a battery current

\subsection{Summary}

This chapter presents a stationary reference extension of the MO tuning technique and demonstrates the optimization of the PR controller for the off-grid voltage source inverters using it. This extended MO method based tuning process has the same features as the original MO in terms of high-frequency response. However, the low-frequency and steadystate behavior is modified to accommodate the sinewave nature of the reference and control signals.

A thorough theoretical analysis of the proposed tuning method was carried out to examine stability, response time and steady-state performance. The validity of the proposed method 
and tuning considerations have been demonstrated through an off-grid, voltage source inverter example.

The method was further validated through laboratory tests using two different hardware platforms. The results of the laboratory tests show good agreement with theoretical results. 


\section{Chapter 6. Novel Systematic Approach for Single-Phase Nanogrid}

\section{Stability Analysis}

At present, the dynamic stability analysis of a single-phase nanogrid relies mainly on a simplified model, which is based on the dynamic of a power-sharing loop. This contradicts the latest trend in small-scale three-phase nanogrid studies: the influence of fast dynamics on system stability. This deficiency is partially because of the complexity of system modelling as one part of the system is operating in the synchronous frame and the other part is in the stationary frame.

This chapter introduces a novel and simple modelling technique that allows obtaining the detailed model of the single-phase inverter in the $d q 0$ frame without loss of information regarding fast dynamics of the inner inverter loops. The developed model is suitable for linearization and use in classic stability analysis. Both computer simulations and laboratory tests have validated the proposed model.

The rest of the chapter organizes as follows. Section 6.1 introduces the proposed modelling approach and provides comprehensive background information regarding single-phase grid-forming inverter control and power-sharing mechanisms in the Low Voltage (LV) grid. Section 6.2 validates the proposed modelling approaches by numerical simulation and laboratory experiments. Section 6.3 studies the impact of the different control blocks on dynamic stability. A summary and future steps are given in Section 6.4. 


\subsection{Theoretical Analysis of the Proposed Modelling Approach}

The understanding of an inverter driven nanogrid relies on understanding the behavior of its key element - the grid-forming inverter and the power-sharing mechanism between inverters.

Fig. 6-1 shows the active power droop diagram. The power-sharing mechanism in Low Voltage (LV) nanogrids is dominated by the resistive impedance [8], [9], [93]. This is contrasts with medium voltage and high voltage grids where the impedance is dominated by inductive impedance [82]. The active and reactive power components that are going into the grid in steady-state conditions are shown in (6-1). The active power component depends on voltage magnitude and the reactive power component is dominated by phase angles when the angle $\theta_{i n v}$ is small.

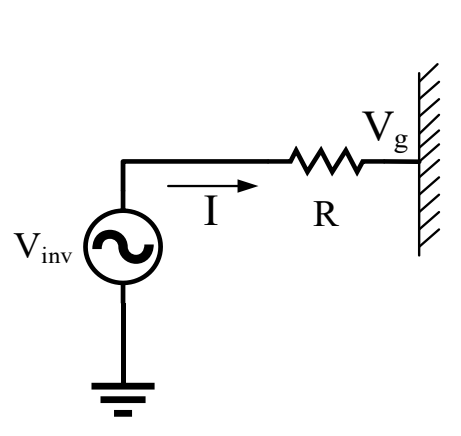

Active Power Sharing

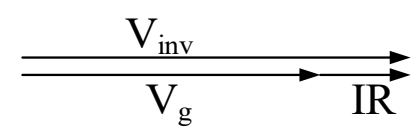

Reactive Power Sharing

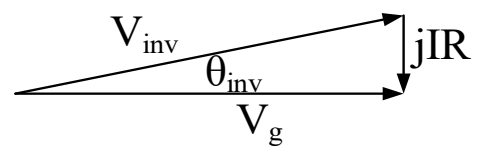

Fig. 6-1 Active and reactive power sharing by active power droop method 


$$
\begin{gathered}
P=\frac{V_{g}}{R}\left(V_{i n v} \cos \theta_{i n v}-V_{g}\right) \\
Q=\frac{V_{g} V_{i n v} \sin \theta_{i n v}}{R}
\end{gathered}
$$

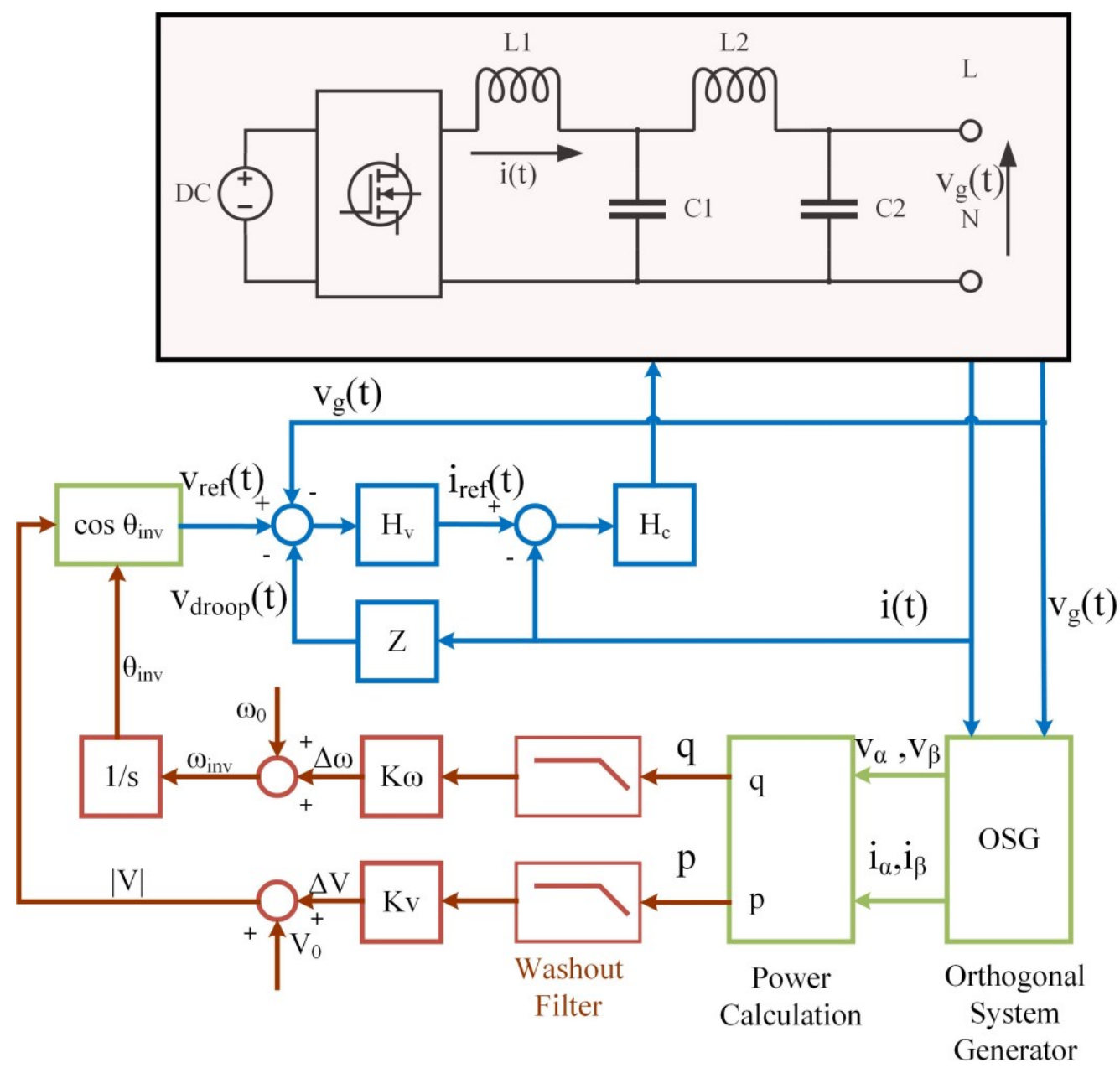

Fig. 6-2 Output cascade of single-phase grid-forming inverter with power-sharing loop. The stationary signals are in blue, the synchronous signals are in red, and interface between two systems are in light green. 
Fig. 6-2 shows typical block-diagram examples of the output cascade of the single-phase, voltage source, grid forming inverter [63], [75].

The example inverter hardware is based on the H-bridge topology. Typically, the inverter control scheme consists of the following control loops:

- Current control loop, stationary frame;

- Voltage and virtual impedance control loop, stationary frame;

- Power-sharing control loop, synchronous frame.

There are three computation blocks to support these control loops:

- Orthogonal system generator (OSG);

- Instantaneous power computation;

- Inverse Park-Clarke modulation.

The external power control loop should fulfill the requirements of power-sharing (6-1), which can also be expressed by the instantaneous power (6-2) together with the control rules (6-3)-(6-4). Equations (6-3)-(6-4) define power-sharing rules. The power-sharing loop computes the magnitude and angle of the voltage vector. Therefore, it could be concluded that the power-sharing loop operates in the synchronous frame. The obtained signal is modulated (6-5) to the stationary frame. The reference signal to the voltage control loop is a superposition of (6-5) and virtual resistance voltage droop (6-6).

- Instantaneous Power: 


$$
\left[\begin{array}{l}
p \\
q
\end{array}\right]=\left[\begin{array}{cc}
v_{\alpha} & v_{\beta} \\
-v_{\beta} & v_{\alpha}
\end{array}\right]\left[\begin{array}{l}
i_{\alpha} \\
i_{\beta}
\end{array}\right]
$$

- Control Rules:

$$
\begin{gathered}
{\left[\begin{array}{c}
V_{i n v} \\
\omega_{i n v}
\end{array}\right]=\left[\begin{array}{cc}
K_{v} & 0 \\
0 & K_{\omega}
\end{array}\right]\left[\begin{array}{l}
p \\
q
\end{array}\right]+\left[\begin{array}{l}
V_{0} \\
\omega_{0}
\end{array}\right]} \\
\frac{d \theta_{i n v}}{d t}=\omega_{i n v} \\
v_{r e f}=V_{\text {inv }} \cos \left(\theta_{\text {inv }}\right) \\
v_{\text {droop }}(s)=I_{\text {grid }}(s) Z(s)
\end{gathered}
$$

The instantaneous power measurement mechanism in the single-phase system is more complex than the one for the three-phase system. It involves the computation of the artificial orthogonal system [71], [73], [94]-[96]. The measured instantaneous values of grid voltage and inductor current pass through OSG [71], [73], [94]-[96]. The outcome of this block is an artificial orthogonal system for instantaneous voltage and current measurements. The OSG, in our example, is implemented by using the Second Order General Integrator (SOGI) filter (6-7) [5], [63], [71], [94]. However, another implementation, such as Hilbert transformation [96], is also possible. The obtained orthogonal components are used for the calculation of the instantaneous active and reactive power (6-2). 


$$
\begin{gathered}
\dot{X}_{\text {sogi }}=\left[\begin{array}{cc}
-k \omega_{n} & -\omega_{n} \\
\omega_{n} & 0
\end{array}\right] X_{\text {sogi }}+\left[\begin{array}{c}
k \omega_{n} \\
0
\end{array}\right] u_{\text {sogi }} \\
Y_{\text {sogi }}=\left[\begin{array}{ll}
1 & 0 \\
0 & 1
\end{array}\right] X_{\text {sog } i}
\end{gathered}
$$

It could be noticed that at steady-state OSG-SOGI resembles the Park transformation [5], [40], [71]. However, unlike the Park transformation which is a linear axis transformation, OSG-SOGI is a filter with transient response, dynamics and cross-coupling (6-7).

\subsubsection{Challenges of Modelling the Single-Phase Grid-Forming Inverter}

It can be easily observed that the control loops of the discussed voltage source grid-forming inverter operate both in:

- stationary frame (current and voltage control loops, artificial impedance)

- synchronous frame (power control loop).

Moreover, they also include the interface between two of these operation frames:

- Stationary to synchronous frame uses OSG-SOGI;

- Synchronous to stationary uses inverse Park-Clarke transformation.

Equations (6-3)-(6-4) represent power-sharing control, equation (6-7) is an OSG, and (6-8) is a stationary portion (power train, current and voltage control loop). It complicates the stability analysis of the single-phase nanogrid. 


$$
\begin{gathered}
\dot{X_{s t}}=A_{s t} X_{s t}+B_{s t} U_{s t} \\
Y_{s t}=C_{s t} X_{s t} \\
U_{s t}=\left[\begin{array}{l}
i_{\text {out }} \\
v_{\text {ref }}
\end{array}\right]
\end{gathered}
$$

\subsubsection{Novel Systematic Approach for Modelling the Single-Phase Inverter in Synchronous dq0 Frame}

The $d q 0$ system of coordinates, the so-called synchronous frame, allows us to eliminate time dependence. However, if $d q 0$ transformation is applied directly to the single-phase system, the obtained results still include a time-dependent component, that cannot fulfill our requirements [46], [48], [49]. For instance, when the sinewave signal (6-9) is multiplied by $\cos (\omega t)$ and $\sin (\omega t)$, the resulting expressions have a time-dependent component (6-10).

$$
\begin{gathered}
u(t)=U \cos \left(\omega t+\theta_{1}\right) \\
u_{c}(t)=\frac{U}{2}\left(\cos \left(\theta_{1}\right)+\cos \left(2 \omega+\theta_{1}\right)\right) \\
u_{s}(t)=\frac{U}{2}\left(\sin \left(-\theta_{1}\right)+\sin \left(2 \omega+\theta_{1}\right)\right)
\end{gathered}
$$

An artificial three-phase system is proposed to address the time-dependence problem of the single-phase transformation to the $d q 0$ frame. This system is introduced by shifting the original system of coordinate by 120 and 240 degrees, respectively (see Fig. 6-3). In this 
case, the new system consists of orthogonal vectors, and each phase is independent of each other.

Assume that $A, B, C$, and $D$ represent a state-space matrix of a single-phase circuit, the state-space equation (6-11) represents an artificial three-phase system as seen in Fig. 6-3.

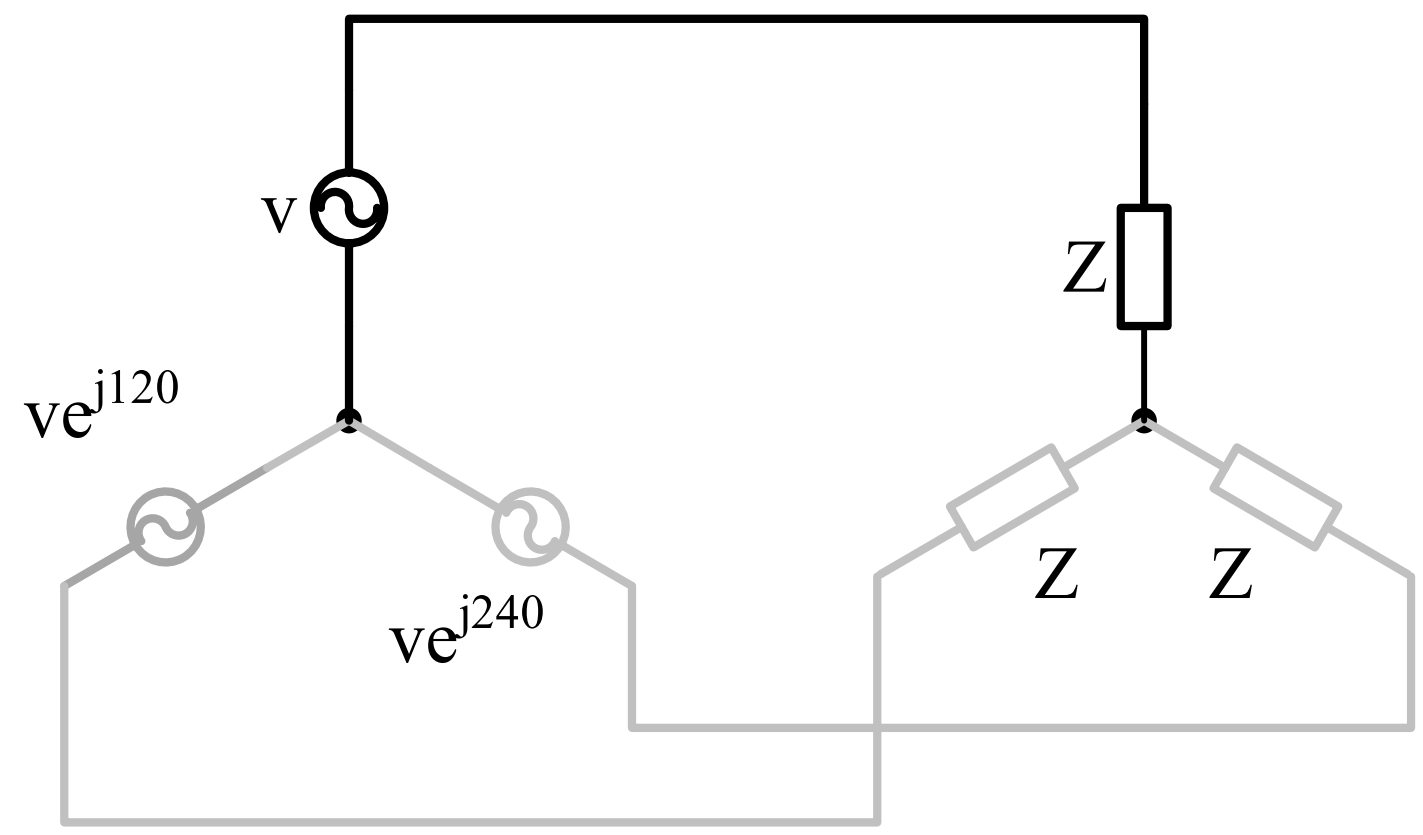

Fig. 6-3 Artificial three-phase grid. Black is an original single-phase grid, and grey is an original one shifted by $120^{\circ}$ and $240^{\circ}$ degree respectively.

$$
\begin{aligned}
\dot{X} & =[\operatorname{diag}(A)] X+[\operatorname{diag}(B)] U \\
Y & =[\operatorname{diag}(C)] X+[\operatorname{diag}(D)] U
\end{aligned}
$$

Applying a Park-Clarke transformation on this artificial three-phase system yields the general form of the transformation(6-12). 


$$
\begin{gathered}
{\left[\begin{array}{c}
\dot{X}_{d} \\
\dot{X}_{q}
\end{array}\right]=\left[\begin{array}{cc}
A & \operatorname{diag}\left(\omega_{i n v}\right) \\
\operatorname{diag}\left(-\omega_{i n v}\right) & A
\end{array}\right]\left[\begin{array}{l}
X_{d} \\
X_{q}
\end{array}\right]+\left[\begin{array}{ll}
B & 0 \\
0 & B
\end{array}\right]\left[\begin{array}{l}
U_{d} \\
U_{q}
\end{array}\right]} \\
{\left[\begin{array}{l}
Y_{d} \\
Y_{q}
\end{array}\right]=\left[\begin{array}{ll}
C & 0 \\
0 & C
\end{array}\right]\left[\begin{array}{l}
X_{d} \\
X_{q}
\end{array}\right]+\left[\begin{array}{ll}
D & 0 \\
0 & D
\end{array}\right]\left[\begin{array}{l}
U_{d} \\
U_{q}
\end{array}\right]}
\end{gathered}
$$

The proposed transformation can be directly applied to the stationary portion of the system under consideration (6-8). However, the synchronous portion (6-3)-(6-4) and an interface between two of them (6-5) - (6-7) requires additional considerations.

\subsubsection{Application of the Proposed Method to Power Sharing Loop Modelling}

The proposed transformation does not affect the power-sharing loop because it is initially in the synchronous frame. However, instead of using the inverse Park-Clarke transformation form (6-5), the following expression is used (6-13).

$$
\begin{aligned}
& V_{d}^{r e f}=V \cos \theta_{i n v} \\
& V_{q}^{r e f}=V \sin \theta_{i n v}
\end{aligned}
$$

\subsubsection{Application of the Proposed Method to Interface between Stationary and Synchronous Frame}

In Fig. 6-2, the OSG-SOGI filter serves as an interface between the stationary frame and the synchronous frame for the single-phase, voltage source inverter. It has to be transformed to interface with the model proposed in this research. The following steps are used to find a synchronous frame representation of the OSG-SOGI interface: 
First, let us assume that the stationary frame portion of inverter has already been transformed according to (6-12). The original synchronous frame, as mentioned in Section 6.1.3 remains the same. Therefore, an inverse Park-Clarke transformation should be added before OSG-SOGI and a Park-Clarke transformation should be added after OSG-SOGI (see Fig. 6-4). Thus, the transfer function of the OSG-SOGI interface takes the form: $G_{O S G-S O G I} d q(s)=U^{\prime}(s) / U(s)$. It can be derived by applying Laplace transformation on (6-14)-(6-16).

$$
\begin{gathered}
u_{a}(t)=\left[\begin{array}{ll}
\cos \left(\omega_{i n v} t\right) & -\sin \left(\omega_{i n v} t\right)
\end{array}\right]\left[\begin{array}{l}
u_{d}(t) \\
u_{q}(t)
\end{array}\right] \\
{\left[\begin{array}{l}
u_{\alpha}(t) \\
u_{\beta}(t)
\end{array}\right]=G_{\text {SOGI }}(t) * u_{a}(t)} \\
{\left[\begin{array}{ll}
u_{d}^{\prime}(t) \\
u_{q}^{\prime}(t)
\end{array}\right]=\left[\begin{array}{cc}
\cos \left(\omega_{i n v} t\right) & \sin \left(\omega_{i n v} t\right) \\
-\sin \left(\omega_{i n v} t\right) & \cos \left(\omega_{i n v} t\right)
\end{array}\right]\left[\begin{array}{l}
u_{\alpha}(t) \\
u_{\beta}(t)
\end{array}\right]}
\end{gathered}
$$

Assuming, that in the real system $\omega_{i n v}$ is in close proximity to $\omega_{n}$, and solving equations (6-14)-(6-16) for $U^{\prime}(s) / U(s)$ yields $G_{O S G-S_{O G I}}(s)(6-18)-(6-21)$.

$$
\begin{gathered}
\operatorname{den}(s)=s^{4}+2 k \omega_{n} s^{3}+\left(k^{2} \omega_{n}^{2}+4 \omega_{n}^{2}\right) s^{2}+4 k \omega_{n}^{3} s+k^{2} \omega_{n}^{4} \\
\frac{u_{d}^{\prime}(s)}{u_{d}(s)}=\frac{k \omega_{n} s^{3}+k^{2} \omega_{n}^{2} s^{2}+2 k \omega_{n}^{3} s+k^{2} \omega^{4}}{\operatorname{den}(s)} \\
\frac{u_{d}^{\prime}(s)}{u_{q}(s)}=\frac{-k \omega_{n}^{2} s^{2}-k^{2} \omega_{n}^{3} s}{\operatorname{den}(s)}
\end{gathered}
$$




$$
\begin{gathered}
\frac{u_{q}^{\prime}(s)}{u_{d}(s)}=\frac{-k \omega_{n}^{2} s^{2}-2 k \omega_{n}^{2} s+k \omega_{n}^{2}}{\operatorname{den}(s)} \\
\frac{u_{q}^{\prime}(s)}{u_{q}(s)}=\frac{k^{3} \omega_{n}^{3} s+k^{2} \omega_{n}^{4}}{\operatorname{den}(s)}
\end{gathered}
$$

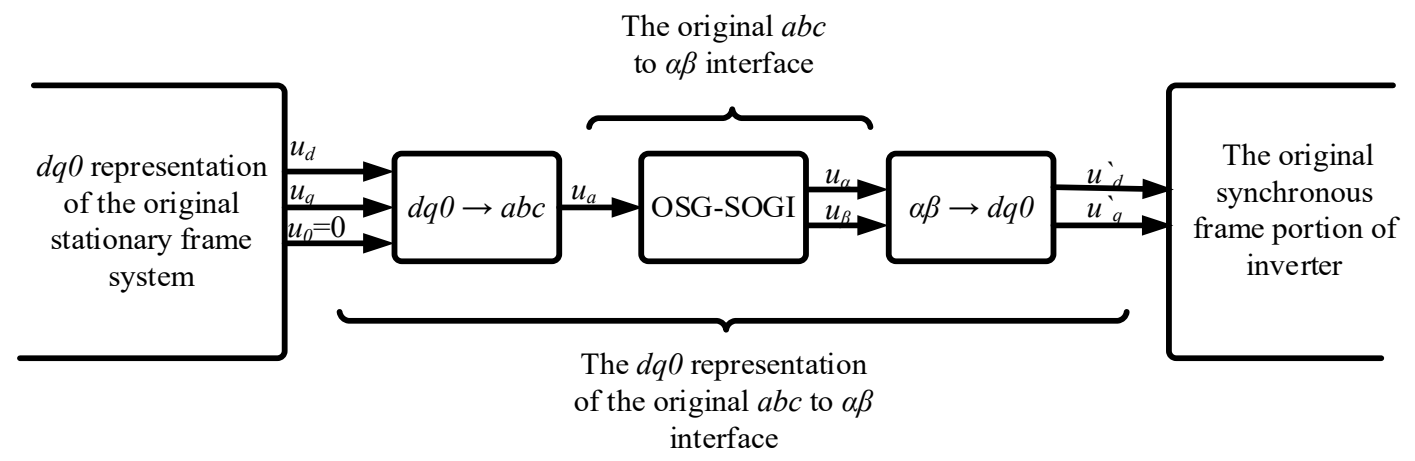

Fig. 6-4 Block-diagram of the original $a b c$ to $\alpha \beta$ interface vs its $d q 0$ representation

Fig. 6-5 shows the step response of the $G_{O S G-S O G I}(s)$ defined by equations (6-18)(6-21). The step response was calculated by using MATLAB. Two conclusions can be drawn from the above analytical and simulation results.

1) In contrast to the three-phase Park-Clarke transformation, the OSG-SOGI transformation is dynamic, due to the nature of the SOGI filter. It could potentially slow-down the power-sharing loop, and this dynamic behavior should be considered during system stability analysis. 
2) There is cross-coupling between the $d$ and $q$ terms, in contrast to the Park-Clarke transformation, which could potentially introduce an undesirable response in the power-sharing loop. Since this phenomenon is well damped, it may not affect small-signal stability; however, its impact on large-signal stability could be visible and require additional investigation.

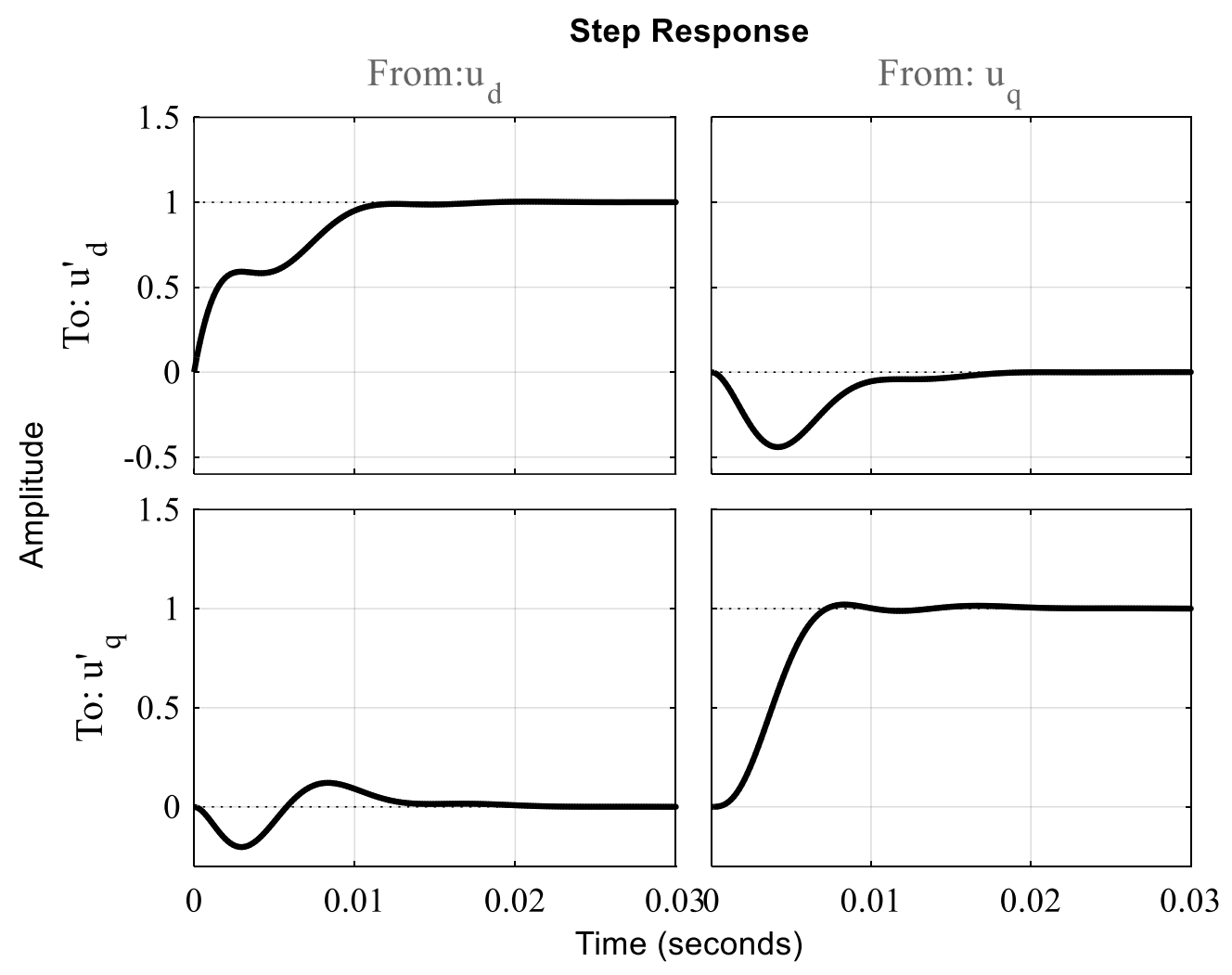

Fig. 6-5 Step response of the GosG-Sogidq (s) transfer function. 


\subsection{Model Validation}

The single-phase, 500VA, bidirectional battery inverter (see Table 5-1 for parameters) was chosen for validation of the proposed theoretical approach by numerical simulation and laboratory test. The H-bridge implements the output cascade of this inverter with bipolar modulation.

The battery inverter could be used as a stand-alone device or as part of a nanogrid. These types of applications require a fast voltage loop that is stable under different load conditions and provides rejection of disturbances from non-linear loads. Solantro Semiconductors mixed-signal MCU SA4041 (IXC64K) [97] was chosen to control the bidirectional battery inverter. SA4041 a control chip designed and manufacturing by Solantro Semiconductors Corp. It includes a computation core, an analog front end, and hardware accelerators.

The control loop structure of this inverter is depicted in Fig. 6-2. The current control loop is implemented by a non-linear, cycle-by-cycle hysteresis controller [40] (see Section 5.2.1 for details). The voltage control loop is implemented with a PR controller [51]-[55], [58][62].

The PR controller (6-22) is chosen for the voltage control loop because it can achieve zero steady-state error at the $\mathrm{AC}$ fundamental frequency and can provide a high rejection ratio for undesired harmonic content with minimum computation burden. The PR controller runs in the CPU of the MCU with an interrupt time $T_{\text {sample }}=60 \mathrm{uS}$. The current reference signal is set for the hysteresis controller at the end of each interrupt cycle. 


$$
\begin{gathered}
{\left[\begin{array}{l}
x_{P R 1} \\
x_{P R 2}^{\dot{ }}
\end{array}\right]=\left[\begin{array}{ll}
-\omega_{c} & \omega_{n} \\
-\omega_{n} & \omega_{c}
\end{array}\right]\left[\begin{array}{l}
x_{P R 1} \\
x_{P R 2}
\end{array}\right]+\left[\begin{array}{c}
K_{i} \\
0
\end{array}\right] u_{e r r}} \\
y_{P R}=\left[\begin{array}{ll}
1 & 0
\end{array}\right]\left[\begin{array}{l}
x_{P R 1} \\
x_{P R 2}
\end{array}\right]+K_{p} v_{e r r}
\end{gathered}
$$

Fig. 6-6 depicts the simulation test-bench for validation of the proposed transformation. The validation was performed in MATLAB/SIMULINK. One of the single-phase systems is modelled in the stationary frame, and the other is modelled in the synchronous frame. Both were simulated under similar operating conditions. The power-sharing loop is not a part of the simulation testbench because it is not affected by the proposed transformation. Artificial impedence $Z$ is set to zero during the test. Both systems start from no-load condition. The same resistive load step is applied when the system reaches its steady-state condition. Fig. 6-7 and Fig. 6-9 show the results of the simulations. Fig. 6-8 shows the result of the laboratory test. 


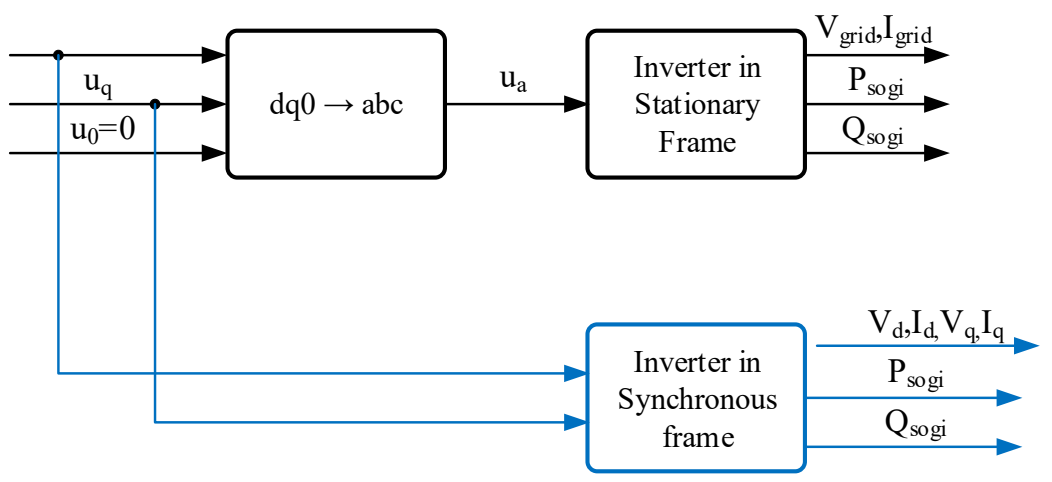

Fig. 6-6: Simulation test bench for the numerical verification of the proposed method. The simulation where performed in MATLAB/SIMULINK

The originally obtained $d q$ voltage and current from the proposed model were modulated from synchronous to stationary frame using inverse Park-Clarke transformation. It can be observed that the voltage and current simulation waveforms are in good agreement between simulation setups and laboratory tests. Fig. 6-9 presents the instantaneous active and reactive power waveforms. It can be seen that the difference between these two plots is in the high-frequency component. This is because that the instantaneous power computation is based on OSG-SOGI transfer functions in the $d q 0$ frame (see equations (6-18)-(6-21)) and these transfer functions have a double frequency component as a result of a modulation-demodulation process artifact. This frequency component is well damped and does not have a major impact on stability analysis. Also, as a result of OSG-SOGI transformation, cross-coupling between both power terms is observed. This phenomenon should be considered for both small and large signal stability analysis. 

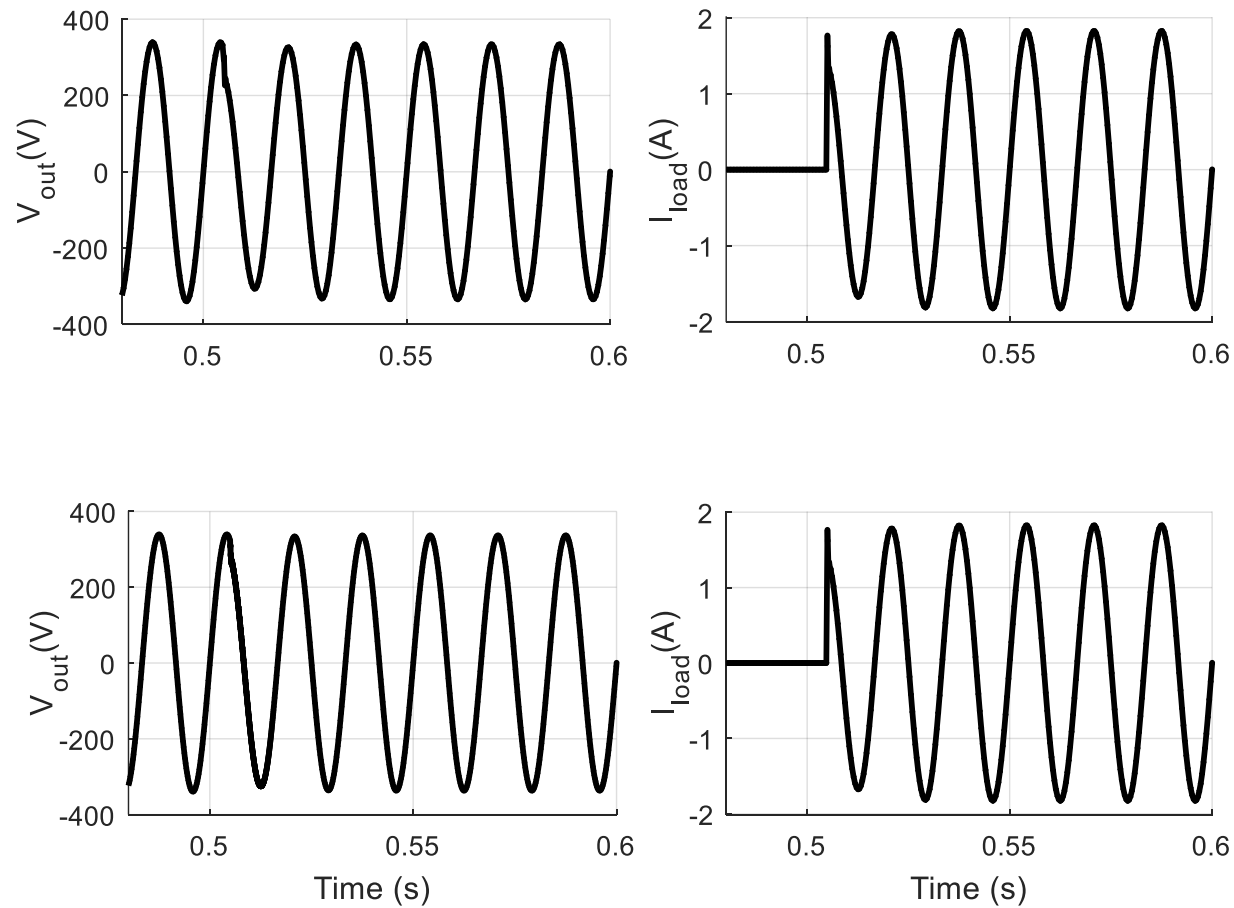

Fig. 6-7 Output voltage and load current of the inverter. Upper left is the resulting stationary model voltage, lower left, modulated synchronous model voltage. Upper right: stationary model load current and lower right is modulated synchronous model load current.

Fig. 6-9 also shows the impact of OSG-SOGI dynamics on the measured instantaneous power results. The measured active power has a significant delay compared to the actual power in the system. The measured power reaches its steady-state value after an approximately $10 \mathrm{~ms}$ delay. One important conclusion can be drawn: during the transient the system remains in an open-loop condition with respect to the power-sharing loop for a significant amount of time. Therefore, the stability of the voltage control loop and internal 
impedance defines the behavior of the system during the transient, and the power-sharing loop affects only the slow frequency load fluctuation.

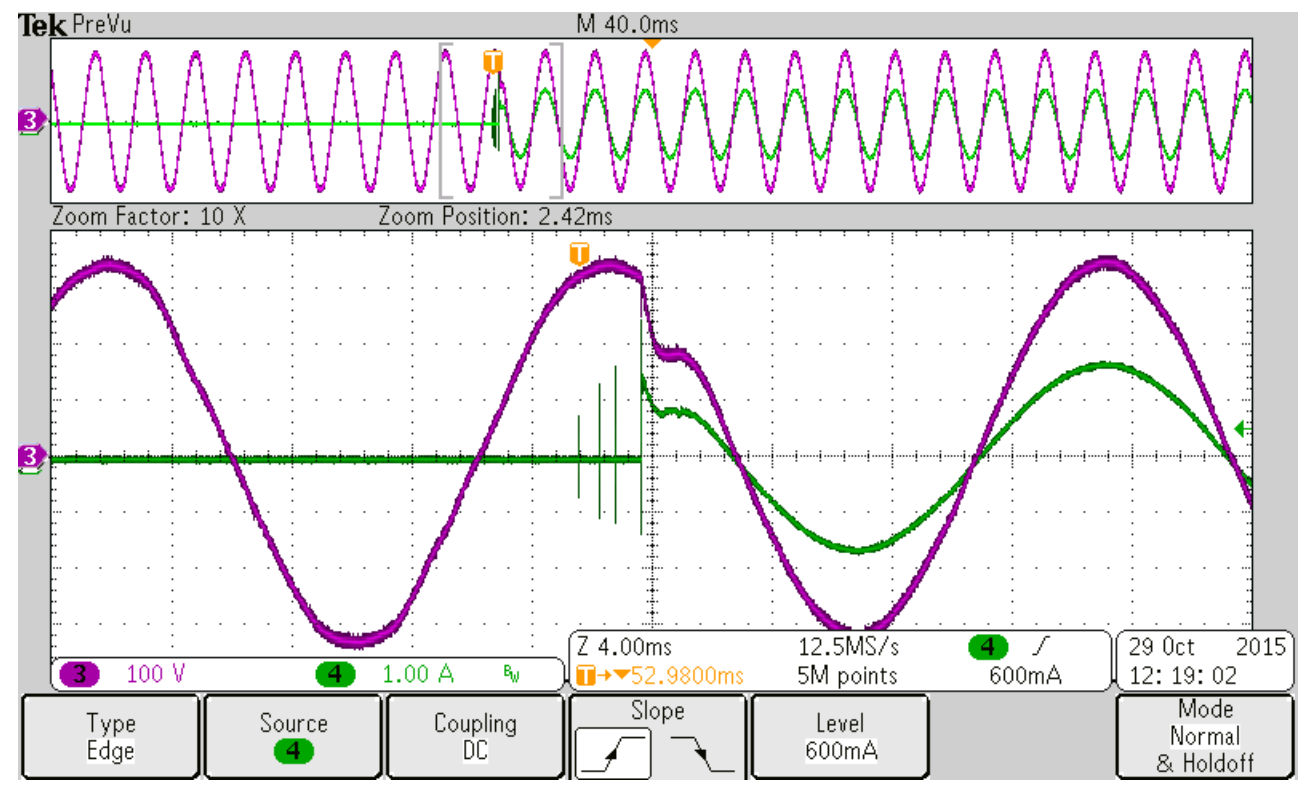

Fig. 6-8. Step response for $300 \mathrm{~W}$ resistive load step. Channel 3 is an output voltage; Channel 4 is an output current. 

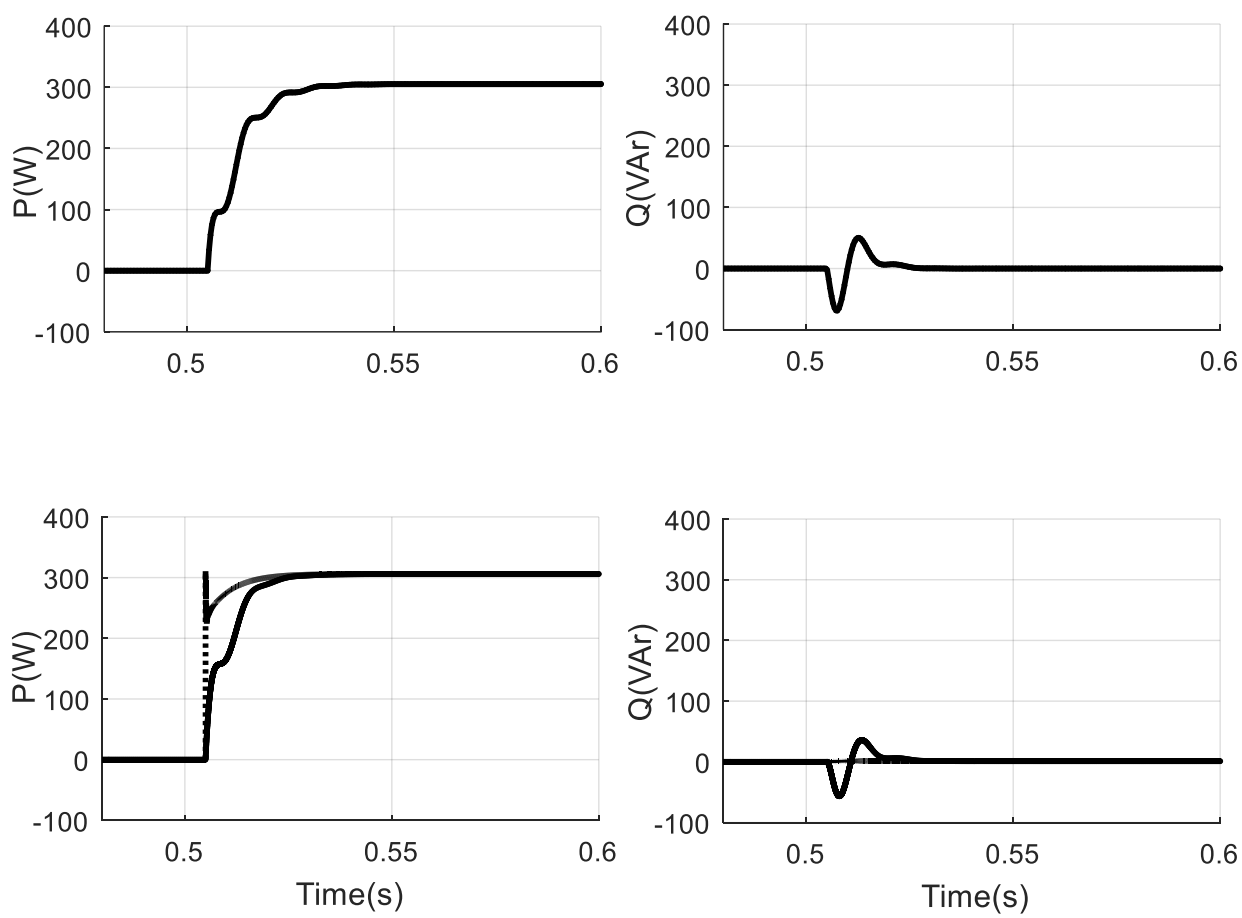

Fig. 6-9 Measured instantaneous output active and reactive power. Upper left is an active power from stationary model, lower left is synchronous model instantaneous reactive power. Upper right is an instantaneous reactive power from stationary model, lower left is instantaneous reactive power from synchronous model. Dashed line: is an actual instantaneous power.

\subsection{Application of the Proposed Modelling Approaches for Voltage Control Loop} and Power Measurement Block Analysis

The model obtained previously in this chapter can be used as a benchmark for stability validation of the single-phase systems. However, it would be interesting to study the impact of the different control blocks on dynamic response and stability. 
The following appoach was taken:

- Firstly, the inverter is modeled using the voltage loop and artificial impedance loop only without considering the external power sharing loop.

- Secondly, the dynamic behavior of the power measurement loop is studied by using proposed method.

This approach is similar to the one used in [82] where a synchronous generator is represented by the classical model without an external control loop and connected to the infinite bus via impedance $Z$.

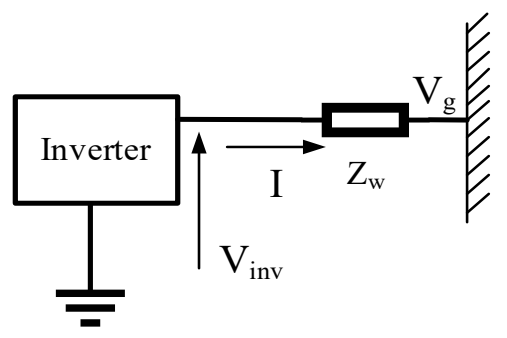

Fig. 6-10 Block diagram of the system under investigation.

Fig. 6-10 shows a grid-forming inverter connected to an infinite bus via impedance $Z_{w}$. This reflects the classical approach to inverter/generator stability analysis and accurately represents the case of microgrid connection to the major grid, an inverter connected to a voltage source of higher power or to rotating machinery (motors or generators). 


\subsubsection{Voltage and Artificial Impedance Loop Analysis}

In this analysis the power-sharing loop is eliminated from the model. The approach is similar to considering synchronous generator stability based on the classical model. This step allows the inverter's stability to be investigated and the effect of artificial impendence $Z$, and leakage term $\omega_{c}$ in the voltage control loop to be understood.

The following assumption has been taken:

- The poles of EMI filter lie above the bandwidth of the voltage control loop. Therefore, the EMI filter can be represented only by its capacitance.

- The closed loop current control has a significantly higher bandwidth than the voltage control loop. Therefore, it can be approximated by unity gain.

The PR controller representation according to proposed modelling approaches is considered first before starting overall inverter modelling. It is important to mention that the PR controller originated from a modulation of the PI controller with an ideal or nonideal integrator from the synchronous frame to the stationary frame [46], [48], [49] (6-23),(6-24). Therefore, modulation back to the synchronous frame should be considered as a demodulation process and provides additional poles with $2 \omega_{n}$ frequency

These artifacts can be dropped as in a regular demodulation process without the loss of system information [98]. The final expression is (6-26). The expression for the ideal controller can be obtained by setting $\omega_{c}=0$ in $\quad(6-26)$. It should be noted that, as the 
original PR controller regulates both components of voltage (in-phase and quadrature), the transformed controller also has two channels for $d q$ components.

$$
\begin{aligned}
& G_{A C}(s)=\frac{1}{2}\left(G_{D C}(s-j \omega)+G_{D C}(s+j \omega)\right) \\
& \frac{1}{s+\omega_{c}} \leftrightarrow \frac{s}{s^{2}+2 s \omega_{c}+\omega^{2}} \\
& {\left[\begin{array}{l}
\dot{x}_{d P R 1} \\
\dot{x}_{d P R 2} \\
\dot{x}_{q P R 1} \\
\dot{x}_{q P R 2}
\end{array}\right]=\left[\begin{array}{cccc}
-\omega_{c} & \omega_{0} & \omega_{i n v} & 0 \\
-\omega_{0} & -\omega_{c} & 0 & \omega_{i n v} \\
-\omega_{i n v} & 0 & -\omega_{c} & \omega_{0} \\
0 & -\omega_{i n v} & -\omega_{0} & -\omega_{c}
\end{array}\right]\left[\begin{array}{l}
x_{d P R 1} \\
x_{d P R 2} \\
x_{q P R 1} \\
x_{q P R 2}
\end{array}\right]} \\
& +\left[\begin{array}{cc}
K_{i} & 0 \\
0 & 0 \\
0 & K_{i} \\
0 & 0
\end{array}\right]\left[\begin{array}{l}
u_{1} \\
u_{2}
\end{array}\right] \\
& {\left[\begin{array}{l}
y_{d P R} \\
y_{q P R}
\end{array}\right]=\left[\begin{array}{llll}
1 & 0 & 0 & 0 \\
0 & 0 & 1 & 0
\end{array}\right]\left[\begin{array}{l}
x_{d P R 1} \\
x_{d P R 2} \\
x_{q P R 1} \\
x_{q P R 2}
\end{array}\right]+[0]\left[\begin{array}{cc}
K_{p} & 0 \\
0 & K_{p}
\end{array}\right]\left[\begin{array}{l}
u_{1} \\
u_{2}
\end{array}\right]} \\
& {\left[\begin{array}{l}
\dot{x}_{d P R} \\
\dot{x}_{q P R}
\end{array}\right]=\left[\begin{array}{cc}
-\omega_{c} & 0 \\
0 & -\omega_{c}
\end{array}\right]\left[\begin{array}{l}
x_{d P R} \\
x_{q P R}
\end{array}\right]+\left[\begin{array}{ll}
\frac{K_{i}}{2} & 0 \\
0 & \frac{K_{i}}{2}
\end{array}\right]\left[\begin{array}{l}
u_{1} \\
u_{2}
\end{array}\right]} \\
& {\left[\begin{array}{l}
y_{d P R} \\
y_{q P R}
\end{array}\right]=\left[\begin{array}{ll}
1 & 0 \\
0 & 1
\end{array}\right]\left[\begin{array}{l}
x_{d P R} \\
x_{q P R 1}
\end{array}\right]+[0]\left[\begin{array}{cc}
K_{p} & 0 \\
0 & K_{p}
\end{array}\right]\left[\begin{array}{l}
u_{1} \\
u_{2}
\end{array}\right]}
\end{aligned}
$$




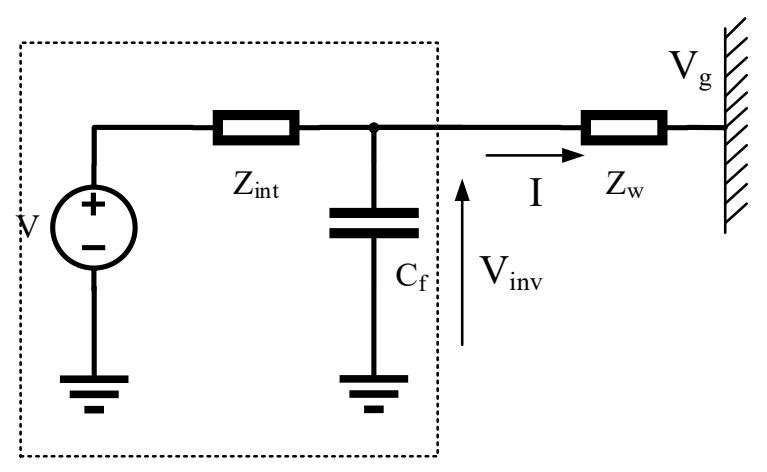

Fig. 6-11 Single-wire Thevenin model of the single-phase grid-forming inverter presented by voltage control loop.

Fig. 6-11 shows the single-wire diagram of the simplified system. The internal impendence of the inverter can be derived from the inverter model using a simplified representation of the PR controller (6-26) for the conditions of $Z=0$ and $\omega_{c}=0$ :

$$
\begin{gathered}
Z_{\text {int }}=\frac{1}{K_{P}} \frac{s+\omega_{c}}{s+\omega_{c}+\frac{K_{I}}{2 K_{P}}, Z=0} \\
Z_{\text {int }}=\frac{1}{K_{P}} \frac{s\left(1+Z(s) K_{P}\right)+Z(s) \frac{K_{I}}{2}}{s+\frac{K_{I}}{2 K_{P}}}, \omega_{c}=0
\end{gathered}
$$

One conclusion which can be drawn from the equations above is that the leakage term in the resonant controller provides the functionality of an artificial resistance. They both can serve as an artificial inverter impendence similar to the reactance of a synchronous generator. Without $\omega_{c}$ and $Z$, the system does not have an internal impedance and has a singular solution when $Z_{w}=0$. 
The equation (6-27) is analyzed under the assumption that the voltage controller is tuned according to symmetrical optimum (see Chapter 5 for details). Therefore, $K_{P} / K_{I}=\sim 1 / \omega_{n}$, and (6-27) takes the form of (6-29).

$$
Z_{\text {int }}=\frac{1}{K_{P}} \frac{s+\omega_{c}}{s+\omega_{c}+\frac{\omega_{n}}{2}} \cong \frac{1}{K_{P}} \frac{s+\omega_{c}}{s+\frac{\omega_{n}}{2}}, Z=0
$$

Fig. 6-12 shows a normilized plot of the equation (6-29). It can be observed, that in this case impedance at low frequencies and high frequincies has a resistive nature, while at frequencies near $2 \omega_{\mathrm{n}}$ the impedance has a capacitive nature.

The usage of artificial impedance $\mathrm{Z}(\mathrm{s})$ is explained below. Let us neglect cross-coupling between axes in artificial impedance when the transformation (6-12) is applied. When $Z(s)=R$ in (6-28), and its value is restricted by single-digit Ohms level for the $1 \mathrm{~kW}$ inverter to fulfill IEEE 1547 requirements for AC voltage limits [99], then $R K_{P}<<1$, and equation (6-28) becomes (6-30). It is obvious that the artificial resistiance has the same dynamic behavior as the non-ideal resonant term in the original PR controller.

$$
Z_{i n t}=\frac{1}{K_{P}} \frac{s+R \frac{K_{I}}{2}}{s+\frac{\omega_{n}}{2}}, \omega_{c}=0
$$




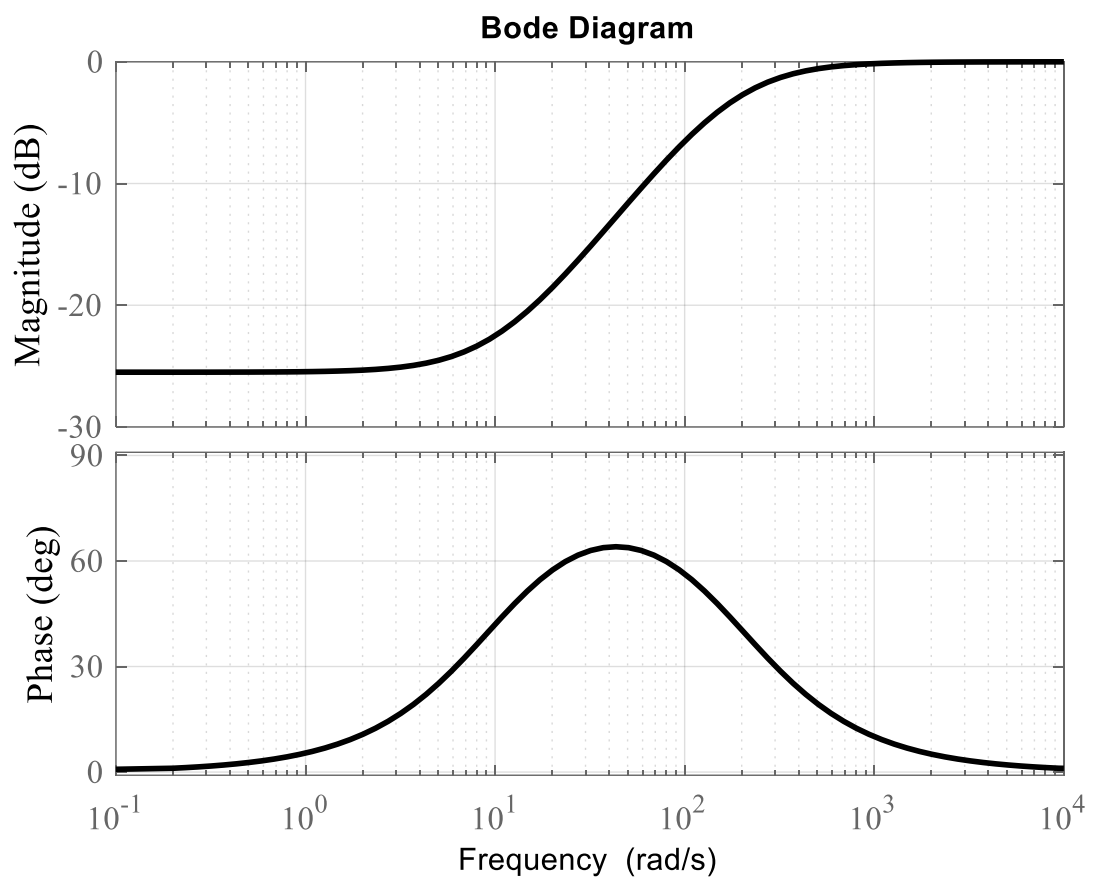

Fig. 6-12 Normalized internal impedance of inverter. The magnitude is normalized with factor $K_{P}, \omega_{c}=10 \mathrm{rad} / \mathrm{s}, Z=0$.

When $Z(s)=R+s L$, expression (6-28) becomes (6-31). It is observed from (6-31) that the resistive portion of $\mathrm{Z}(\mathrm{s})$ defines the dynamic behaviour at low frequency. The inductive portion of $Z(s)$ defines the dynamic behaviour at high-frequency. This inductance can potentially resonate with capacitance present in the microgrid, such as the input filter capacitance.

$$
Z_{\text {int }}=\frac{1}{K_{P}} \frac{s\left(1+R K_{P}+L \frac{K_{I}}{2}\right)+s^{2} L K_{P}+R \frac{K_{I}}{2}}{s+\frac{\omega_{n}}{2}}, \omega_{c}=0
$$


If the artificial impedance has an capacitive nature, i.e., $Z(s)=R+1 /(s C)$, then the expression (6-28) becomes (6-32). It should be noted that capacitive impedance has an infinite value at DC. Therefore, use of capacitive impedance is unpractical.

$$
Z_{\text {int }}=\frac{1}{K_{P}} \frac{s^{2}\left(1+R K_{P}\right)+s\left(R \frac{K_{I}}{2}+\frac{1}{C} K_{P}\right)+\frac{1}{C} \frac{K_{I}}{2}}{s\left(s+\frac{K_{I}}{2 K_{P}}\right)}, \omega_{c}=0
$$

A stability analysis is conducted for the three systems with internal impedances defined by equations (6-29), (6-31), and (6-32). Fig. 6-11 shows a single-wire diagram of the system under investigation. The system includes an inverter connected to an infinite bus via impedance $Z_{w}$. The inverter is represented by a voltage source, internal impedance, and capacitance of the output filter.

First, assuming that $Z_{w}=0$, the system can be representedy by (6-29), which has a pole at $s=-\omega_{c}$, and remains stable from a small-signal perspective. The maximum current is restricted by the internal impedance (6-29) for large signal analysis.

The system with inductive impedance (6-31), when $R=0$, has a pole at $s=0$, and becomes unstable. The system with capacitive impedance (6-32), when $R=0$, at $C \leq \frac{K_{P}}{2 \omega_{n}}$ has a pole at the right side plane and become unstable. If the capacitance impedance at $C>\frac{K_{P}}{2 \omega_{n}}$, then the system has two conjugate poles at $s=-\frac{K_{P}}{C} \pm j \sqrt{\frac{K_{P}}{C}\left(\frac{K_{P}}{C}-2 \omega_{n}\right)}$. 


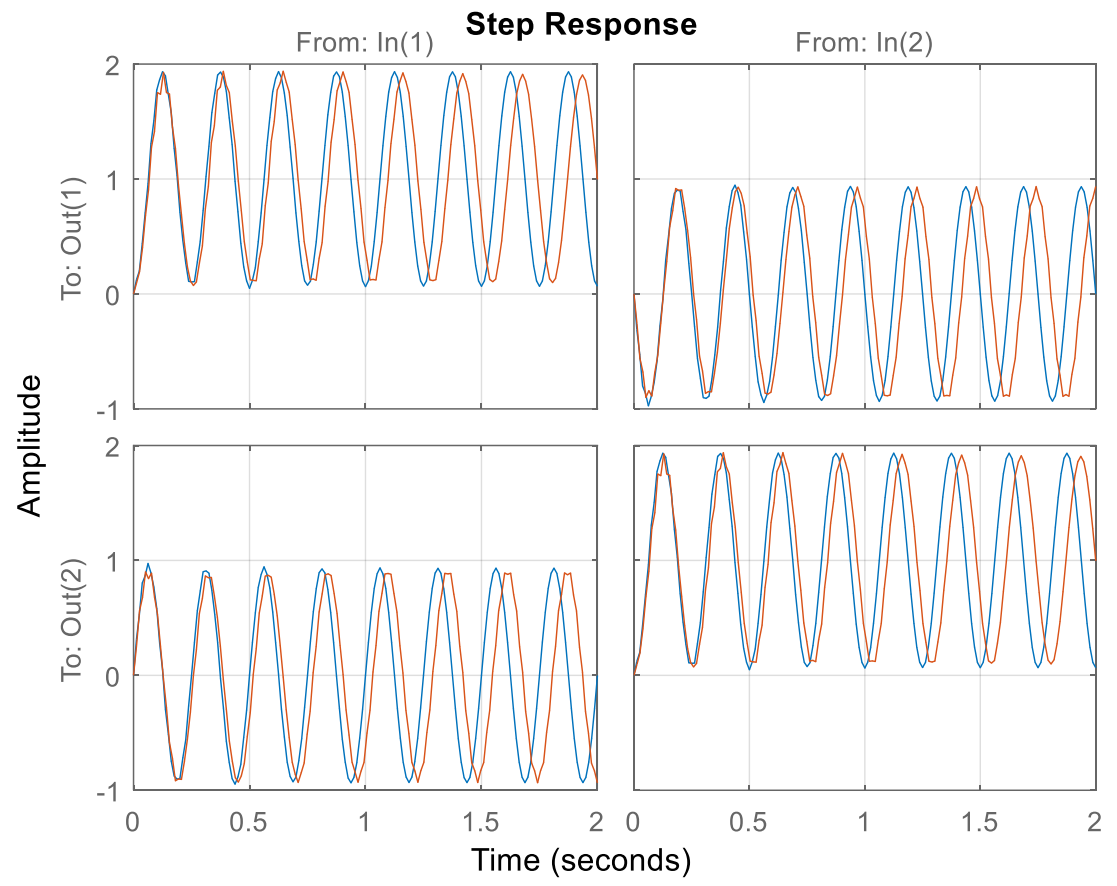

Fig. 6-13 Original (blue) and simplified (red) system in sub-stability region. In(1) is a inverter voltage reference, $\operatorname{In}(2)$ is an infinite bus voltage, Out(1) is an inverter current, and Out(2) is a bus current

It can be observed that the introduction of an artificial impedance of different types other than resistive can potentially cause system instability. The artificial impedance in nanogrid/microgrid systems has one purpose: to stabilize the system by adding damping and inertia. Since the introduction of inductive impedance can potentially cause system instability, and capacitive impedance is unpractical due to its infinite value at low frequencies, it was decided to limit the study to resistive impedance. Moreover, the 
approach with a non-ideal integrator (resonant term) was chosen for further investigation due to the following reasons:

- Provides resistive damping at low and high frequencies (see Fig. 6-12);

- Simplifies the design and tuning of the control loop;

- Use of non-ideal resonant controller prevents practical implementation issues[49]. An additional test was conducted to validate the fidelity of the simplified system against the original one. The step change was applied to both systems which operate on the edge of the stability region (see Fig. 6-13). As it can be observed, the proposed simplification does not affect the amplitude of oscillation and has a neglectable impact on the oscillation frequency.

\subsubsection{Power Measurement Loop Analysis}

The dynamic of the power measurement block, which includes OSG-SOGI and power computation, is investigated in this subsection.

The effect of OSG-SOGI on instantaneous power measurements was previously shown in Fig. 6-9. To study this effect, a linearized transfer function was developed to represent the power measurement block. Fig. 6-14 shows the frequency response of the linearized transfer function on active power measurements and Fig. 6-15 shows the same for reactive power. 


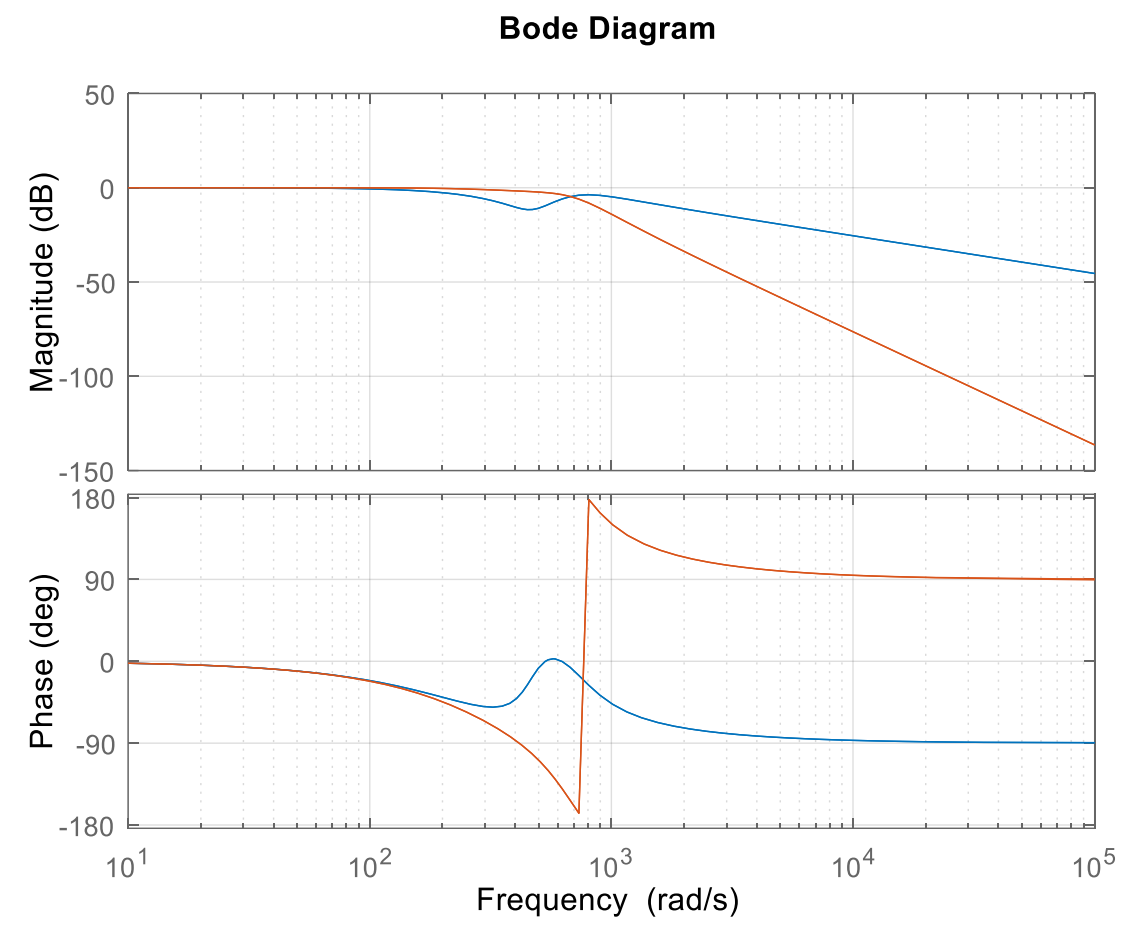

Fig. 6-14 Bode plot of linearized transfer function Psogi(s)/Pmeas(s) at $V_{d}=1, I_{d}=1, V_{q}=0, I_{q}=0$ (blue), and $V_{d}=0, I_{d}=0, V_{q}=1, I_{q}=1$ (red)

The instantaneous power measurement loop has an effective bandwidth of $\sim 30 \mathrm{~Hz}$. This confirms the delay previously observed in the time-domain simulations (see Fig. 6-9). The typical bandwidth of the voltage loop and associated artificial impedance loop is between $1 \mathrm{kHz}$ and $2 \mathrm{kHz}$, Therefore, one important conclusion can be drawn: the voltage and artificial impedance loop and the power sharing loop have a minimal impact on each other due to clear time separation. Moreover, the artificial impedance loop is responsible for power sharing during transient, or at non-linear load situation. 


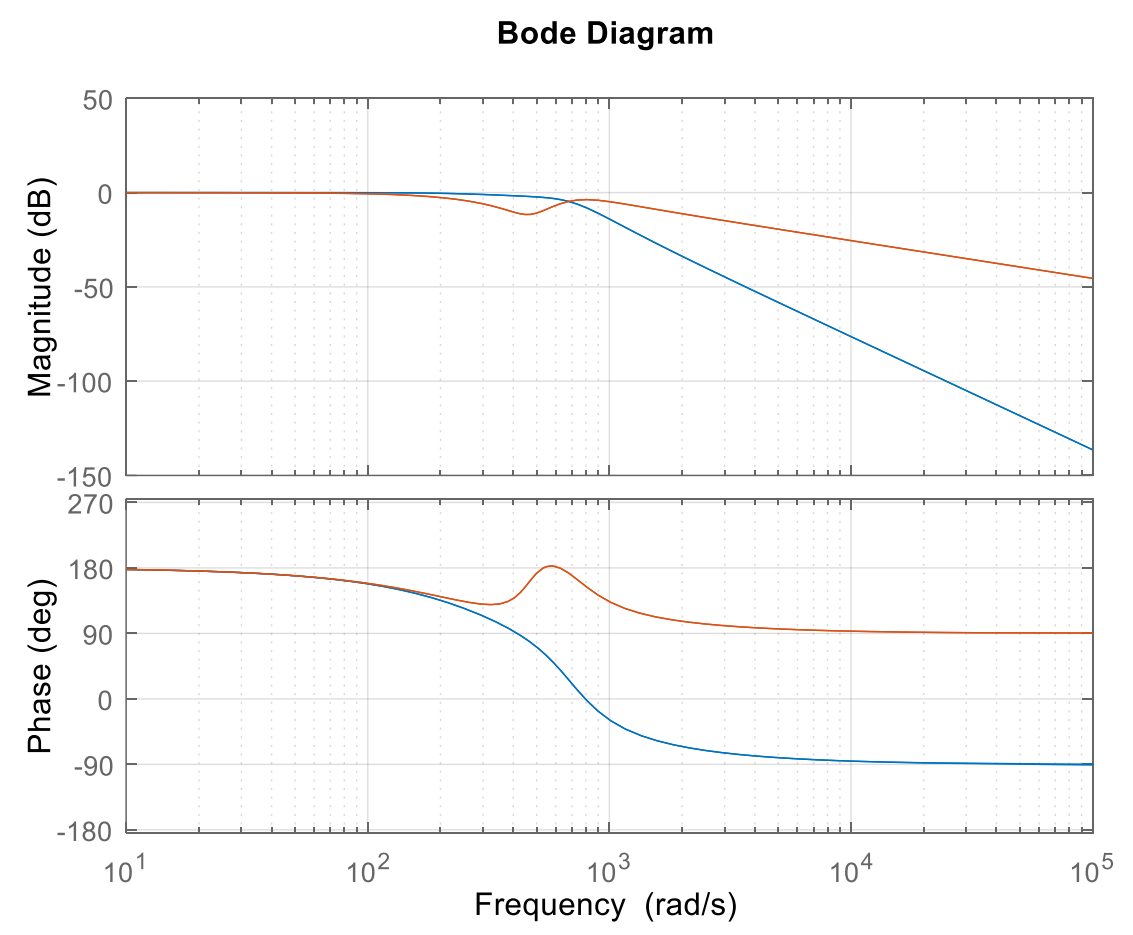

Fig. 6-15 Bode plot of linearized transfer function $Q_{\text {sogI }}(s) / Q_{\text {MEAs }}(s)$ at $V_{d}=1, I_{d}=0, V_{q}=0, I_{q}=1$ (blue), and $V_{d}=0, I_{d}=1, V_{q}=1, I_{q}=0$ ( red)

\subsubsection{Experimental Validation}

A series of tests were performed to verify the results from the theoretical analysis. The parameters of the control loop are artificial impedance $Z=0$ and $\omega_{c}=10 \mathrm{rad} / \mathrm{sec}$. The wire impedance $Z_{w}$ is neglectable.

Fig. 6-16 shows a single-wire diagram of the experimental setup for load sharing. Fig. 6-17 and Fig. 6-18 show test results: transient response of inverters and sharing of high crest- 
factor load. Fig. 6-19 shows a single-wire diagram set up for an air-compressor start-up test, and Fig. 6-20 shows the test results. It can be observed that the current is distributed evenly between inverters during transient and non-linear load conditions. The system also remains stable during no-load conditions.

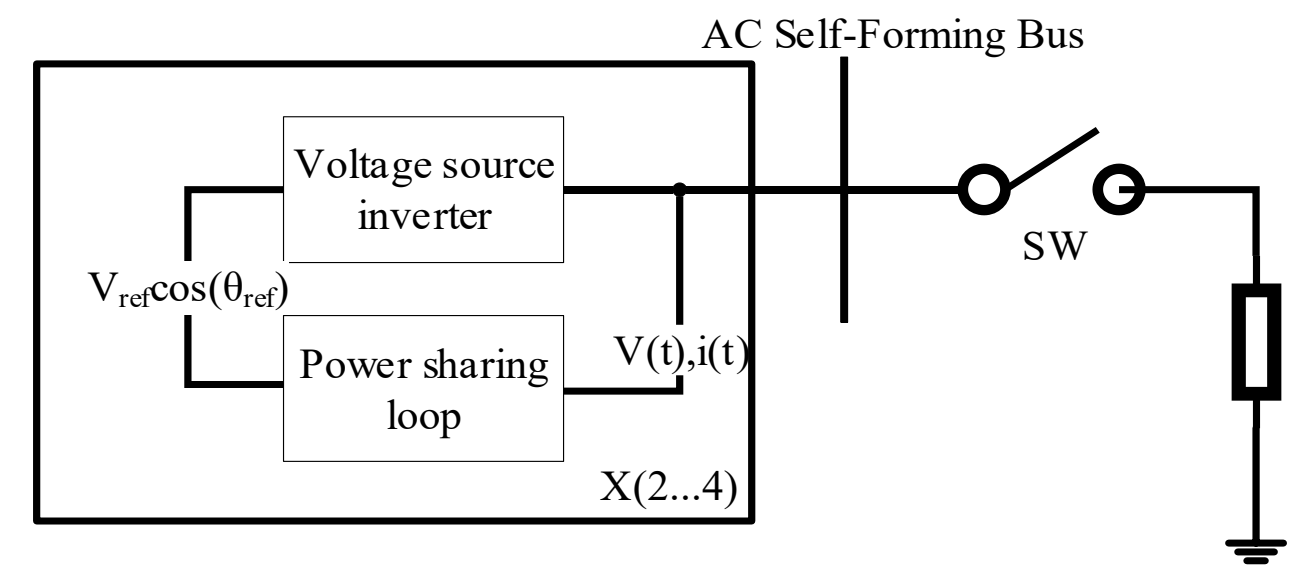

Fig. 6-16 Single-wire diagram of the test bench for investigation of load sharing during transient and non-linear load sharing. Artificial impedance $Z=0$, and $\omega_{c}=10 \mathrm{rad} / \mathrm{sec}$. The wire impedance, $Z_{w}$ is negligible. 


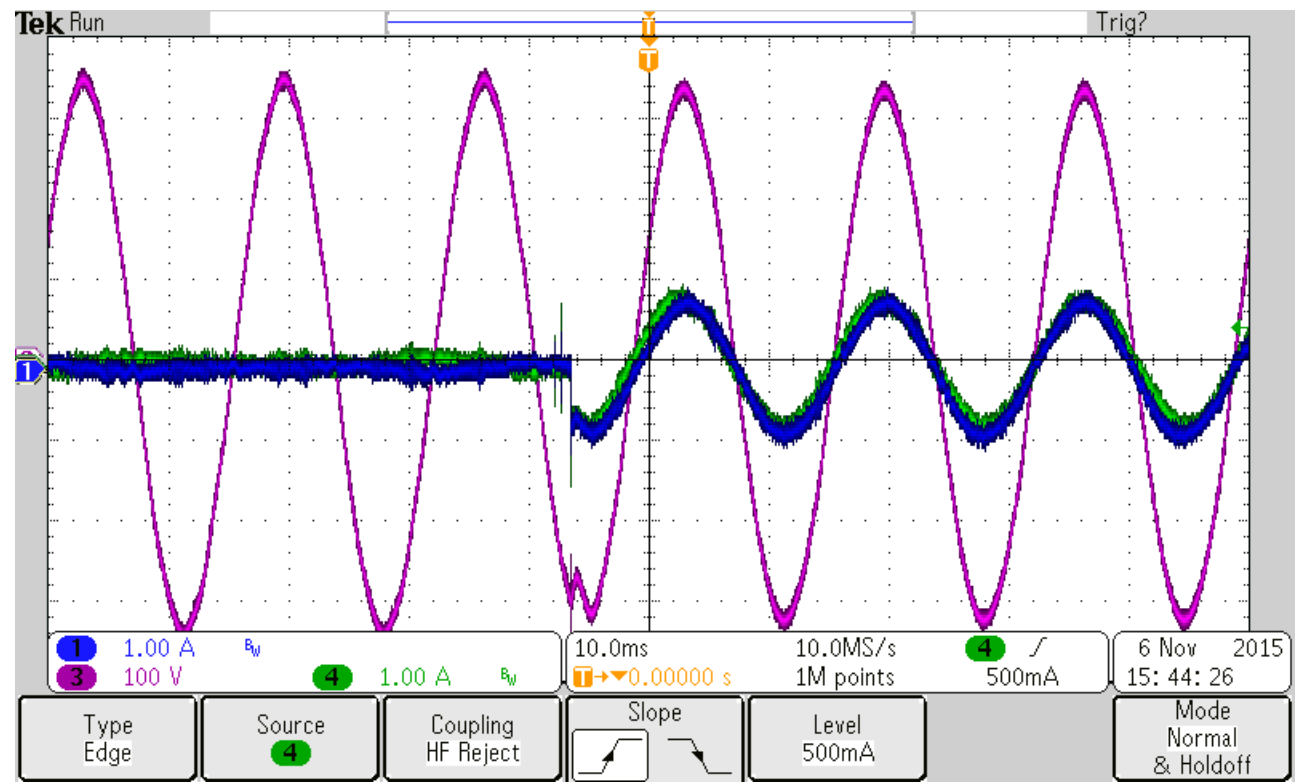

Fig. 6-17 Load step on AC. Channel 3 is an AC bus voltage Channels 1, and 4 are output currents of battery inverter \#1, and $\# 2$ respectively. Artificial impedance $Z=0$, and $\omega_{c}=10 \mathrm{rad} / \mathrm{sec}$, wire impedance, $Z_{w}$ is negligible. 


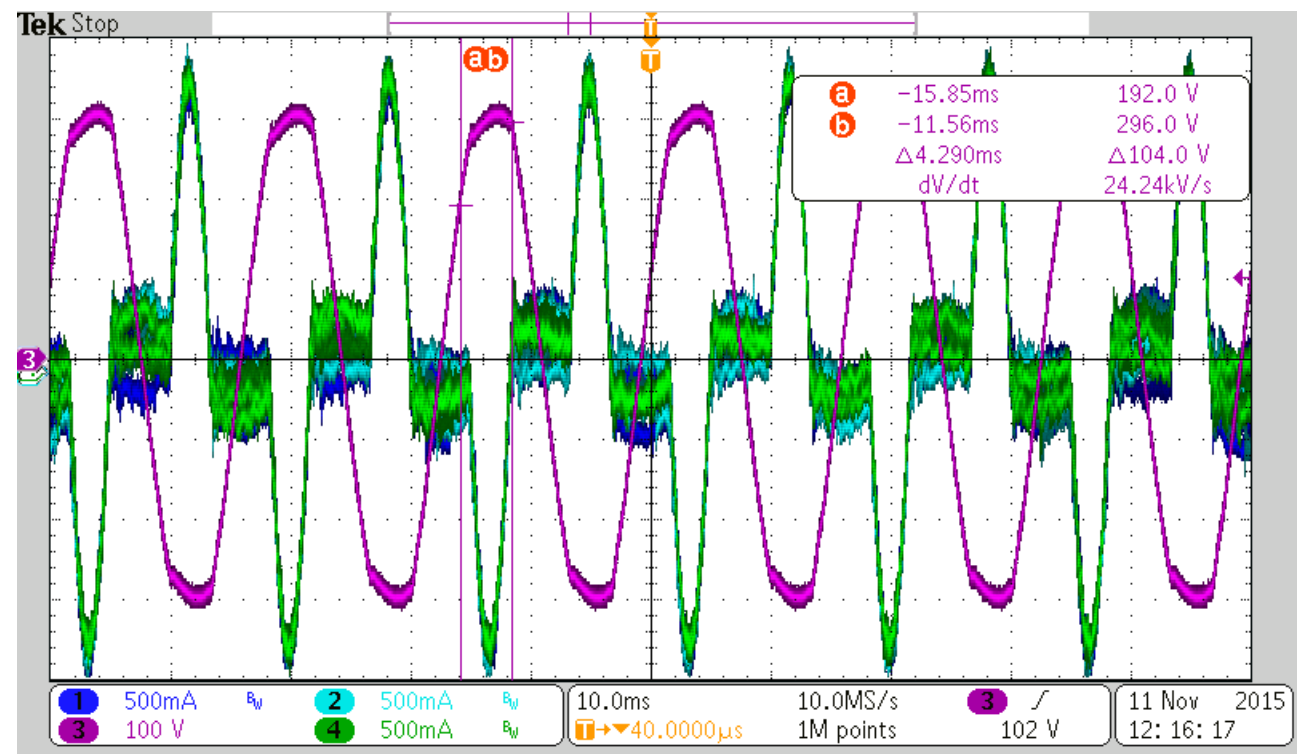

Fig. 6-18 Sharing of high crest-factor load by four grid-forming inverters. Harmonic compensator is off. Channel 1 is an inverter 1 current, Channel 2 is an inverter 2 current, Channel 3 is inverter 3 current, and Channel 4 is self-forming microgrid voltage. Current of the fourth inverter is not presented due to scope channels imitation. Artificial impedance $Z=0$, and $\omega_{\mathrm{c}}=10 \mathrm{rad} / \mathrm{sec}$. Wire impedance, $Z_{w}$ is negligible.

AC Self-Forming Bus

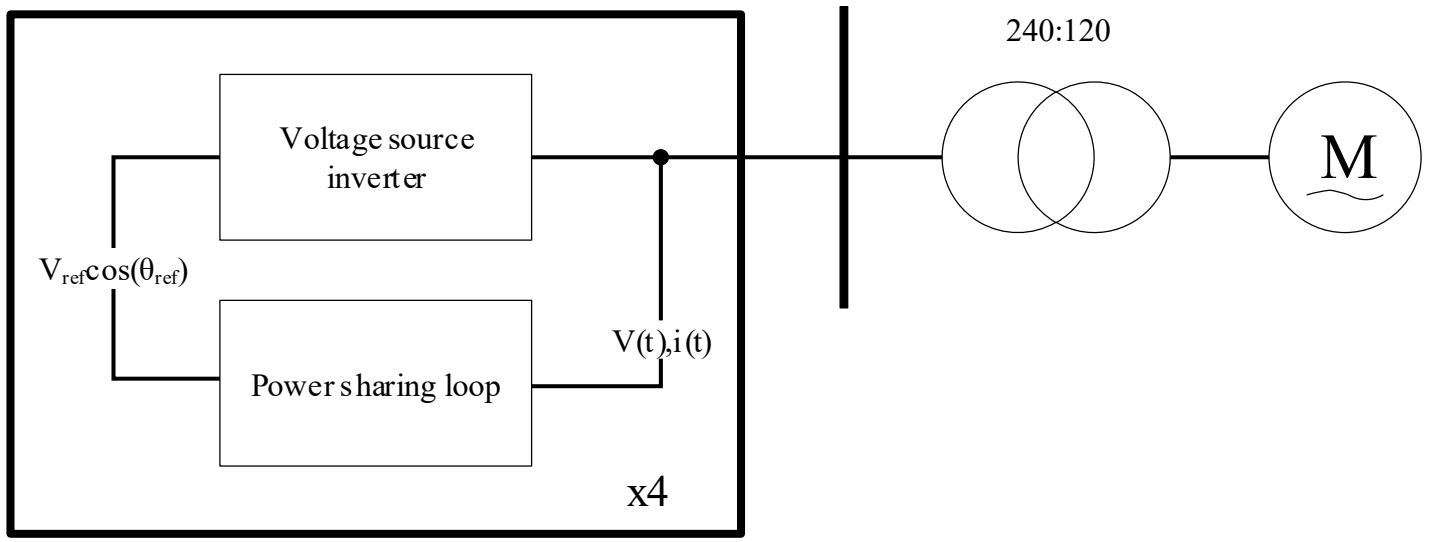

Fig. 6-19 Single-line diagram of air compressor start-up experimental setup. Artificial impedance $Z=0$, and $\omega_{c}=10 \mathrm{rad} / \mathrm{sec}$. The wire impedance, $Z_{w}$ is negligible. 


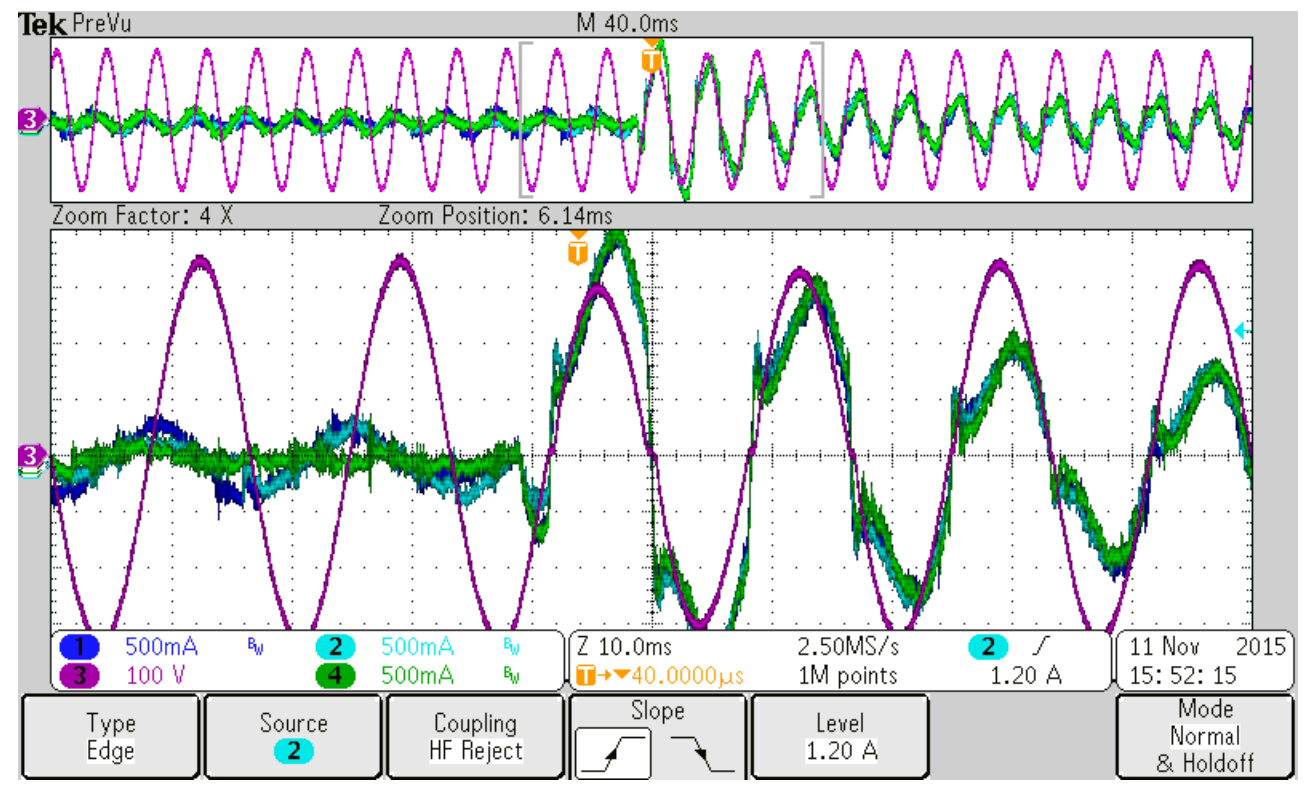

Fig. 6-20 Air-Compressor start-up. Air-compressor is connected through step-down transformer to $\mathrm{AC}$ bus formed by four inverters. Channel 3 is an AC bus voltage Channels 1, 2 and 4 are output currents of battery inverter \#1, \#2 and \# 3 respectively. Output current of battery inverter \#4 was not acquired due to scope channel limitation. Artificial impedance $Z=0$, and $\omega_{c}=10 \mathrm{rad} / \mathrm{sec}$. The wire impedance, $Z_{w}$ is negligible.

\subsection{Summary}

This chapter presents a systematic approach for modelling the single-phase, grid-forming inverter in synchronous $d q 0$ frame. The proposed approach includes the effect of the stationary frame voltage, current and artificial impedance control loops into the $d q 0$ model. The effect of high-dynamic components is crucial for small-signal stability investigation of the small-scale nanogrid because of its significant contribution to model fidelity. 
The proposed method is based on an artificial extension of the single-phase system to threephase with special consideration given to the interface between the stationary and synchronous frame. The proposed modelling approach leads to a time-invariant, non-linear model which is commonly used in power system analysis [82]

A set of comprehensive validation tests was conducted to verify the fidelity of the proposed modelling method. Numerical simulation of the stationary frame model and synchronous model of the same inverter was also conducted and compared with laboratory test results. This work has both theoretical implications and practical applications. It enhances our knowledge on understanding the dynamic behavior of single-phase voltage source inverter. The result of this research can serve as a basis for small-signal stability analysis of the standalone inverter and single-phase nanogrid. Moreover, a reduced-order high-fidelity model can also be obtained using the proposed approach, which includes the effect of highfrequency dynamics.

It can be concluded that the proposed modelling method could be considered as the most comprehensive modelling method for single-phase inverter to date. The obtained theoretical results and simulations results are in good agreement with laboratory test results. 


\section{Chapter 7. Conclusions and Future Work}

This chapter summarizes the contributions of this research. The limitation of this research and potential future work are also described in this chapter.

\subsection{Conclusions}

The main contributions and conclusions of this research are summarized as follows:

- This thesis studies an application of the hysteretic control method for WBS based power converters. The hybrid DCHC control method mitigates the computational burden of high-frequency switching. A novel method of efficiency optimization, based on DCHC, is introduced. This method is based on experimental methodology and does not require expensive 3-D finite element software. An 80 PLUS Titanium Level efficiency can be achieve using the proposed control method.

- An extended MO method based tuning technique is proposed to optimize the PR controller for off-grid voltage source inverters. The extended MO method based tuning technique has the same features as the original $\mathrm{MO}$ for high-frequency response. Low-frequency and steady-state behavior is modified to accommodate the sinewave nature of the reference and control signals. A thorough analysis of the proposed tuning method was carried out to examine stability, response time and steady-state performance.

- A systematic modelling approach of the single-phase, grid-forming inverter in synchronous dq0 frame is presented in this thesis. The proposed modelling 
approach includes the effect of stationary frame voltage, current and artificial impedance controller into the dq0 model. The effect of fast-dynamics components is crucial for small-signal stability investigation of small-scale nanogrid because

of its significant contribution to model fidelity. The proposed modelling approach leads to a time-invariant, non-linear model which is commonly used in power system analysis and can be used by engineers with a classical education background.

Overall, this thesis presents a deep investigation of the characteristics of inverter control, modelling and performance optimizations in the single-phase nanogrid. The analysis methods and conclusions derived from the thesis support the adaptation of inverter-based DG technologies in modern power systems.

\subsection{Thesis Limitation and Suggestion for Future Work}

The limitations of this thesis are as follows:

- This research is limited to the single-phase nanogrid; however, the author believes that the results and methodology described in this thesis can be easily adapted to a three-phase nanogrid of similar capacity.

- The thesis uses only an optimum control method, other control methods such as adaptive methods are outside the scope of the presented research 
In continuation of the work of this thesis, the following topics are suggested for future research:

- With the massive introduction of the high-frequency WBS, the following philosophical question was raised by the power electronics community: should WBS be used as a substitute for conventional devices or should new topology be introduced? A similar question was raised regarding control methods: should conventional constant frequency control be used, or non-linear variable -frequency control methods be considered? Therefore, the DCHC method for control and optimization of the WBSs based topologies is an important research topic. These research activities are currently underway and covering the Totem-Pole PFC topology.

- Initially, the goal of this research was to conduct a comprehensive stability investigation of the single-phase nanogrid. This topic remains open. The proposed modelling technique opens the way to conduct this type of investigation. Stability analysis of the single-phase nanogrid using the proposed model is an important topic to help with single-phase nanogrid adaption.

- To comply with the state-of-art microgrids modelling requirements, the simplified high-fidelity model for single-phase grid -forming inverters should be used, as well as the active load, high-fidelity model. 


\section{References}

[1] National Resource Canada, "Energy Fact Book 2016 - 2017,” 2016.

[2] U.S. Energy Information Administration, "Electric Power Annual 2015," Washington ,DC, 2016.

[3] M. Smith and D. Ton, "Key Connections: The U.S. Department of Energy's Microgrid Initiative,” IEEE Power Energy Mag., vol. 11, no. 4, pp. 22-27, Jul. 2013.

[4] W. Warwick, T. Hardy, M. Hoffman, and J. Homer, "Electricity Distribution System Baseline Report," 2016.

[5] J. Rocabert, A. Luna, F. Blaabjerg, and P. Rodríguez, "Control of Power Converters in AC Microgrids," IEEE Trans. Power Electron., vol. 27, no. 11, pp. 4734-4749, Nov. 2012.

[6] J. Van Roy, N. Leemput, F. Geth, J. Buscher, R. Salenbien, and J. Driesen, "Electric Vehicle Charging in an Office Building Microgrid With Distributed Energy Resources,” IEEE Trans. Sustain. Energy, vol. 5, no. 4, pp. 1389-1396, Oct. 2014.

[7] S. Di Bitonto and R. Trost, "Electromobility in Germany: Vision 2020 and Beyond," 2015.

[8] N. Hatziargyriou, Microgrid : architectures and control. Wiley-IEEE Press, 2014.

[9] P. Vorobev, P.-H. Huang, M. Al Hosani, J. L. Kirtley, and K. Turitsyn, "HighFidelity Model Order Reduction for Microgrids Stability Assessment," IEEE Trans. Power Syst., pp. 1-1, 2017. 
[10] V. Mariani, F. Vasca, J. C. Vasquez, and J. M. Guerrero, "Model Order Reductions for Stability Analysis of Islanded Microgrids With Droop Control," IEEE Trans. Ind. Electron., vol. 62, no. 7, pp. 4344-4354, Jul. 2015.

[11] X. Guo, Z. Lu, B. Wang, X. Sun, L. Wang, and J. M. Guerrero, "Dynamic PhasorsBased Modeling and Stability Analysis of Droop-Controlled Inverters for Microgrid Applications," IEEE Trans. Smart Grid, vol. 5, no. 6, pp. 2980-2987, Nov. 2014.

[12] C. Li, S. K. Chaudhary, M. Savaghebi, J. C. Vasquez, and J. M. Guerrero, "Power Flow Analysis for Low-Voltage AC and DC Microgrids Considering Droop Control and Virtual Impedance," IEEE Trans. Smart Grid, vol. 8, no. 6, pp. 2754-2764, Nov. 2017.

[13] C. Liu, K. T. Chau, D. Wu, and S. Gao, "Opportunities and Challenges of Vehicleto-Home, Vehicle-to-Vehicle, and Vehicle-to-Grid Technologies," Proc. IEEE, vol. 101, no. 11, pp. 2409-2427, Nov. 2013.

[14] C. Jin, J. Tang, and P. Ghosh, "Optimizing Electric Vehicle Charging With Energy Storage in the Electricity Market," IEEE Trans. Smart Grid, vol. 4, no. 1, pp. 311320, Mar. 2013.

[15] A. Kwasinski, R. Vicini, O. Micheloud, and H. Kumar, "Transformer and home energy management systems to lessen electrical vehicle impact on the grid," IET Gener. Transm. Distrib., vol. 6, no. 12, pp. 1202-1208, Dec. 2012.

[16] N. G. Paterakis, I. N. Pappi, O. Erdinc, R. Godina, E. M. G. Rodrigues, and J. P. S. 
Catalao, "Consideration of the Impacts of a Smart Neighborhood Load on Transformer Aging," IEEE Trans. Smart Grid, vol. 7, no. 6, pp. 2793-2802, Nov. 2016.

[17] R. Wang, P. Wang, and G. Xiao, "Two-Stage Mechanism for Massive Electric Vehicle Charging Involving Renewable Energy," IEEE Trans. Veh. Technol., vol. 65, no. 6, pp. 4159-4171, Jun. 2016.

[18] R. Faria, P. Moura, J. Delgado, and A. T. de Almeida, "Managing the Charging of Electrical Vehicles: Impacts on the Electrical Grid and on the Environment," IEEE Intell. Transp. Syst. Mag., vol. 6, no. 3, pp. 54-65, 2014.

[19] V. Aravinthan and W. Jewell, "Controlled Electric Vehicle Charging for Mitigating Impacts on Distribution Assets," IEEE Trans. Smart Grid, vol. 6, no. 2, pp. 9991009, Mar. 2015.

[20] N. Leemput, F. Geth, J. Van Roy, A. Delnooz, J. Buscher, and J. Driesen, "Impact of Electric Vehicle On-Board Single-Phase Charging Strategies on a Flemish Residential Grid,” IEEE Trans. Smart Grid, vol. 5, no. 4, pp. 1815-1822, Jul. 2014.

[21] J. de Hoog, T. Alpcan, M. Brazil, D. A. Thomas, and I. Mareels, "Optimal Charging of Electric Vehicles Taking Distribution Network Constraints Into Account," IEEE Trans. Power Syst., vol. 30, no. 1, pp. 365-375, Jan. 2015.

[22] H. Turker, S. Bacha, D. Chatroux, and A. Hably, "Low-Voltage Transformer Lossof-Life Assessments for a High Penetration of Plug-In Hybrid Electric Vehicles 
(PHEVs)," IEEE Trans. Power Deliv., vol. 27, no. 3, pp. 1323-1331, Jul. 2012.

[23] M. Yilmaz and P. T. Krein, "Review of the Impact of Vehicle-to-Grid Technologies on Distribution Systems and Utility Interfaces," IEEE Trans. Power Electron., vol. 28, no. 12, pp. 5673-5689, Dec. 2013.

[24] K. Clement-Nyns, E. Haesen, and J. Driesen, "The Impact of Charging Plug-In Hybrid Electric Vehicles on a Residential Distribution Grid," IEEE Trans. Power Syst., vol. 25, no. 1, pp. 371-380, Feb. 2010.

[25] Goverment of Ontario, "Microgrids | Ontario.ca." [Online]. Available: https://www.ontario.ca/document/projects-funded-smart-gridfund/microgrids\#section-2. [Accessed: 16-Feb-2019].

[26] N. Radimov, G. Li, M. Tang, and X. Wang, "Three-Stage SiC-Based Bi-Directional On-Board Battery Charger with Titanium Level Efficiency," IET Power Electron., pp. 1-4, 2020.

[27] N. Radimov, S. Liu, and X. Wang, "Extended Modulus Optimum Method for OffGrid Inverter's Voltage Control System," in 2019 IEEE Canadian Conference of Electrical and Computer Engineering (CCECE), 2019, pp. 1-5.

[28] Solantro Semiconductors, "SGF Project Milstone Report \#2," 2017.

[29] Solantro Semiconductors, "SGF Project Milstone Report \#1," 2016.

[30] Solantro Semiconductors, "SGF Project Milstone Report \#3," 2018.

[31] Solantro Semiconductors, "Battery Inverter Hardware and Test Report for Smart 
Grid Fund Project," Ottawa, 2017.

[32] Pacific Gas and Electric Company, "Electric Rule No. 21: Generating Facility Interconnection." San Francisco, p. 287, 2018.

[33] M. Yilmaz and P. T. Krein, "Review of battery charger topologies, charging power levels, and infrastructure for plug-in electric and hybrid vehicles," IEEE Trans. Power Electron., vol. 28, no. 5, pp. 2151-2169, May 2013.

[34] M. C. Kisacikoglu, B. Ozpineci, and L. M. Tolbert, "EV/PHEV bidirectional charger assessment for V2G reactive power operation," IEEE Trans. Power Electron., vol. 28, no. 12, pp. 5717-5727, 2013.

[35] B. Whitaker et al., "A high-density, high-efficiency, isolated on-board vehicle battery charger utilizing silicon carbide power devices," IEEE Trans. Power Electron., vol. 29, no. 5, pp. 2606-2617, May 2014.

[36] L. Xue, Z. Shen, D. Boroyevich, P. Mattavelli, and D. Diaz, "Dual Active BridgeBased Battery Charger for Plug-in Hybrid Electric Vehicle with Charging Current Containing Low Frequency Ripple,” IEEE Trans. Power Electron., vol. 30, no. 12, pp. 7299-7307, 2015.

[37] M. Nasr, S. Poshtkouhi, N. Radimov, C. Cojocaru, and O. Trescases, "Fast average current mode control of dual-active-bridge DC-DC converter using cycle-by-cycle sensing and self-calibrated digital feedforward," 2017 IEEE Applied Power Electronics Conference and Exposition (APEC). pp. 1129-1133, 2017. 
[38] J. S. Lai, L. Zhang, Z. Zahid, N. H. Tseng, C. S. Lee, and C. H. Lin, "A highefficiency 3.3-kW bidirectional on-board charger," 2015 IEEE 2nd Int. Futur. Energy Electron. Conf. IFEEC 2015, pp. 1-5, 2015.

[39] N. Radimov, R. Orr, and T. K. Gachovska, "Bi-Directional CLLC Converter FrontEnd for Off- Grid Battery Inverters,” in 2015 IEEE Canada International Humanitarian Technology Conference (IHTC2015), 2015, pp. 0-3.

[40] S. Buso and P. Mattavelli, "Digital control in power electronics," Morgan \& Claypool Publishers, vol. 1, no. 1. Morgan \& Claypool, San Rafael, California (1537 Fourth Street, San Rafael, CA 94901 USA), pp. 1-231, 2015.

[41] P. A. Dahono, "New hysteresis current controller for single-phase full-bridge inverters," IET Power Electron., vol. 2, no. 5, pp. 585-594, Sep. 2009.

[42] V. Repecho, D. Biel, J. M. Olm, and E. F. Colet, "Switching Frequency Regulation in Sliding Mode Control by a Hysteresis Band Controller," IEEE Trans. Power Electron., vol. 32, no. 2, pp. 1557-1569, Feb. 2017.

[43] T. K. Gachovska et al., "High density control circuit integration for low cost grid tied inverter," 2015 IEEE Energy Conversion Congress and Exposition (ECCE). pp. 466-469, 2015.

[44] T. K. Gachovska et al., "300 W 4Q PV inverter using new high density control integrated circuits," 2017 IEEE Applied Power Electronics Conference and Exposition (APEC). pp. 3076-3082, 2017. 
[45] F. Blaabjerg, Z. Chen, and S. B. Kjaer, "Power Electronics as Efficient Interface in Dispersed Power Generation Systems," IEEE Trans. Power Electron., vol. 19, no. 5, pp. 1184-1194, Sep. 2004.

[46] A. Timbus, M. Liserre, R. Teodorescu, P. Rodriguez, and F. Blaabjerg, "Evaluation of Current Controllers for Distributed Power Generation Systems," IEEE Trans. Power Electron., vol. 24, no. 3, pp. 654-664, Mar. 2009.

[47] M. P. Kazmierkowski and L. Malesani, "Current control techniques for three-phase voltage-source PWM converters: a survey," IEEE Trans. Ind. Electron., vol. 45, no. 5, pp. 691-703, 1998.

[48] F. Blaabjerg, R. Teodorescu, M. Liserre, and A. V. Timbus, "Overview of Control and Grid Synchronization for Distributed Power Generation Systems," IEEE Trans. Ind. Electron., vol. 53, no. 5, pp. 1398-1409, Oct. 2006.

[49] R. Teodorescu, F. Blaabjerg, M. Liserre, and P. C. C. Loh, "Proportional-resonant controllers and filters for grid-connected voltage-source converters," IEE Proceedings.-Electrical Power Appl., vol. 153, no. 5, p. 750, 2006.

[50] J. G. Hwang, P. W. Lehn, and M. Winkelnkemper, "A Generalized Class of Stationary Frame-Current Controllers for Grid-Connected AC-DC Converters," IEEE Trans. Power Deliv., vol. 25, no. 4, pp. 2742-2751, Oct. 2010.

[51] A. Kuperman, "Proportional-Resonant Current Controllers Design Based on Desired Transient Performance," IEEE Trans. Power Electron., vol. 30, no. 10, pp. 
5341-5345, Oct. 2015.

[52] D. N. Zmood and D. G. Holmes, "Stationary frame current regulation of PWM inverters with zero steady-state error," IEEE Trans. Power Electron., vol. 18, no. 3, pp. 814-822, May 2003.

[53] R. Teodorescu, F. Blaabjerg, U. Borup, and M. Liserre, "A new control structure for grid-connected LCL PV inverters with zero steady-state error and selective harmonic compensation," in Nineteenth Annual IEEE Applied Power Electronics Conference and Exposition, 2004. APEC '04., vol. 1, pp. 580-586.

[54] R. Chattopadhyay, A. De, and S. Bhattacharya, "Comparison of PR controller and damped PR controller for grid current control of LCL filter based grid-tied inverter under frequency variation and grid distortion," in 2014 IEEE Energy Conversion Congress and Exposition (ECCE), 2014, pp. 3634-3641.

[55] W. Lenwari, M. Sumner, and P. Zanchetta, "The Use of Genetic Algorithms for the Design of Resonant Compensators for Active Filters," IEEE Trans. Ind. Electron., vol. 56, no. 8, pp. 2852-2861, Aug. 2009.

[56] A. Vidal et al., "Assessment and Optimization of the Transient Response of Proportional-Resonant Current Controllers for Distributed Power Generation Systems," IEEE Trans. Ind. Electron., vol. 60, no. 4, pp. 1367-1383, Apr. 2013.

[57] Z. Zhou and S. Shi, "Research on Discrete PR Controller with LCL Filter Based on DRNN for Photovoltaic Grid-Connected Inverter," 2015 5th Int. Conf. Electr. Util. 
Deregul. Restruct. Power Technol., pp. 2084-2088, Nov. 2015.

[58] S. Paulo, F. O. Martinz, K. C. M. de Carvalho, N. R. N. Ama, W. Komatsu, and L. Matakas, "Optimized Tuning Method of Stationary Frame Proportional Resonant Current Controllers," in The 2014 International Power Electronics Conference, 2014, pp. 2988-2995.

[59] D. G. Holmes, T. A. Lipo, B. P. McGrath, and W. Y. Kong, "Optimized Design of Stationary Frame Three Phase AC Current Regulators," IEEE Trans. Power Electron., vol. 24, no. 11, pp. 2417-2426, Nov. 2009.

[60] G. Shen, X. Zhu, M. Chen, and D. Xu, "A New Current Feedback PR Control Strategy for Grid-Connected VSI with an LCL Filter," in 2009 Twenty-Fourth Annual IEEE Applied Power Electronics Conference and Exposition, 2009, pp. $1564-1569$.

[61] X. Wang, P. C. Loh, and F. Blaabjerg, "Stability Analysis and Controller Synthesis for Single-Loop Voltage-Controlled VSIs," IEEE Trans. Power Electron., vol. 32, no. 9, pp. 7394-7404, Sep. 2017.

[62] F. de Bosio, L. Ribeiro, F. Freijedo, M. Pastorelli, and J. Guerrero, "Discrete-Time Domain Modelling of Voltage Source Inverters in Standalone Applications: Enhancement of Regulators Performance by Means of Smith Predictor," IEEE Trans. Power Electron., pp. 1-1, 2016.

[63] A. Micallef, M. Apap, C. Spiteri-Staines, J. M. Guerrero, and J. C. Vasquez, 
"Reactive Power Sharing and Voltage Harmonic Distortion Compensation of Droop Controlled Single Phase Islanded Microgrids," IEEE Trans. Smart Grid, vol. 5, no. 3, pp. 1149-1158, May 2014.

[64] A. Micallef, M. Apap, C. Spiteri-Staines, and J. M. Guerrero, "Single-Phase Microgrid With Seamless Transition Capabilities Between Modes of Operation,” IEEE Trans. Smart Grid, vol. 6, no. 6, pp. 2736-2745, Nov. 2015.

[65] I. P. Nikolakakos, H. H. Zeineldin, M. S. El Moursi, and J. L. Kirtley, "ReducedOrder Model for Inter-Inverter Oscillations in Islanded Droop-Controlled Microgrids," IEEE Trans. Smart Grid, pp. 1-1, 2017.

[66] M. Rasheduzzaman, J. A. Mueller, and J. W. Kimball, "Reduced-order small-signal model of microgrid systems," IEEE Trans. Sustain. Energy, vol. 6, no. 4, pp. 1292 1305, Oct. 2015.

[67] I. P. Nikolakakos, H. H. Zeineldin, M. S. El-Moursi, and N. D. Hatziargyriou, "Stability Evaluation of Interconnected Multi-Inverter Microgrids Through Critical Clusters," IEEE Trans. Power Syst., vol. 31, no. 4, pp. 3060-3072, Jul. 2016.

[68] W. S. Levine, Control system fundamentals. CRC Press, 2011.

[69] W. S. Levine, Control system advanced methods. CRC Press, 2011.

[70] M. Tarafdar Haque, "Single-phase pq theory for active filters," in 2002 IEEE Region 10 Conference on Computers, Communications, Control and Power Engineering. TENCOM '02. Proceedings., vol. 3, pp. 1941-1944. 
[71] S. Golestan, M. Monfared, and J. M. Guerrero, "Second order generalized integrator based reference current generation method for single-phase shunt active power filters under adverse grid conditions," PEDSTC 2013 - 4th Annu. Int. Power Electron. Drive Syst. Technol. Conf., pp. 510-517, 2013.

[72] B. N. Singh, V. Khadkikar, and A. Chandra, "Generalised single-phase p-q theory for active power filtering: simulation and DSP-based experimental investigation," IET Power Electron., vol. 2, no. 1, pp. 67-78, Jan. 2009.

[73] H. Akagi, E. H. Watanabe, and M. Aredes, Instantaneous Power Theory and Applications to Power Conditioning. Hoboken, NJ, USA: John Wiley \& Sons, Inc., 2007.

[74] M. Gao, M. Chen, C. Jin, J. M. Guerrero, and Z. Qian, "Analysis, design, and experimental evaluation of power calculation in digital droop-controlled parallel microgrid inverters," J. Zhejiang Univ. Sci. C, vol. 14, no. 1, pp. 50-64, 2013.

[75] J. M. Guerrero, J. C. Vasquez, J. Matas, M. Castilla, and L. G. de Vicuna, “Control Strategy for Flexible Microgrid Based on Parallel Line-Interactive UPS Systems," IEEE Trans. Ind. Electron., vol. 56, no. 3, pp. 726-736, Mar. 2009.

[76] H. Liu, L. Yu, H. Wu, G. Liu, and W. Wang, "Small signal modeling and stability analysis on parallel photovoltaic inverters in microgrid," in 2015 IEEE Energy Conversion Congress and Exposition (ECCE), 2015, pp. 3754-3759.

[77] E. A. A. Coelho, P. C. Cortizo, and P. F. D. Garcia, "Small-signal stability for 
parallel-connected inverters in stand-alone AC supply systems," IEEE Trans. Ind. Appl., vol. 38, no. 2, pp. 533-542, 2002.

[78] B. B. Johnson, S. V. Dhople, A. O. Hamadeh, and P. T. Krein, "Synchronization of Nonlinear Oscillators in an LTI Electrical Power Network," IEEE Trans. Circuits Syst. I Regul. Pap., vol. 61, no. 3, pp. 834-844, Mar. 2014.

[79] M. Sinha, F. Dorfler, B. B. Johnson, and S. V. Dhople, "Synchronization of Liénardtype oscillators in uniform electrical networks," in 2016 American Control Conference (ACC), 2016, pp. 4311-4316.

[80] S. V. Dhople, B. B. Johnson, F. Dorfler, and A. O. Hamadeh, "Synchronization of Nonlinear Circuits in Dynamic Electrical Networks With General Topologies," IEEE Trans. Circuits Syst. I Regul. Pap., vol. 61, no. 9, pp. 2677-2690, Sep. 2014.

[81] M. Sinha, F. Dorfler, B. B. Johnson, and S. V. Dhople, "Synchronization of Liénardtype oscillators in heterogenous electrical networks," in 2018 Indian Control Conference (ICC), 2018, pp. 240-245.

[82] P. (Prabha) Kundur, N. J. Balu, and M. G. Lauby, Power system stability and control. McGraw-Hill, 1994.

[83] J. He and Y. W. Li, "Analysis, Design, and Implementation of Virtual Impedance for Power Electronics Interfaced Distributed Generation," IEEE Trans. Ind. Appl., vol. 47 , no. 6 , pp. 2525-2538, Nov. 2011.

[84] N. Pogaku, M. Prodanovic, and T. C. Green, "Modeling, Analysis and Testing of 
Autonomous Operation of an Inverter-Based Microgrid," IEEE Trans. Power Electron., vol. 22, no. 2, pp. 613-625, Mar. 2007.

[85] S. Leitner, M. Yazdanian, A. Mehrizi-Sani, and A. Muetze, "Small-Signal Stability Analysis of an Inverter-Based Microgrid with Internal Model-Based Controllers," IEEE Trans. Smart Grid, pp. 1-1, 2017.

[86] F. Katiraei, M. R. Iravani, and P. W. Lehn, "Small-signal dynamic model of a microgrid including conventional and electronically interfaced distributed resources," IET Gener. Transm. Distrib., vol. 1, no. 3, p. 369, 2007.

[87] M. Rasheduzzaman, J. A. Mueller, and J. W. Kimball, "An Accurate Small-Signal Model of Inverter- Dominated Islanded Microgrids Using dq Reference Frame," IEEE J. Emerg. Sel. Top. Power Electron., vol. 2, no. 4, pp. 1070-1080, Dec. 2014.

[88] A. A. A. Radwan and Y. A.-R. I. Mohamed, "Modeling, Analysis, and Stabilization of Converter-Fed AC Microgrids With High Penetration of Converter-Interfaced Loads," IEEE Trans. Smart Grid, vol. 3, no. 3, pp. 1213-1225, Sep. 2012.

[89] N. Bottrell, M. Prodanovic, and T. C. Green, "Dynamic Stability of a Microgrid With an Active Load," IEEE Trans. Power Electron., vol. 28, no. 11, pp. 51075119, Nov. 2013.

[90] S.-Y. Ou, C.-Y. Tang, and Z.-J. Chen, "Design and Implementation of a ZCS-PWM Half-Bridge Boost Rectifier With Output Voltage Balance Control," IEEE Trans. Ind. Electron., vol. 59, no. 12, pp. 4646-4656, Dec. 2012. 
[91] W. Konrad, G. Deboy, and A. Muetze, "A Power Supply Achieving Titanium Level Efficiency for a Wide Range of Input Voltages," IEEE Trans. Power Electron., vol. 32, no. 1, pp. 117-127, Jan. 2017.

[92] N. Radimov, S. Liu, and X. Wang, "Extended Modulus Optimum Method for OffGrid Inverter's Voltage Control System," in CCECE, 2019.

[93] Shuya Wang, Jianhui Su, Xiangzhen Yang, Yan Du, Yong Tu, and Huadian Xu, “A review on the small signal stability of microgrid," in 2016 IEEE 8th International Power Electronics and Motion Control Conference (IPEMC-ECCE Asia), 2016, pp. $1793-1798$.

[94] Y. Han, M. Luo, X. Zhao, J. M. Guerrero, and L. Xu, "Comparative Performance Evaluation of Orthogonal-Signal-Generators based Single-Phase PLL Algorithms A Survey," IEEE Trans. Power Electroctronics, 2015.

[95] J. C. Montano, "Reviewing Concepts of Instantaneous and Average Compensations in Polyphase Systems," IEEE Trans. Ind. Electron., vol. 58, no. 1, pp. 213-220, Jan. 2011.

[96] M. Saitou and T. Shimizu, "Generalized theory of instantaneous active and reactive powers in single-phase circuits based on Hilbert transform," in 2002 IEEE 33rd Annual IEEE Power Electronics Specialists Conference. Proceedings (Cat. No.02CH37289), pp. 1419-1424.

[97] "Solantro SA4000 (IXC32/64K Micro-Inverter Controller Series)." Solantro 
Semiconductors, 2016.

[98] A. V. Oppenheim and A. S. Willsky, Signals and Systems, 2nd ed. Prentice Hall International.

[99] IEEE, "IEEE standard for interconnecting distributed resources with electric power systems.” IEEE Std 1547-2003, p. 16, 2003. 